\title{
Einfluß einwandernder Espen (Populus tremuloides) auf den Stickstoffhaushalt nordamerikanischer Prärieökosysteme
}

\author{
Influence of Invading Aspen (Populus tremuloides) \\ on the Nitrogen Cycle of \\ North-American Prairie Ecosystems
}

Diplomarbeit
vorgelegt von

\section{Martin Köchy}

aus

Wolfenbüttel

\begin{abstract}
angefertigt
im Systematisch-Geobotanischen Institut

der Georg-August-Universität zu Göttingen
\end{abstract}


Einfluß einwandernder Espen (Populus tremuloides)

auf den Stickstoffhaushalt

nordamerikanischer Prärieökosysteme

\author{
Influence of Invading Aspen (Populus tremuloides) \\ on the Nitrogen Cycle of \\ North-American Prairie Ecosystems
}

\author{
Diplomarbeit \\ vorgelegt von
}

\title{
Martin Köchy
}

aus

Wolfenbüttel

\begin{abstract}
angefertigt
im Systematisch-Geobotanischen Institut der Georg-August-Universität zu Göttingen
\end{abstract}


Referent:

Korreferent:

Tag der mündlichen Prüfung:

Tag der Abgabe der Diplomarbeit:
Prof. Dr. M. Runge

Prof. Dr. W. Schmidt

23. Oktober 1992

9. März 1994

(c) 1994 Martin Köchy, Maschmühlenweg 39, 37081 Göttingen

Diese Diplomarbeit einschließlich aller ihrer Teile ist urheberrechtlich geschützt. Jede Verwertung außerhalb der Grenzen des Urheberrechtgesetzes ist ohne meine Zustimmung unzulässig. 
Die Flagge der Provinz Saskatchewan

Gelb — die Prärie

Grün — der Wald 
1. EINLEITUNG 5

1.1. Auswahl des Versuchsbiotops 6

1.2. Biome der Espeneinwanderung 6

1.2.1. Prärie 6

1.2.2. Espenwälder und Espenparkland 8

1.3. Das Einwandern der Espe 10

1.4. Streu als Stickstoffquelle 11

1.5. Ziel der Transektuntersuchung und des Versuches 15

$\begin{array}{ll}\text { 2. MATERIAL UND METHODEN } & 17\end{array}$

2.1. Untersuchung der Espenhaintransekte 17

2.2. Experiment zur Streuzersetzung 19

2.2.1. Versuchsgelände 19

2.2.2. Versuchsgebiete und Biotopfaktor 20

$\begin{array}{ll}\text { 2.2.3. Streusortenfaktor } & 21\end{array}$

$\begin{array}{lll}\text { 2.2.4. Beschattungsfaktor } & 23\end{array}$

2.2.5. Abhängige Größen 26

2.2.5.1. Masseverlust 26

$\begin{array}{ll}\text { 2.2.5.2. Stickstoffflüsse } & 27\end{array}$

2.2.5.1. Bewertung der

$\begin{array}{ll}\text { Ionenaustauschmethode } & 27\end{array}$

2.2.5.2.2. Durchführung 29

2.2.6. Unabhängige Größen 33

2.2.7. Statistische Auswertung 34 
3. ERGEBNISSE 36

3.1. Untersuchung des Transektes 36

3.2. Experiment zur Streuzersetzung 38

3.2.1. Umweltbedingungen 38

3.2.2. Streuzersetzung und Stickstoffflüsse 40

3.2.3. Masseverlust 41

3.2.4. Stickstoffdeposition 44

3.2.5. Stickstoffflüsse 45

3.2.6. Stickstoffgehalt der Streu $\quad 47$

4. DISKUSSION 50

4.1. Espenhaintransekt 50

4.2. Streuzersetzung 51

4.2.1. Vergleichbarkeit von Klima und Streu 51

4.2.2. Masseverlust 53

4.2.3. Stickstoffflüsse 56

4.2.4. Gesamtwirkung der Faktoren 58

4.3. Streuzersetzung und Mineralstickstoff 58

5. ZUSAMMENFASSUNG 60

$\begin{array}{lll}\text { 6. SUMMARY } & 61\end{array}$

7. QUELLENVERZEICHNIS 62 
1. Verbreitung der Präriegesellschaften

Distribution of prairie types

2. Mischgrasprärie (Stipo-Boutelouetum)

Mixed-grass prairie

3. Espenhain (Bromo-Populetum tremuloides) Aspen bluff

4. Transektansicht

View of a transect

5. Klimadiagramm für Regina, Saskatchewan

Climate diagram for Regina, Saskatchewan

6. Netze mit Espen- und Grasstreu Litter bags containing aspen and grass litter

7. Beschattungsvorrichtung in einer Prärieteilfläche Shading installation in a prairie sub-plot

8. Mineralstickstoffgehalt des Bodens in Abhängigkeit von

Baumalter, Bodenfeuchte und Lichtdurchlaß

Content of mineral nitrogen in soil in relation to tree age, oil moisture, and light penetration

9. Temperaturverlauf

Temperatures

10. Niederschläge Precipitation

11. Wassergehalt des Bodens Water content of soil

12. Aktuelle Evapotranspiration Actual evapotranspiration

13. Zeitlicher Verlauf der Streuzersetzung Litter decomposition during the experiment

14. Masseverlust der Streu nach 146 Tagen

Mass loss of litter after 146 days

15. Zersetzungsraten

Decomposition rates

16. Stickstoffdeposition

Nitrogen deposition

17. Zeitlicher Verlauf der Stickstoffflüsse

Nitrogen fluxes during the experiment

18. Stickstoffabgabe der Streu nach 146 Tagen

Nitrogen loss from litter after 146 days

19. Stickstoffflußraten

Rates of nitrogen fluxes

20. Kohlenstoff- und Stickstoffgehalt der Streu 
21. Korrigierter Stickstoffvorrat der Streu Adjusted nitogen storage in litter

22. Kompartimentmodell Compartment model

1. Stickstoffgehalt und -vorrat der Streu (oberirdisch)

Nitrogen content and storage of litter (aboveground)

2. Stickstoffgehalt und -vorrat im Bestandesabfall (gesamt) Nitrogen content and storage of litter (total)

3. Versuchsplan Design of experiment

4. Biotopvergleich: mineralischer Stickstoff und unabhängige Variablen

Comparison of habitats: mineral nitrogen and independent variables

5. Gesamtwirkung der Faktoren Total effect of treatments

6. Zersetzungsraten - Vergleich mit Angaben aus der Literatur Decomposition rates - Comparison with reported values 


\section{Danksagungen}

Ich danke dem Saskatchewan Department of Parks and Recreation für die Erlaubnis, in White Butte arbeiten zu dürfen, Herrn und Frau Taube für die Erlaubnis, ihre Wiesen zu benutzen, Herrn Prof. Binkley Ph.D. an der Staatsuniversität Colorado für Ratschläge zur Austauschermethode, Herrn Prof. Dr. Brunner am Institut für Medizinische Statistik der Universität Göttingen für Rat bei der statistischen Auswertung und ganz besonders meinem Betreuer an der Universität Regina, Prof. S. D. Wilson Ph.D. 
n Stichprobenumfang

Sample size

P Überschreitungswahrscheinlichkeit für eine Teststatistik Significance probability of a test statistic

SD Mittlere quadratische Abweichung, Standardabweichung Standard deviation

SE Standardabweichung des Mittelwertes

Standard error 


\section{Einleitung}

Die Gesamteigenschaften eines Ökosystems, zum Beispiel Primärproduktion, Zersetzung und Nährstoffkreisläufe (VITOUSEK 1986), können von einer einzelnen Art gesteuert sein (VITOUSEK 1986; HOBBIE 1992; TILMAN 1990; WEDIN \& TILMAN 1990). Dies ist am auffälligsten, wenn eine fremde Art in ein Ökosystem einwandert oder eingeschleppt wird und dort zum "Unkraut" wird. Innerhalb dieses Ökosystems muß eine solche "steuernde" Art entweder in der Lage sein, die Ressourcen des Systems in Zeiträumen, in denen die anderen Arten inaktiv sind, oder aus Bereichen, die den anderen Arten unzugänglich sind, aufzunehmen, oder diese Art muß die Ressourcen besser als die anderen Arten verwerten können (VITOUSEK 1986). Es wurden Mechanismen vorgeschlagen, durch die eine einwandernde Art die Gesamteigenschaften eines Ökosystems in eine Richtung steuern kann, die ihre eigene weitere Ausbreitung ermöglicht (VITOUSEK 1990; CHAPIN et al. 1986; HOBBIE 1992). Einer dieser Mechanismen, ein rückgekoppelter Stickstoffkreislauf, wird in Abschnitt 1.4. genauer beschrieben.

Als Beispiel für die "Einwanderung" einer einheimischen Art mit Folgen für das Ökosystem kann das Vordringen der Nordamerikanischen Espe ( $P O$ pulus tremuloides MICHX.) in die Prärie gelten (BUELL \& FACEY 1960; ARCHIBOLD \& WILSON 1980). Es ist offensichtlich, daß nach der Ansiedlung der Bäume die Beschattung in der Prärie zunimmt. Darüberhinaus scheint sie aber auch den Gehalt des mineralischen Stickstoffs im Boden zu erhöhen (WILSON 1993a). Der höhere Stickstoffgehalt begünstigt die Espe, weil sie weniger genügsam ist und daher im Wettbewerb um Bodenressourcen den Präriegräsern unterliegt (WILSON 1993a). Höhere Stickstoffverfügbarkeit unter Baumkronen wurde auch in anderen Graslandgesellschaften festgestellt (DAVIDSON et al. 1990; KELLMAN 1979; ZINKE 1962; PETRANKA \& MCPHERSON 1979). Die Erhöhung der Stickstoffverfügbarkeit wurde mit Stammabfluß und Kronenauswaschung in Verbindung gebracht (GERSPER \& HOLLOWAYCHUK 1970; KeLLMAN 1979).

Die Bäume können aber auch unmittelbar an der Erhöhung beteiligt sein, da die Verfügbarkeit des Bodenstickstoffs durch die Bindungsform und die Menge des zugeführten Stickstoffs, die Verlustrate des Ökosystems (TAMM 1991: 7-33; PASTOR et al. 1984) und die Wirksamkeit der Zersetzer gesteuert wird. Folglich können Pflanzen durch eine Änderung der abiotischen Lebensbedingungen der mikrobiellen Zersetzer, Denitrifikanten und Stickstoffixierer (HOBBIE 1992), durch Stickstoffaufnahme und -speicherung (VITOUSEK 1982) und die Menge und chemische Zusammensetzung der 
Streu (MELILLO et al. 1982; PASTOR et al. 1984) auf den Stickstoffkreislauf einwirken.

Es ist daher anzunehmen, daß Laubabwurf und Streuzersetzung für die Erhöhung des Mineralstickstoffs im Boden unter Baumkronen sehr wichtig sind. Das Ziel dieser Diplomarbeit ist es, diese Vermutung am Beispiel der Espenstreu zu überprüfen und die Bedeutung der Streuzersetzungsvorgänge für die Einwanderung der Espen in die Prärie zu diskutieren.

\subsection{Auswahl des Versuchsbiotops}

Espenhaine eignen sich aus mehreren Gründen gut dafür, den Einfluß der Laubzersetzung auf die Erhöhung des mineralischen Bodenstickstoffs zu untersuchen:

1. Die zu beobachtende Ausweitung der Haine kann als andauernde, natürliche Sukzession betrachtet werden.

2. Die Haine werden von Espen dominiert, Versuchsergebnisse können daher durch die Einwirkung einer einzigen Art erklärt werden.

3. Da die Haine im Umfang wachsen, stellen sie eine Chronosequenz dar, an der die Stickstoffanreicherung beobachtet werden kann und bei der wegen der Kleinräumigkeit Klima oder Bodentyp vernachlässigbar sind.

4. Der Einfluß der Espen auf die Stickstoffverfügbarkeit kann mit der ursprünglichen Prärie verglichen werden. Außerdem ist ein experimenteller Streuaustausch zwischen Hainen und Prärie auf kleinem Raum möglich.

5. Einwandernde Espen könne auch als Baumgrenze betrachtet werden. Baumgrenzen sind eine weltweite Erscheinung, die sowohl an den Grenzen zu Steppen und Savannen als auch zu alpinen Rasen und zur Tundra auftreten.

Erkenntnisse aus dieser Diplomarbeit könnten daher eine weitreichende Bedeutung haben. Ein Nachteil der Espenhaine ist aber, daß Ressourcen zwischen den Wurzelschößlingen bis zu drei Jahrzehnten verlagert werden können (ZAHNER \& DEBYLE 1965), was den unmittelbaren Einfluß eines Baumes auf die Stickstoffverfügbarkeit verschleiern kann.

\subsection{Biome der Espeneinwanderung}

\subsubsection{Prärie}

Für ein Viertel der festen Erdoberfläche sind Graslandgesellschaften die potentielle natürliche Vegetation (SHANTZ 1954). Sie sind auf allen Erdteilen außer der Antarktis vertreten. Grasland kommt dort vor, wo 
zumindest zeitweise während eines Jahres das vorhandene Bodenwasser für Wälder unzureichend ist, aber den Ansprüchen von Grasartigen genügt (LAUENROTH 1979). In den meisten Jahren wird das Wachstum der Grasartigen durch Stickstoffmangel eingeschränkt, nur in ausgesprochenen Dürrejahren ist Wasser der begrenzende Faktor (TILMAN 1990).

Das größte Grasland Nordamerikas ist die "Prärie" (Festuco-Stipea LOOMAN 1978). Sie bedeckt im Regenschatten des Felsengebirges die Great Plains. Die Prärie erstreckt sich in Nord-Süd-Richtung vom Fluß Saskatchewan bis zum Golf von Mexiko, nach Osten bis zum 95. Längengrad, mit einem Ausläufer in den Bundesstaat Illinois, südlich des Michigansees.

Die Verbreitung der wichtigsten Präriegesellschaften, Langgras-, Mischgras- und Kurzgrasprärie, entspricht der Abnahme der Niederschlagsmenge von Ost nach West (Abb. 1). Innerhalb der Präriegesellschaften nimmt der Anteil der Kräuter mit zunehmender Jahresmitteltemperatur nach Süden ab (WALTER 1984: 273). Der trockenste Teil, das südöstliche Viertel der Great Plains, wird von Kurzgrasprärie eingenommen, deren wichtigsten Gräser die 0,05 bis 0,4 m hohen Bouteloua gracilis (HBK.) LAG. und Buchloë dactyloides ENGELM. sind. Nach SHELFORD (1963: 330) erstreckt sich die Kurzgrasprärie sogar noch weiter nach Norden bis in die kanadischen Provinzen Alberta und Saskatchewan. Die Langgrasprärie reicht von Südostmanitoba bis zur Südspitze von Texas und schließt die Central Plains

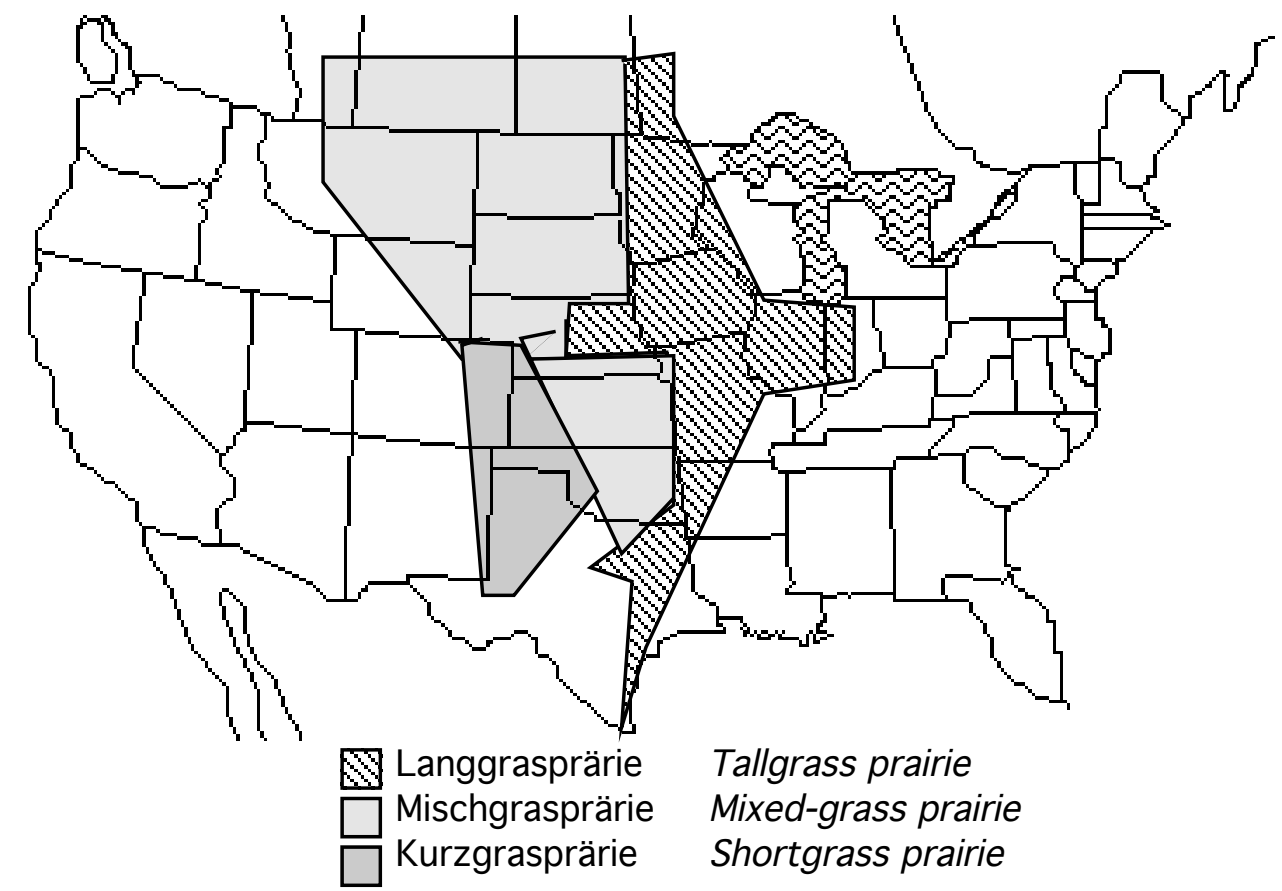

Abb. 1. Vereinfachte Darstellung der Verbreitung der wichtigsten Präriegesellschaften in Nord-Amerika. Nach FRENCH (1979a).

Fig. 1. Simplified presentation of the distribution of the major prairie types in NorthAmerica. Adapted from FRENCH (1979a). 
ein. Diese Präriegesellschaft ist durch 0,5 bis $1 \mathrm{~m}$ hohe Gräser gekennzeichnet, die mit Blütenständen sogar $2 \mathrm{~m}$ Höhe erreichen können. Wichtigste Vertreter sind die beiden Bartgrasarten Andropogon scoparius MICHX. und A. gerardii VITMAN und die Federgräser (Stipa sp.). Die Mischgrasprärie (Abb. 2) umfaßt den südlichen Teil Saskatchewans, Südostalberta und die meisten Anrainerstaaten des Mississippi. In dieser Präriegesellschaft treten sowohl Kurz- als auch Langgräser auf und bilden somit den Übergangsbereich zwischen den anderen beiden Präriegesellschaften (COUPLAND 1950, 1961; WALTER 1985).

Die zonalen Böden der Prärie sind Schwarzerden und Braunerden (WALTER 1984: 272). Die Landschaft ist flach bis wellig, sie steigt von $300 \mathrm{~m}$ im Osten bis auf 1500 m ü.N.N. im Westen an. Das Großklima der Prärie ist arid gemäßigt (WALTER 1984).

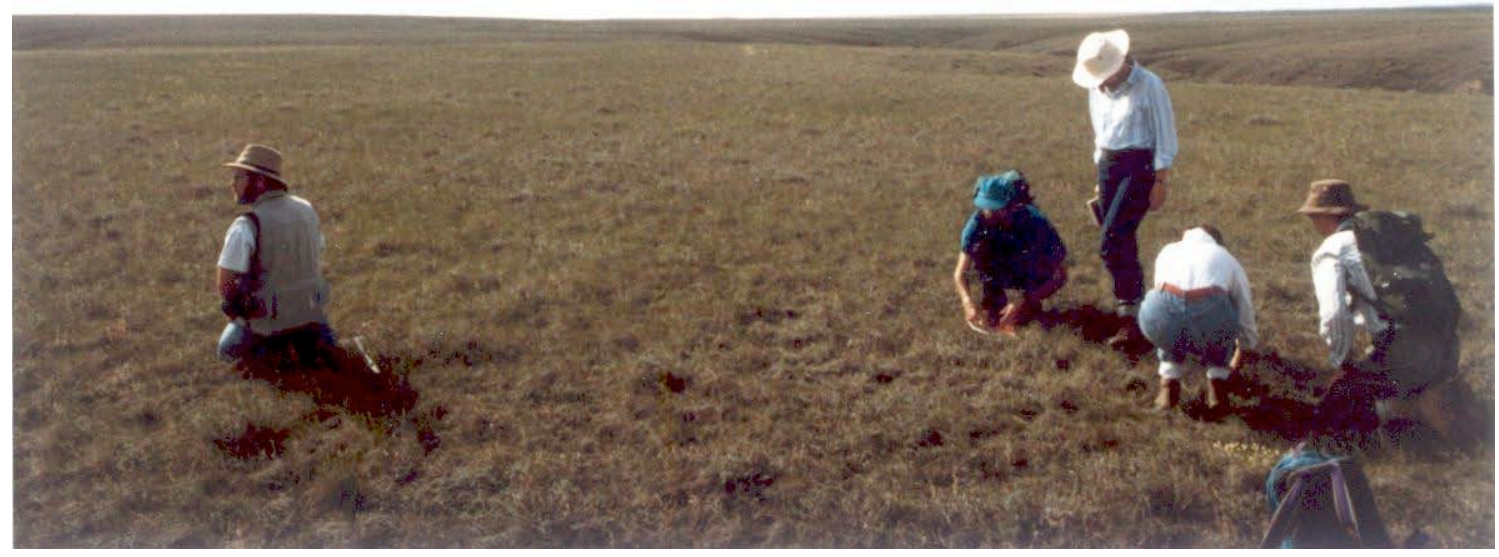

Abb. 2. Mischgrasprärie (Stipo-Boutelouetum). Abgebildet ist die Agropyron-KoeleriaSubassoziation. Aufgenommen im Juni 1993 bei der Matador-Feldstation des Internationalen Biologischen Programms, Saskatchewan, Kanada.

Fig. 2. Mixed-grass prairie ( Stipo-Boutelouetum). The photograph shows the Agropyron-Koeleria sub-association. Photograph taken in June 1993 near Matador field station of the International Biological Program, Saskatchewan, Canada.

\subsubsection{Espenwälder und Espenparkland}

Die Nordamerikanische Espe ist im gesamten borealen Nadelwald verbreitet, gelangt jedoch erst südlich des Nadelwaldes zur Vorherrschaft. Wo der Espenwald auf die Mischgrasprärie stößt, löst sich der Wald in kleine Waldinseln auf, deren Größe nach Süden hin abnimmt und deren Abstände 
untereinander zunehmen. Schließlich bilden kleine Haine, von den Einheimischen "bluffs" genannt, die Waldgrenze zur Prärie (BIRD 1930, 1961; BARNES 1966). Dieser Übergangsbereich zwischen Wald und Prärie ist das sogenannte Espenparkland. Für aride Gebiete und wahrscheinlich für Waldgrenzen im allgemeinen ist diese Verinselung des Waldes kennzeichnend (SHelFord 1963; ElLENBERG 1986: 521). Das Parkland zieht sich in einem 80 bis 250 km breiten Bogen von Südostalberta durch Mittelsaskatchewan nach Südwestmanitoba. Abgesehen von kleinen Gebieten in Norddakota und Minnesota ist das Parkland auf Kanada beschränkt. Das Espenparkland ist eingehend von BIRD (1930) beschrieben worden. Espenhaine (Populetalia tremuloides LOOMAN 1987) werden von 1,5 bis $4 \mathrm{~m}$ hohen und 5 bis $8 \mathrm{~cm}$ starken Wurzelschößlingen der Espe und von Schneebeerbüschen (Symphoricarpos albus (L.) BLAKE) beherrscht (Abb. 3).

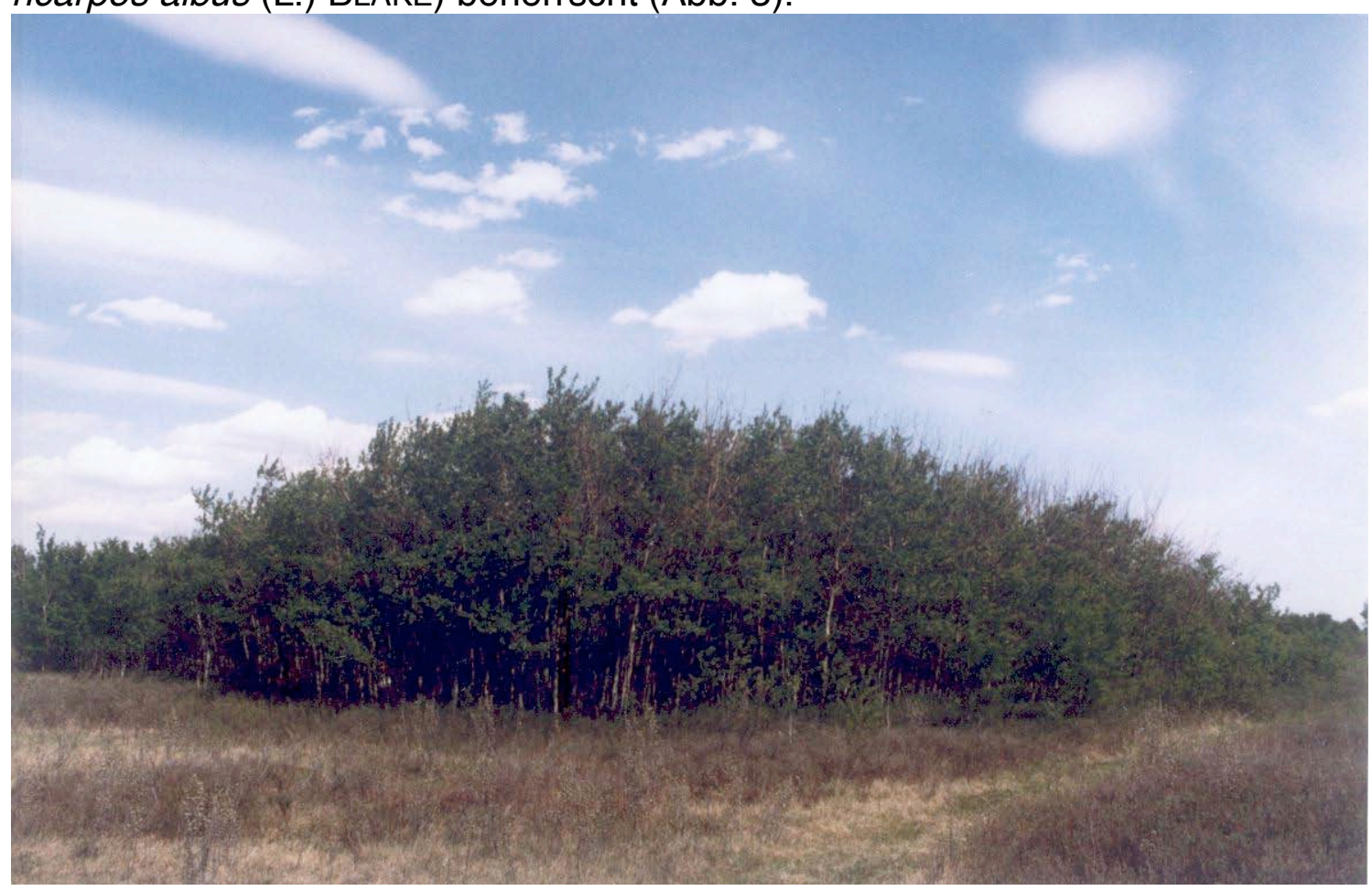

Abb. 3. Espenhain (Bromo-Populetum tremuloides LOOMAN 1987) im Versuchsgelände "W". Aufgenommen Anfang Mai 1993 in der White Butte Provinvial Recreation Area, Saskatchewan, Kanada.

Fig. 3. Aspen bluff (Bromo-Populetum tremuloides LOOMAN 1987) in experimental plot "W." Photograph taken in early May 1993 in White Butte Provincial Recreation Area, Saskatchewan, Canada.

Die Strauchschicht bilden neben den Espenschößlingen vor allem Amerikanische Hasel (Corylus americana WALT.), Virginische Traubenkirsche (Prunus virginiana L.) und Schöne Rose (Rosa blanda AIT.) (BIRD 1930). Die Espe verbreitet sich hauptsächlich durch Wurzelsprosse, daher bestehen Haine fast immer aus nur einem Klon (BARNES 1966). Junge Wurzelschößlinge werden etwa 25 Jahre von den Elternbäumen mit Nährstoffen und 
Wasser versorgt (ZAHNER \& DEBYLE 1965). Die Lebenserwartung einzelner Bäume beträgt 50 Jahre (MAINI 1960: 39), der Klon kann jedoch mehrere Jahrhunderte alt werden (BARNES 1966). Der Alterungsvorgang wird meistens durch Feuerschwamm- (Phellinus tremulae (BONDARTSEV) BONDARTSEV \& BORISOV) und Käferbefall (Saperda calcerata SAY.) beschleunigt (BIRD 1930). Die vielen Rhizome der Espe können mehr als 30 $m$ in die Prärie vordringen (BARNES 1966; BUeLL \& BUeLL 1959). Die Mitte der Espenhaine wird manchmal von Nadelbäumen, vor allem der WeißFichte (Picea glauca (MOENCH) VOSS) gebildet (SHELFORD 1963: 319; Severson 1982). Ausführliche Beiträge zur Biologie der Espe sind bei MAINI (1960) und PETERSON \& PETERSON (1992) zu finden.

Die Prärievegetation des Espenparklandes gehört zum Mischgrastyp, vorwiegend handelt es sich um die Stipo-Boutelouetum-Assoziation (LOOMAN 1980). In die Prärie sind kleine Strauchgruppen, zum Prunion melanocarpae LOOMAN 1983 und Elaeagnion commutatae LOOMAN 1983 gehörend, eingesprengt. Dürrejahre und Nässeperioden wirken sich stark, aber nicht dauerhaft auf die Artenzusammensetzung der Prärie aus (CLARKE et al. 1943 in COUPLAND 1950; COUPLAND 1958).

Das Ausgangsmaterial der Böden im Parkland ist eiszeitlichen Ursprungs, nach der kanadischen Bodeneinteilung handelt es sich um bei innen um Ausgelaugte typische Schwarzerden ("eluviated Black chernozemic soils"), Typische dunkelgraue Schwarzerden ("orthic Darkgrey chernozemic soils") und Schwarzer Solonez ("Black solonetz soils"). Der Gesamtstickstoffgehalt repräsentativer Profile von Schwarzerden schwankt zwischen 0,32 und $1,0 \%$ in den oberen $10 \mathrm{~cm}$ (CLAYTON et al. 1977).

\subsection{Das Einwandern der Espe}

In verschiedenen Untersuchungen wird berichtet, daß Espen seit der Ansiedlung der Europäer zu Beginn des 19. Jahrhunderts in die Mischgrasprärie einwandern (CLEMENTS et al. 1929 in WALTER 1935; PYNE 1986; ARCHIBOLD \& WILSON 1980). Es wird vermutet, daß die Siedler die häufigen Präriebrände eindämmten, die angeblich bis dahin die Espenausbreitung verhindert hatten (WRIGHT \& BAILEY 1982; WALTER 1985: 221). Andererseits ist die Triebfreudigkeit der Espe gerade nach Bränden bekannt (PETERSON \& PETERSON 1992: 114f). Da die Häufigkeit der Brände aber auch schon vor der Siedelung der Europäer geschwankt hat (MITCHELL et al. 1944; PYNE 1986), ohne daß es zu einer Änderung des Espenareals kam (ARCHIBOLD \& WILSON 1980), ist das Vordringen der Espen vermutlich ein natürlicher, von der Brandeindämmung unabhängiger Vorgang. 
BIRD (1930) beschreibt die Ansiedlung der Espen als eine Folge von Buschstufen: Die Schneebeere (Symphoricarpos albus) keime in Senken, feuchten Stellen und Bodenaufwürfen, die oft von grabenden Dachsen (Taxidea taxus WATERHOUSE) oder Taschenratten (Thomomys talpoides WIED) verursacht werden. Der Busch wachse dicht und "ersticke" das Gras. Auf trockeneren Standorten siedele sich eher die Silber-Ölweide (Elaeagnus commutata BERNH. ex RYDB.) an. Sie "bewahre" die [Boden-] Feuchtigkeit und ermögliche der Schneebeere, gefolgt von der Espe, Fuß zu fassen.

Die Annahme, daß Aufwürfe von Dachsen und Taschenratten Keimplätze für Sträucher sind, konnte jedoch durch eine Vegetationskartierung nicht bestätigt werden (LAYCOCK 1958). Auch die Unterstützung durch Schneebeere und Ölweide bei der Espenansiedlung ist fraglich. Ich habe zum Beispiel mehrere junge Espenhaine gesehen, in deren Nähe keine der beiden Arten vorkam; ebensowenig erwähnt BARNES (1966) diese Straucharten in seiner Espenhainuntersuchung, statt dessen beschreibt er die Ansiedlung durch Keimlinge.

Die Westliche Rosenkranz-Pappel (Populus deltoides BARTRAM ex MARSHALL var. occidentalis RYDB.), die in Südsaskatchewan der Espe morphologisch sehr ähnlich ist, ist dem Präriegras Bouteloua gracilis im Wettbewerb um Bodenressourcen sowohl unter einem Kronendach als auch in der offenen Prärie unterlegen (WILSON 1993a). Wenn Espen sich gegenüber Präriegräsern genauso verhalten, muß es einen Vorgang geben, der der Espe einen Wettbewerbsvorteil verschafft, so daß sie sich in der Prärie ansiedeln kann. Im folgenden Abschnitt werde ich untersuchen, ob ein rückgekoppelter Stickstoffkreislauf solch ein Vorgang sein kann.

\subsection{Streu als Stickstoffquelle}

Der Boden in Espenhainen enthält mehr mineralischen Stickstoff als der Boden in der benachbarten Prärie (WILSON 1993a). Man kann davon ausgehen, daß sich die Stickstoffgehalte vor der Ansiedlung des Hains nicht unterschieden und daß folglich dieser Anstieg von den Espen eingeleitet wurde. Der Anstieg läßt sich durch einen Rückkopplungskreislauf erklären: Ein hoher Stickstoffgehalt der Streu ermöglicht im allgemeinen eine schnelle Zersetzung der Streu und Mineralisierung des in der Streu enthaltenen Stickstoffs (MELILLO et al. 1982; FOG 1988). Dadurch wird mehr Stickstoff im Boden verfügbar (STUMP \& BINKLEY 1993). Gegenüber anderen Arten, die Stickstoff sparsam einsetzen, begünstigt eine hohe Stickstoffverfügbarkeit solche Arten, die verhältnismäßig viel Stickstoff für den Gewebeaufbau aus dem Boden aufnehmen müssen, weil sie zum Beispiel vor dem Blattabwurf nur wenig Stickstoff aus dem Blatt in die überdauernden Pflanzenteile 
zurückverlagern (TILMAN 1982; TILMAN \& WEDIN 1991). Die Blattstreu dieser "verschwenderischen" Arten hat deshalb einen hohen Stickstoffgehalt (CHAPIN 1980; CHAPIN et al. 1986; VITOUSEK 1986). In der Folge kann sich ein Kreislauf entwickeln, der die Stickstoffverfügbarkeit im Ökosystem insgesamt erhöht (VITOUSEK 1990). Ein derartiger Kreislauf führt dazu, daß Espen im Waldbau als "Bodenverbesserer" gelten (STOECKLER 1961), besonders wenn sie in Nadelwaldforsten, in denen Stickstoff im allgemeinen schlecht verfügbar ist, angepflanzt werden (FRANCK \& BORCHGREVINK 1982; PETERSON \& PETERSON 1992: 54). Wenn dieser Kreislauf von einer einzelnen, in die Prärie eingewanderten Espe ausgeht, kann dies erklären, wie der höhere Stickstoffgehalt des Bodens zustande kommt und wie die Espen den Wettbewerb gegen die Gräser bestehen.

Eine Zusammenstellung von Angaben über Espenstreu und Grasstreu zeigt aber, daß sich diese Streusorten nicht signifikant in ihrem Stickstoffgehalt unterscheiden (Tab. 1; $t=1,1, P>|t| 0,26)$. Der Stickstoffgehalt der Espenstreu hat eine so weite Spanne, weil der Stickstoff erst kurz vor dem Blattfall in die überdauernden Organe zurückverlagert wird (TEW 1970; VERRY \& TIMMONS 1976; CRAGG et al. 1977) und deshalb Blätter, die durch äußere Einwirkung abgetrennt werden, mehr Stickstoff enthalten als abgeworfene Blätter (TAYLOR \& PARKINSON 1988a; KILLINGBECK et al. 1990).

Ein deutlicher Unterschied besteht jedoch in den Stickstoffvorräten der jährlichen Streumenge (Tab. 1). Und zwar ist der Vorrat in Grasstreu $\left(2,4 \mathrm{~g} / \mathrm{m}^{2}\right)$ fast doppelt so groß wie in Espenstreu $\left(1,3 \mathrm{~g} / \mathrm{m}^{2}\right)$. Obwohl nur zwei Angaben für den Stickstoffvorrat der Grasstreu vorliegen, kann der Mittelwert als repräsentativ gelten, denn er stimmt genau mit den Angaben für aride russische Steppengesellschaften $\left(2,4 \mathrm{~g} / \mathrm{m}^{2}\right.$, RODIN \& BAZILEVICH 1967: 166) überein.

Auch der höhere Stickstoffgehalt im Espenzweigabfall (1,0\%; CRAGG et al. 1977; BARTOS \& DEBYLE 1981) kann nicht den Gesamtstickstoffvorrat erhöhen, weil der Jahresvorrat von $0,18 \mathrm{~g} / \mathrm{m}^{2}$ dazu zu gering ist.

Wurzeln können eine reiche Stickstoffquelle sein (Stanton 1988), doch es gibt nur wenige Untersuchungen über die Gehalte in abgestorbenen Wurzeln. Zudem sind die Angaben nicht sehr zuverlässig, wenn das Wurzelmaterial nicht nach Zerfallszustand getrennt wurde (zum Beispiel Black \& Wight 1979), denn der Zerfallszustand hat einen erheblichen Einfluß auf den Stickstoffgehalt (Clark 1977). Die folgenden Werte (Tab. 2) können daher nicht mehr als Näherungen sein. Für die Nordamerikanische Espe liegen keine Angaben über den Stickstoffgehalt abgestorbener Wurzeln vor. 
Tab. 1. Stickstoffkonzentrationen in Gras- und Espenstreu in der Literatur. Alle Grasarten sind in der Mischgrasprärie einheimisch. Nomenklatur der Gräser nach LOOMAN (1982)

Tab. 1. Literature review of nitrogen content of aspen and grass litter. All grass species are native to mixed-grass prairie. Nomenclature of grasses follows LOOMAN (1982).

\begin{tabular}{|c|c|c|c|}
\hline $\begin{array}{c}\text { Art } \\
\text { Species } \\
\end{array}$ & $\begin{array}{c}\mathrm{N}-\text {-Gehalt } \\
N \text { concentration }\end{array}$ & $\begin{array}{l}\mathrm{N} \text {-Vorrat } \\
N \text { storage }\end{array}$ & $\begin{array}{c}\text { Quelle } \\
\text { Reference } \\
\end{array}$ \\
\hline Agropyron smithii & $3,4 \mathrm{mg} / \mathrm{g}$ & & SMOLIAK \& BEZEAU 1967 \\
\hline Elymus canadensis & 4,0 & & HEINRICHS \& CARSON 1956 \\
\hline Stipa viridula & 6,4 & & HEINRICHS \& CARSON 1956 \\
\hline Koeleria cristata & 7,2 & & SMOLIAK \& BEZEAU 1967 \\
\hline Stipa comata & 7,4 & & SMOLIAK \& BEZEAU 1967 \\
\hline [Bouteloua gracilis, & 8,1 & & TAYLOR et al. 1989 \\
\hline \multicolumn{4}{|c|}{ Stipa comata, Agropyron spp.] } \\
\hline Bouteloua gracilis & 8,2 & & SMOLIAK \& BEZEAU 1967 \\
\hline Carex filifolia & 9,7 & & SMOLIAK \& BEZEAU 1967 \\
\hline Poa secunda & 10,1 & & SMOLIAK \& BEZEAU 1967 \\
\hline [Bouteloua gracilis, & 11,1 & & diese Diplomarbeit this thesis \\
\hline \multicolumn{4}{|c|}{ Koeleria cristata, St. comata, Carex sp.] } \\
\hline Bouteloua gracilis & 12 & & HUNT et al. 1988 \\
\hline Stipa comata & 14,4 & & PIGDEN 1953 \\
\hline Bouteloua gracilis & & $2,5 \mathrm{~g} / \mathrm{m}^{2}$ & CLARK 1977 \\
\hline \multicolumn{2}{|c|}{ Mischgrasprärie Mixed Grass Prairie } & 2,2 & REDMANN 1991 \\
\hline Populus tremuloides & & $0,9-1,4$ & VAN CLEVE \& NOONAN 1975 \\
\hline Populus tremuloides & 4,4 & 0,6 & BARTOS \& DEBYLE 1981 \\
\hline Populus tremuloides & 5,6 & & DAUBENMIRE \& PRUSSO 1963 \\
\hline Populus tremuloides & 6,2 & & diese Diplomarbeit this thesis \\
\hline Populus tremuloides & 6,3 & & DAUBENMIRE 1953 \\
\hline Populus tremuloides & 6,5 & & TAYLOR \& PARKINSON 1988a \\
\hline Populus tremuloides & 7,3 & & STUMP \& BINKLEY 1993 \\
\hline Populus tremuloides & 7,4 & & VERRY \& TIMMONS 1976 \\
\hline Populus tremuloides & 7,8 & 1,2 & CRAGG et al. 1977 \\
\hline Populus tremuloides & 8,8 & 1,2 & PASTOR \& BOCKHEIM 1984 \\
\hline Populus tremuloides & 9,2 & & KILLINGBECK et al. 1990 \\
\hline Populus tremuloides & 10,5 & 2,4 & LOUSIER \& PARKINSON 1976, 1978 \\
\hline Gräser Grasses & 8,5 & 2,4 & Mittelwert Average $(n=12)$ \\
\hline Populus tremuloides & 7,3 & 1,3 & Mittelwert Average $(n=10)$ \\
\hline
\end{tabular}


RODIN \& BAZILEVICH (1967: 116) geben aber Werte für die Europäische Espe (Populus tremula L.), die vikariierende Schwesterart in Eurasien (DANSEREAU 1957: 24) an, die allerdings ein Siebtel mehr Stickstoff in der gesamten Trockenmasse enthält (RODIN \& BAZILEVICH 1967; BARTOS \& JOHNSTON 1978; PASTOR \& BOCKHEIM 1984). Wenn dieser höhere Anteil bei den Angaben für die Wurzeln abgezogen wird, ergeben sich als Stickstoffgehalt in abgestorbenen Wurzeln der Nordamerikanischen Espe etwa 0,6\% beziehungsweise $0,6 \mathrm{~g} / \mathrm{m}^{2}$. Absterbende Wurzeln des Präriegrases Bouteloua gracilis einschließlich der auf den Wurzeln befindlichen Mikroorganismen enthalten 2,6 \% Stickstoff, das entspricht einem Vorrat von $8,8 \mathrm{~g} / \mathrm{m}^{2}$ in den oberen $10 \mathrm{~cm}$ des Bodens (CLARK 1977). Angaben für abgestorbene Wurzeln in ariden, russischen Steppengesellschaften reichen von 0,9 bis $1,3 \%$ und 2,9 bis $8,4 \mathrm{~g} / \mathrm{m}^{2}$ (RODIN \& BAZILEVICH 1967: 166). Tabelle 2 faßt die Angaben über Stickstoffgehalte und -vorräte bei Präriegräsern und Espe zusammen (Schätzwerte sind kursiv dargestellt).

Tab. 2. Stickstoffkonzentration und -vorrat in abgestorbenen Organen von Espe (Populus tremuloides) und Präriegräsern. Die Werte wurden aus Literaturangaben gemittelt (Quellen, siehe Text).

Tab. 2. Concentration and storage of nitrogen in various dead compartments of aspen (Populus tremuloides) and prairie grasses. Values are averaged from those reported in the literature. (See text for references.)

\begin{tabular}{|c|c|c|c|c|}
\hline \multirow{3}{*}{ Kind of litter } & \multirow{2}{*}{\multicolumn{2}{|c|}{$\begin{array}{c}\mathrm{N}-\text { Gehalt (\% Trockenmasse) } \\
\text { Concentration of N (\% dry mass) }\end{array}$}} & \multirow{2}{*}{\multicolumn{2}{|c|}{$\begin{array}{l}\text { Stickstoffvorrat }\left(\mathrm{g} \mathrm{m}^{-2} \mathrm{a}^{-1}\right) \\
\text { Storage of Nitrogen }\left(\mathrm{g} \mathrm{m}^{-2} \mathrm{a}^{-1}\right)\end{array}$}} \\
\hline & & & & \\
\hline & P. tremuloides & Gräser Grasses & P. tremuloides & Gräser Grasses \\
\hline Blätter Leaves & 0,85 & 0,75 & 1,3 & 2,4 \\
\hline Zweige & 1,01 & - & 0,2 & - \\
\hline Wurzeln Roots & 0,6 & 0,8 & 0,6 & 8,8 \\
\hline Gesamt Total & & & 2,1 & 11,2 \\
\hline
\end{tabular}

Gras- und Espenstreu werden unter gleichen Umweltbedingungen gleich schnell zersetzt (TAYLOR et al. 1989). Das liegt vielleicht unter anderem daran, daß beide Streusorten fast den gleichen Ligningehalt aufweisen (TAYLOR et al. 1989). In ihren ursprünglichen Biotopen wird die Streuzersetzung jedoch verzögert, und zwar bei Espenstreu stärker als bei Grasstreu. Die Halbwertszeit der Espenstreu beträgt 2,4 Jahre (BARTOS \& DEBYLE 1981; LOUSIER \& PARKINSON 1976), die der Grasstreu 1,4 Jahre (ABOUGUENDIA \& WHITMAN 1979; PASTOR et al. 1987; SEASTEDT et al. 1991).

Zusammenfassend läßt sich also sagen, daß der Stickstoffvorrat der Espenstreu nicht im Zusammenhang mit der Erhöhung der Stickstoffverfüg- 
barkeit in Espenhainen steht und der Espe daher auch keinen Wettbewerbsvorteil bei der Einwanderung in die Prärie bringt.

Wärme und Feuchtigkeit, können einen größeren Einfluß auf die Streuzersetzung und damit auf die Stickstoffverfügbarkeit haben als der Stickstoffgehalt der Streu (MEENTEMEYER 1978; MORECROFT et al. 1992;

NADELHOFFER et al. 1991; UPADHYAY et al. 1985). Durch den Schatten eines geschlossenen Kronendaches wird die Temperatur an der Bodenoberfläche vermindert, dadurch die Evapotranspiration verringert und die Bodenfeuchte erhöht (SKIDMORE \& HAGEN 1973; LARCHER 1973: 250f; ETHERINGTON 1982: 26). Auf diese Weise könnte das Kronendach eingewanderter Espen die abiotischen Lebensbedingungen der mikrobiellen Zersetzer verbessern und die Stickstofffreisetzung beschleunigen. Daß Haine ihren Ursprung oft in feuchten Senken haben (BIRD 1930; MAINI 1960), ist ein Hinweis darauf, daß eine gewisse Bodenfeuchte für die Ausbreitung der Haine wichtig ist. Auch wachsen Haine auf ihrer Leeseite schneller als auf ihrer Luvseite (G. SUTTER, unveröffentlichter Bericht), da es dort wahrscheinlich trockener und heißer ist (MAINI 1960).

Wenn also ein geschlossenes Kronendach in irgendeiner Weise wichtig für die Erhöhung der Stickstoffverfügbarkeit im Boden ist, sollte auch die Zeit, in der der Stickstoffgehalt ansteigt, von der Zeit, die zur Bildung eines geschlossenen Kronendaches nötig ist, mithin vom Alter der Bäume, abhängen. Um diese Vermutung zu überprüfen, wurde ein Transekt durch einen Espenhain daraufhin untersucht, ob die Stickstoffverfügbarkeit im Boden mit dem Alter der Bäume zusammenhängt.

Da keine Veröffentlichung vorliegt, in der der Einfluß von Beschattung auf Zersetzung und Stickstofffreisetzung bei verschiedenen Streusorten untersucht wird, wurde ein Versuch durchgeführt, um die Annahme zu überprüfen, daß Beschattung die Zersetzung der Espenstreu stärker als die der Grasstreu beschleunigt.

\subsection{Ziel der Transektuntersuchung und des Versuches}

Durch die Untersuchung der Transekte in Espenhainen soll die Annahme überprüft werden, daß ein Zusammenhang zwischen dem Alter der Bäume beziehungsweise dem Vorhandensein eines geschlossenen Kronendaches und der Menge des verfügbaren Stickstoffs unter den Bäumen besteht. Darüberhinaus soll die Einwirkung des Kronendaches auf Temperatur, Lichtdurchlaß und Bodenfeuchtigkeit beschrieben werden, weil anzunehmen ist, daß diese Merkmale in engerem Zusammenhang zur Streuzersetzung stehen als das Alter der Bäume. Da durch die Untersuchung von WILSON 
(1993a) bereits bekannt war, daß im Boden der Espenhaine des

Versuchsgeländes White Butte ${ }^{1}$ mehr Stickstoff verfügbar ist als im Boden der benachbarten Prärie, sollte durch die Wahl eines entfernter liegenden Untersuchungsgebietes festgestellt werden, ob dieses Verhältnis auch außerhalb des Versuchsgeländes auftritt.

Durch den Streuzersetzungsversuch soll die Hypothese überprüft werden, daß die Höhe des Mineralstickstoffgehaltes im Boden von Espenhainen weniger vom Stickstoffgehalt der Streu oder vom Hainstandort abhängt als von einer schnelleren Streuzersetzung, die durch eine Senkung der Evapotranspiration und damit eine Verbesserung der Lebensbedingungen der Streuzersetzer durch den Kronendachschatten hervorgerufen wird. Dazu wurden die Raten des Gewichtsverlusts und der Stickstoffabgabe von Grasund Espenstreu (Streusortenfaktor) unter zwei Beschattungsstufen (Beschattungsfaktor) in zwei Biotopen (Biotoptypfaktor) gemessen. Es ist notwendig, den Einfluß des Biotoptyps zu bestimmen, um der "Huhn-oder-EiStreitfrage" (TAMM 1991: 29f) zu entgehen, ob die Vegetation die Erhöhung der Stickstoffverfügbarkeit bewirkt hat, oder ob die Biozönose dort entstanden ist, wo bereits vorher mehr Stickstoff verfügbar war. Falls künstliche Beschattung in der Prärie den gleichen Einfluß auf die Streuzersetzung hat wie die natürliche Beschattung des Kronendaches, kann davon ausgegangen werden, daß nicht die Espen an sich, sondern deren Schatten für den Anstieg des Mineralstickstoffgehaltes im Espenhainboden verantwortlich ist.

\footnotetext{
${ }^{1}$ sprich [bju:t]
} 


\subsection{Untersuchung der Espenhaintransekte}

Die Haintransekte wurden auf einer mit Espenhainen bestandenen Gruppe von Wiesen in Oakshela bei Grenfell, 125 km östlich von Regina ${ }^{2}$, Saskatchewan $\left(50^{\circ} 26^{\prime} \mathrm{N} / 102^{\circ} 44^{\prime} \mathrm{W}\right)$, untersucht. Die Wiesen werden nach Angaben der Besitzer und nach dem Zustand der Vegetation sehr extensiv genutzt. Der Boden ist ein frischer bis trockener Schwarzer Solonez auf Lehm. Die Espenhaine besitzen eine unvollständige Krautschicht. Die Wiesenvegetation wird vom Kleinen und Großen Bartgras (Andropogon scoparius und $A$. gerardii) beherrscht. Sie kann den Hochgrasprärie-Gesellschaften (Stipo-Andropogonetea LoOMAN 1980) zugeordnet werden.

In sechs Espenhainen wurden auf je einem Transekt Mineralstickstoffgehalt und Bodenfeuchte (im Juli) sowie Lichteinfall und Temperatur (im August) gemessen. Die Transekte erstreckten sich von der Mitte der Haine bis zu einem Punkt $5 \mathrm{~m}$ vom Hainsaum entfernt in der Prärie (Abb. 4), wobei angenommen wurde, daß die drei ältesten Bäume die Mitte des Haines bildeten. Die Richtung der Transekte wurde jeweils durch Zufallsauswahl festgelegt. Die Messungen wurden in der Hainmitte, auf dem ersten und zweiten Drittel der Strecke zum Hainsaum, im Saum und in der Prärie 2,5m und $5 \mathrm{~m}$ vom Saum entfernt vorgenommen. Als Hainsaum wurde die Grenze des geschlossenen Kronendachs festgelegt. Da die Espenschößlinge aber auch vereinzelt außerhalb des Saumes in der Prärie wachsen, fiel der Altersgradient nicht auf allen Transekten bis auf Null ab (vgl. Abb. 8a). Die älteste Espe in der Prärie war 14 Jahre alt und hatte einen Stammdurchmesser von $3,9 \mathrm{~cm}$ in drei Dezimetern Höhe.

Für die Bestimmung des Mineralstickstoffgehaltes und der Bodenfeuchte wurden zylindrische Bodenproben (ohne Streuauflage) mit einem Durchmesser von $2 \mathrm{~cm}$ aus 0-10 cm Tiefe genommen. Eine Teilprobe von $7 \mathrm{~g}$ wurde 24 $\mathrm{h}$ lang in einer 0,02 M KCl-Lösung extrahiert, die Lösung dekantiert und bis zur Stickstoffanalyse eingefroren. Der Rest der Bodenprobe wurde zur Bestimmung der Bodenfeuchte und des Trockengewichtes verwendet. In der $\mathrm{KCl}$-Lösung gelöstes Nitrat wurde durch zugesetztes Titanchlorid zu Ammoniak reduziert und Ammonium unter Einsatz von Natriumhydroxid durch eine $\mathrm{pH}$-Erhöhung auf 11 ebenfalls in Ammoniak umgewandelt. Die Ammoniakkonzentration in der Lösung wurde dann mit einer zuvor geeichten Ionenelektrode ( $F^{a}$ ORION) gemessen und die Meßwerte auf Gramm

\footnotetext{
${ }^{2}$ sprich [ri: d3aina]
} 


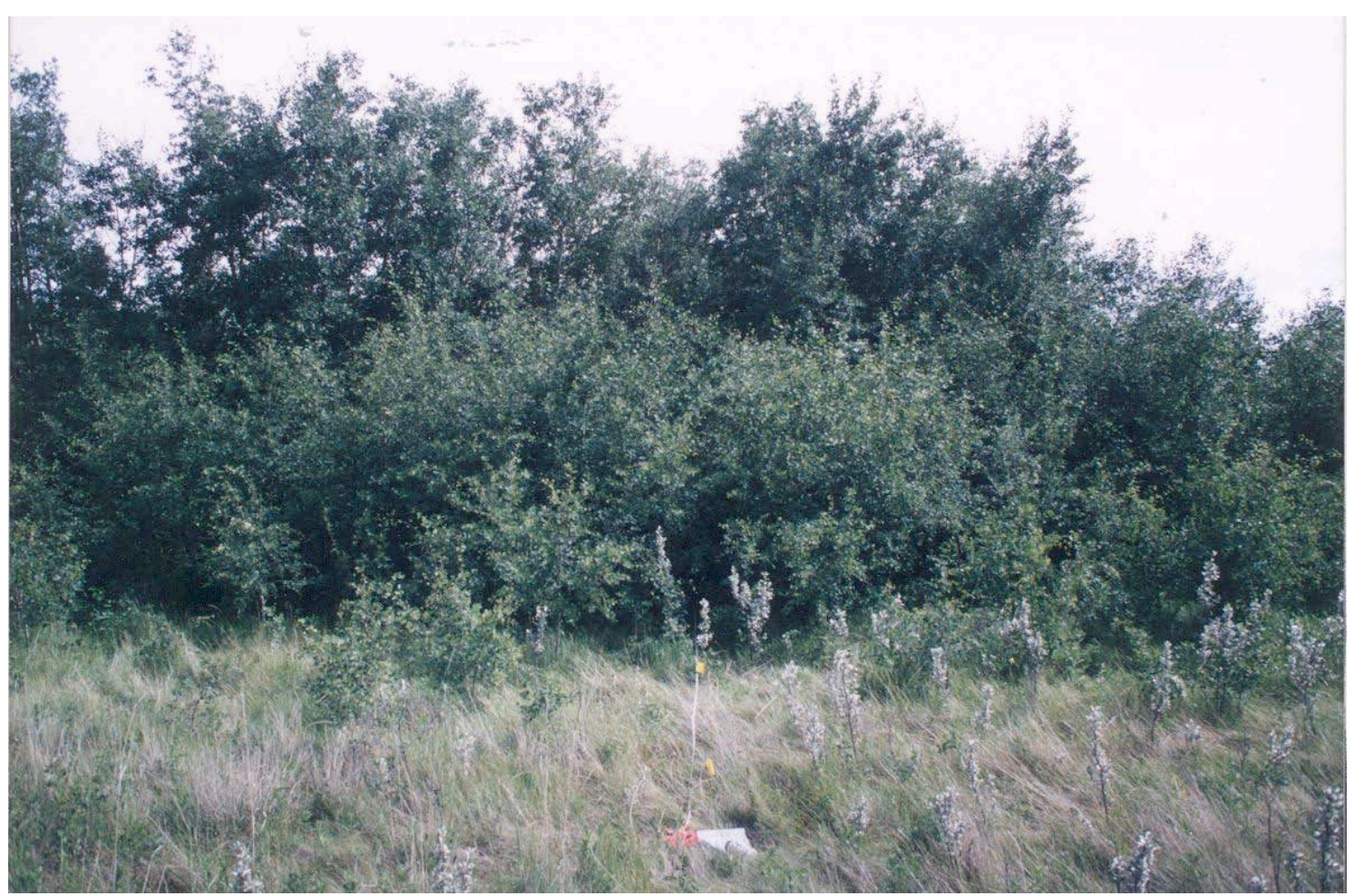

Abb. 4. Transekt von der Hainmitte bis $5 \mathrm{~m}$ in der Prärie vom Hainrand entfernt. Aufgenommen in Oakshela, Saskatchewan, Kanada, im Juli 1993.

Fig. 4. Transect from the centre of a bluff to $5 \mathrm{~m}$ distance from the bluff margin in the prairie. Photograph taken at Oakshela, Saskatchewan, Canada, in July 1993.

Stickstoff je Kilogramm Bodentrockenmasse umgerechnet. Der so ermittelte Stickstoffgehalt ist eine gute Annäherung für den zum Meßzeitpunkt verfügbaren Stickstoff im Boden, der bislang mit keiner Methode genau gemessen werden kann (BINKLEY \& VITOUSEK 1991). Im Vergleich zu anderen Methoden der Stickstoffmessung wird mit der $\mathrm{KCl}$-Extraktion etwa 1 $\%$ des Gesamtstickstoffs erfaßt (BINKLEY \& VITOUSEK 1991).

Lichtdurchlaß und Temperatur wurden $1 \mathrm{~cm}$ über der Bodenoberfläche an jedem Transektpunkt gemessen. Lichtdurchlaß wurde als Verhältnis von Lichtintensität im Bestand zur Intensität außerhalb des Bestandes berechnet. Die Lichtintensität wurde mit einem $40 \mathrm{~cm}$ langen integrierenden PhARempfindlichen Photometer ( $F^{\mathrm{a}}$ DECAGON DEVICES) gemessen. Aus den Temperaturmessungen wurde der Temperaturunterschied zur Hainmitte berechnet. Ferner wurde im Umkreis von einem Meter um jeden Transektpunkt das Alter der drei ältesten Bäume bestimmt. Bäumen mit einem Durchmesser von mehr als $2 \mathrm{~cm}$ in $30 \mathrm{~cm}$ Höhe wurden Bohrkerne entnommen, dünnere Bäume wurden abgeschnitten, um vollständige Querschnitte zu erhalten. Die Holzproben wurden angefeuchtet, um das Zählen der Jahresringe zu erleichtern. 
Es wurden Korrelationen mit Baumalter, Lichtdurchlaß, Temperaturunterschied und Bodenfeuchte als unabhängigen Variablen sowie Mineralstickstoffgehalt als abhängiger Variable berechnet, um Faktoren, die mit der Stickstoffanreicherung im Boden im Zusammenhang stehen, aufzudekken. Da nicht alle Korrelationen in der graphischen Auftragung linear erschienen, wurde neben Maßkorrelationen (parametrisch) auch Kendalls Rangkorrelation (nicht-parametrisch) berechnet. Um die Anreicherungsrate zu bestimmen, wurden für signifikante Maßkorrelationen lineare Regressionen berechnet.

\subsection{Experiment zur Streuzersetzung}

\subsubsection{Versuchsgelände}

Der Versuch wurde in natürlicher Vegetation in der kanadischen Provinz Saskatchewan, 18 km östlich der Provinzhauptstadt Regina in der White Butte Provincial Recreation Area (50²8' N / $104^{\circ} 22^{\prime} \mathrm{W}$ ) durchgeführt. Die Grasvegetation des Versuchsgeländes ist eine Mischgrasprärie (StipoBoutelouetum LOOMAN 1980) mit eingesprengten Trespen-Espenhainen (Bromo-Populetum tremuloides LoOMAN 1987, Abb. 3). Als vorherrschende Arten wurden auf den Prärieversuchsflächen die Gräser Bouteloua gracilis, Stipa comata, Koeleria gracilis PERS. (Zierliches Schillergras), eine Seggenart (Carex filifolia NUTT. oder C. eleocharis BAILEY; COUPLAND 1950) sowie Selaginella densa RYDB. (Dichter Moosfarn) beobachtet.

Der Bodentyp wurde an jeweils drei zufällig gewählten Bohrstockproben innerhalb der Versuchsflächen untersucht. Es handelt sich um einen Regosol auf schluffigem Sand mit einem F-Mull oder mullartigem Moder als Humusauflage. Der A-Horizont hat eine Mächtigkeit von zwei bis drei Dezimetern in der Prärie, in den Espenhainen jedoch nur von einem Dezimeter.

Das Gelände unterliegt einem ariden, kalt-gemäßigten Klima (WALTER \& LIETH 1967; MÜLLER 1982; Abb. 5). Die mittlere Jahrestemperatur in Regina, Saskatchewan $\left(50^{\circ} 26^{\prime} \mathrm{N} / 104^{\circ} 40^{\prime} \mathrm{W}\right)$ ist $2,6^{\circ} \mathrm{C}$. Im Januar beträgt das Tagesmittel -17 $( \pm 6)^{\circ} \mathrm{C}$ (die Spanne in Klammern ergibt die durchschnittlichen Tageshöchst- und -tiefstwerte), im Juli $19( \pm 7)^{\circ} \mathrm{C}($ ENVIRONMENT CANADA 1993). Von Mai bis September liegen die Tagesmitttel über Null, doch kann es in allen Monaten zu Frosteinbrüchen kommen. Siebzig Prozent des gesamten Niederschlages (364 mm) fallen in den Monaten Mai bis September. Ab Juli ist mit einer relativen Trockenzeit im Sinne von WALTER \& LIETH (1967), d. h. IMonatsniederschlag/3I < IMonatsmittel der Temperaturl, zu rechnen. Die potentielle Evapotranspiration ist sogar von Mai bis Oktober höher als die Niederschläge (MüLLER 1982). 


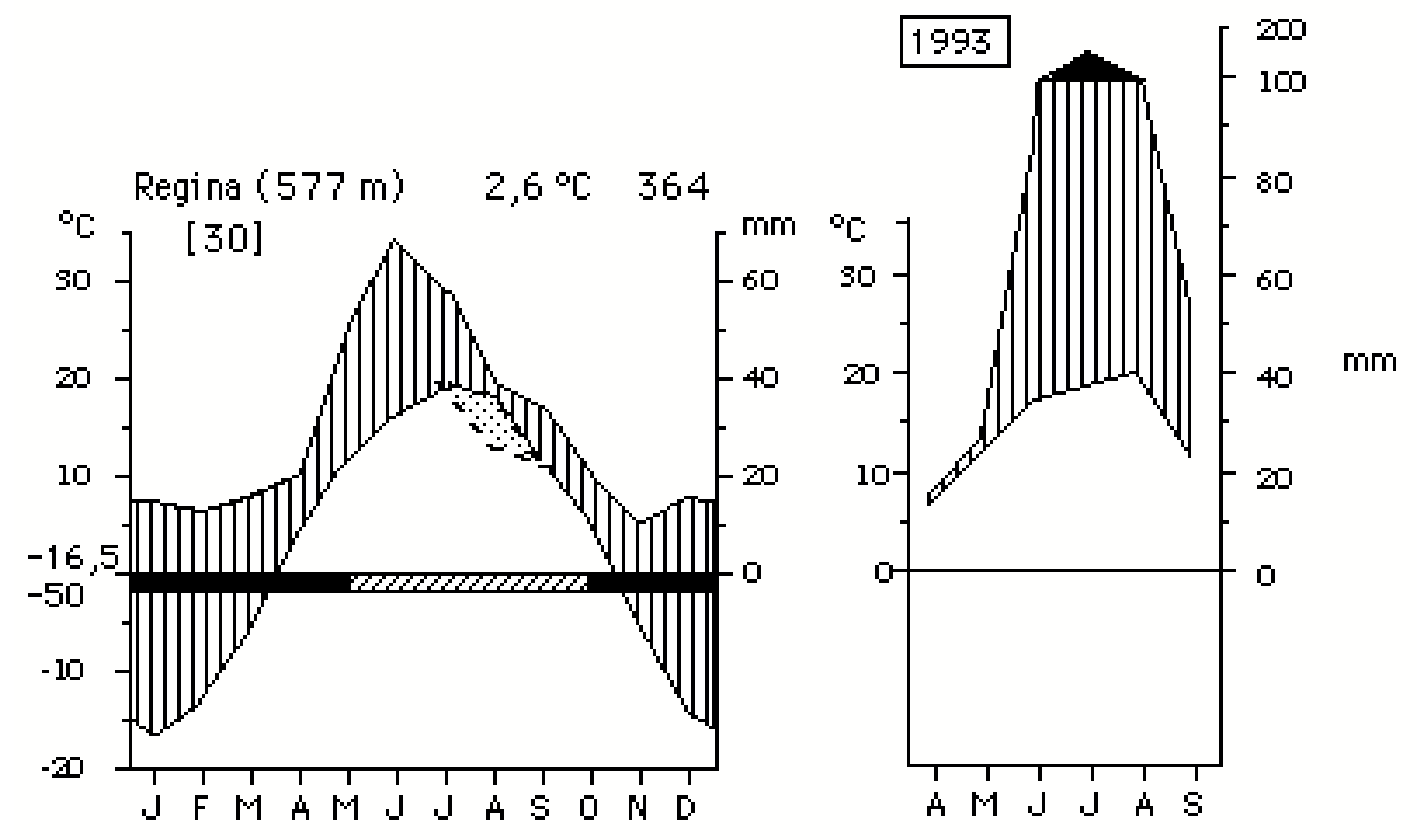

Abb. 5 Klimadiagramme nach WALTER und LIETH (1967) für Regina, Sask. Links: langjährige Mittel 1960-1990 (ENVIRONMENT CANADA 1993), rechts: Monatswerte AprilSeptember 1993.

Fig. 5. Climate diagram after WALTHER and LIETH (1967) for Regina, Sask. Left: longterm averages 1960-1990 (ENVIRONMENT CANADA 1993), right: monthly values AprilSeptember 1993.

Als Einflüsse auf den Masse- und Stickstoffverlust der Streu sollten

- der Biotoptyp (Prärie und Espenhain),

- die Streusorte (Espe und Gras)

- und die Beschattung (offen und beschattet)

sowohl in ihrer Einzel- als auch in ihrer Gesamtwirkung untersucht werden.

Es ergeben sich also bei Kombination der drei Faktoren mit je zwei

Faktorstufen insgesamt acht Versuchsvarianten. In der ersten Maiwoche wurden alle Laubstreuproben ausgebracht und jeweils ein Viertel nach 4, 8, 16 und 21 Wochen wieder eingeholt. Von der geernteten Streu wurden Masse- und Stickstoffverlust gemessen. Für jede Versuchsvariante und jeden Meßzeitpunkt ("Ernte") wurden vier Parallelen geplant. Der Versuchsaufbau als Ganzes wurde an drei Stellen (Gebiet E, S und W) im Versuchsgelände zeitgleich wiederholt. Das heißt, es wurden 384 Streunetze eingesetzt, deren Masseverlust und Stickstoffabgabe gemessen wurde (Tab. 3).

\subsubsection{Versuchsgebiete und Biotopfaktor}

Für den Versuch wurden ebene bis schwach geneigte Gebiete im WhiteButte-Gelände gewählt, in denen natürliche Prärievegetation und natürliche, kuppelförmige Espenhaine mit spärlicher Untervegetation eng benachbart sind. Die Gebiete sollten nicht stärker als $5^{\circ}$ geneigt sein, damit ausgeschlos- 
Tab. 3. Versuchsplan für Gebiet E. Derselbe Versuchsplan gilt für die zwei übrigen Gebiete, S und W. Für jede Versuchsvariante wurden zu jeder Ernte von vier Streuproben der Masseverlust und die Stickstoffauswaschung bestimmt.

Tab. 3. Design of experiment for location E. The same design was applied in the other two locations, $S$ and $W$. For each treatment unit mass loss and nitrogen loss was determined of each litter sample at each harvest.

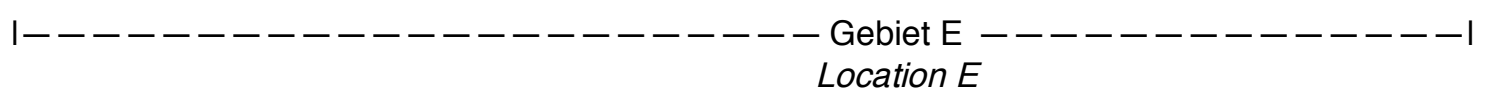

\begin{tabular}{|c|c|c|c|c|}
\hline & \multicolumn{2}{|c|}{$\begin{array}{l}\text { Espenstreu } \\
\text { Aspen litter }\end{array}$} & \multicolumn{2}{|c|}{$\begin{array}{l}\text { Grasstreu } \\
\text { Grass litter }\end{array}$} \\
\hline & $\begin{array}{l}\text { Prärie } \\
\text { Prairie }\end{array}$ & $\begin{array}{l}\text { Hain } \\
\text { Bluff }\end{array}$ & $\begin{array}{l}\text { Prärie } \\
\text { Prairie }\end{array}$ & $\begin{array}{l}\text { Hain } \\
\text { Bluff }\end{array}$ \\
\hline $\begin{array}{l}\text { beschattet } \\
\text { shaded }\end{array}$ & $\begin{array}{l}4 \times \text { Ernte } 1 \\
4 \times \text { Ernte } 2 \\
4 \times \text { Ernte } 3 \\
4 \times \text { Ernte } 4\end{array}$ & $\ldots$ & $\ldots$ & $\ldots$ \\
\hline $\begin{array}{l}\text { offen } \\
\text { open }\end{array}$ & $\ldots$ & $\ldots$ & $\ldots$ & $\begin{array}{l}4 \times \text { Harvest } 1 \\
4 \times \text { Harvest } 2 \\
4 \times \text { Harvest } 3 \\
4 \times \text { Harvest } 4\end{array}$ \\
\hline
\end{tabular}

sen werden konnte, daß Stickstoff oder Streu mit Hangwasser verlagert wird. Die Haine sollten eine Kuppelform, die als Kennzeichen der fortdauernden Ausbreitung gilt (BARNES 1966; MAINI 1960) besitzen, da unter Umständen innerhalb sich ausbreitender Haine ein anderes Mikroklima herrscht als in ruhenden. Die Haine sollten eine spärliche Untervegetation haben, damit Einflüsse anderer Arten wenig ins Gewicht fallen. In den Hainen wurde die Untersuchungsfläche in den ältesten Teil, der noch ein geschlossenes Kronendach aufwies, gelegt. Die Bäume innerhalb dieser Hainflächen waren im Mittel 29 Jahre alt $(S D= \pm 7, n=13)$. Die Entfernung zwischen der Präriefläche und der Hainfläche betrug in zwei Gebieten ungefähr 30 m, in einem Gebiet jedoch $200 \mathrm{~m}$. Die Flächen wurden in 1,5 × 1,5 m² große Teilflächen unterteilt. Beschattung, Streusorte und Erntedatum wurden den Teilflächen innerhalb eines Biotops zufällig zugewiesen.

\subsubsection{Streusortenfaktor}

Für die Untersuchung des Einflusses der Streusorte wurde nur Blattstreu verwendet. Wurzelstreu wurde nicht untersucht, weil die Streu zum Wiegen aus dem Boden genommen werden müßte und diese Störung wahrscheinlich die Einflüsse der anderen Faktoren überdeckte (VITOUSEK et al. 1979). Da die Stickstoffkonzentration der Wurzelstreu der der Laubstreu ähnlich ist (RODIN \& BAZILEVICH 1967), können die Ergebnisse des Laubstreu- 
experimentes zumindest näherungsweise auf die Wurzelstreu übertragen werden.

Die Espenstreu für das Experiment wurde der Ol-Schicht der Humusauflage der Espenhaine, außerhalb der eigentlichen Versuchsflächen, entnommen. Die Form der Blätter war noch fast unverändert, weder skelettiert noch gebleicht. Deshalb kann davon ausgegangen werden, daß es sich um den Laubabfall des vorausgegangenen Herbstes handelte. Aus der eingesammelten Streu wurden -soweit erkennbar- die Streu anderer Arten sowie Zweige und Borke aussortiert. Die Grasstreu stammte vom Rande der Prärieuntersuchungsflächen. Die Streu enthielt auch einen Seggenanteil, "Grasstreu" ist daher als vereinfachender Sammelbegriff zu verstehen. Um Grasstreu vom Vorjahr zu ernten, wurde vor dem Schneiden das Gras mit einem groben Rechen durchkämmt und ältere, lose Streu entfernt. AnschlieBend wurde das Gras etwa einen Zentimeter über dem Boden abgeschnitten. Alle grünen Pflanzenteile wurden aussortiert. Die von verschiedenen Wuchsorten stammende Gras- und Espenstreu wurde jeweils für sich vereinigt und gut durchmischt. Von jeder Streusorte wurden Teilproben genommen (18 Grasstreu- und 14 Espenstreuproben), gewogen und drei Tage bei $105^{\circ} \mathrm{C}$ getrocknet. Die getrockneten Proben wurden erneut gewogen und der Wasser- und Trockenmasseanteil der Streufrischmasse bestimmt. Damit konnte die Trockenmasse der verwendeten frischen Laubstreu berechnet werden; alle weiteren Angaben im Text beziehen sich also, soweit nicht anders vermerkt, auf die Trockenmasse. Der Bestandesabfall des Vorjahres, der aus der gesammelten Streumenge berechnet wurde, betrug 0,2 kg/m2 Espenstreu und 0,05 kg/m2 Grasstreu. Von der Streu wurden jeweils $2 \mathrm{~g}$ in rechteckige Netze mit 9 bis $10 \mathrm{~cm}$ Kantenlänge gefüllt, die Netze an allen Seiten zugenäht und nummeriert, damit Anfangs- und Endmasse jedes einzelnen Netzes jeweils eindeutig zugeordnet werden konnte. Bei der Füllung wurde darauf geachtet, daß die Streu gleichmäßig im Netz verteilt war. Die Füllmenge eines Netzes entspricht der Espenstreumenge, die je Quadratdezimeter gesammelt wurde. Für Grasstreu wurde die gleiche Menge gewählt, damit die Netze gut gefüllt waren und später die lonenaustauscherbeutel gut bedecken konnten (s. Abschnitt 2.2.5.2.2.). Die Netze bestanden aus einem Kunststoffgeflecht mit $3 \mathrm{~mm}$ weiten Maschen. Diese Maschenweite ist groß genug, um Makrofauna in die Netze eindringen zu lassen, verhindert aber, daß emporwachsende Pflanzen die Netze von unten anheben. Stattdessen konnten die Pflanzen durch die Maschen hindurchwachsen (LOUSIER \& PARKINSON 1976). Grasstreu fiel leichter aus den Netzen als Espenstreu. Das zeigte sich während des Transportes der gefüllten Netze 
vom Labor zur Untersuchungsfläche. Die mit Gras gefüllten Netze verloren 4 $\%$ ihrer Masse, die Espennetze aber nur 0,3\%. Im Mittel enthielten die Netze, als sie auf den Versuchsflächen ausgelegt wurden, 1,82 $\mathrm{g}$ Grasstreu ( $\mathrm{SE}=0,01 \mathrm{~g}, \mathrm{n}=181$ ) oder 2,06 g Espenstreu ( $\mathrm{SE}=0,01 \mathrm{~g}, \mathrm{n}=184$ ). Die Streunetze wurden etwa in die Mitte der Versuchsteilflächen über lonenaustauscherbeutel gelegt und mit rostfreien Stahlheringen auf dem Boden befestigt (Abb. 6). Die lonenaustauscherbeutel wurden zur Messung des von der Streu abgegebenen oder durchgelassenen Stickstoffs verwendet (s. Abschnitt 2.2.5.2.).

Abgestorbene Grasblätter verbleiben oft noch ein halbes bis ein Jahr ohne Bodenberührung an der lebenden Pflanze (SIMS \& COUPLAND 1979). Wenn daher die Netze mit Grasstreu flach auf den Boden gelegt werden, könnten sich größere Zersetzungsraten als unter natürlichen Umständen ergeben (LOUSIER \& PARKINSON 1978), weil die Besiedelung der Streu durch Zersetzer schneller erfolgen kann, oder weil sich das Mikroklima an der Bodenoberfläche von dem in größerer Höhe unterscheidet. Es liegt nur eine Veröffentlichung (SEASTEDT et al. 1992) vor, in dem die Bedeutung der Bodenberührung für die Streuzersetzung untersucht wird. Leider unterschied sich der Stickstoffgehalt der dazu verwendeten Streu bereits zu Beginn der Untersuchung, so daß die Ergebnisse nicht eindeutig sind. Im vorliegenden Versuch werden beide Streusorten gleich behandelt, damit die Ergebnisse nicht durch einen zusätzlichen Faktor beeinflußt werden.

\subsubsection{Beschattungsfaktor}

Die Hälfte der Streunetze in den Prärieteilflächen wurde beschattet, um vergleichbare Bedingungen für die Streuzersetzung wie in den Hainen zu schaffen. Es wurde angenommen, daß sich wegen der niedrigeren Temperatur im Schatten die Evaporation verringern und infolgedessen die Bodenfeuchte erhöhen würde.

Die Sonneneinstrahlung wurde mit Beschattungsmatten (47\%iges Schattiergewebe) zunächst auf $53 \%$ reduziert, um das sich entwickelnde Laub in den Espenhainen zu simulieren. Im Juni, als das Espenlaub voll entwickelt war, wurde mit zusätzlichen Matten die Sonneneinstrahlung auf $16 \%$ gesenkt. 

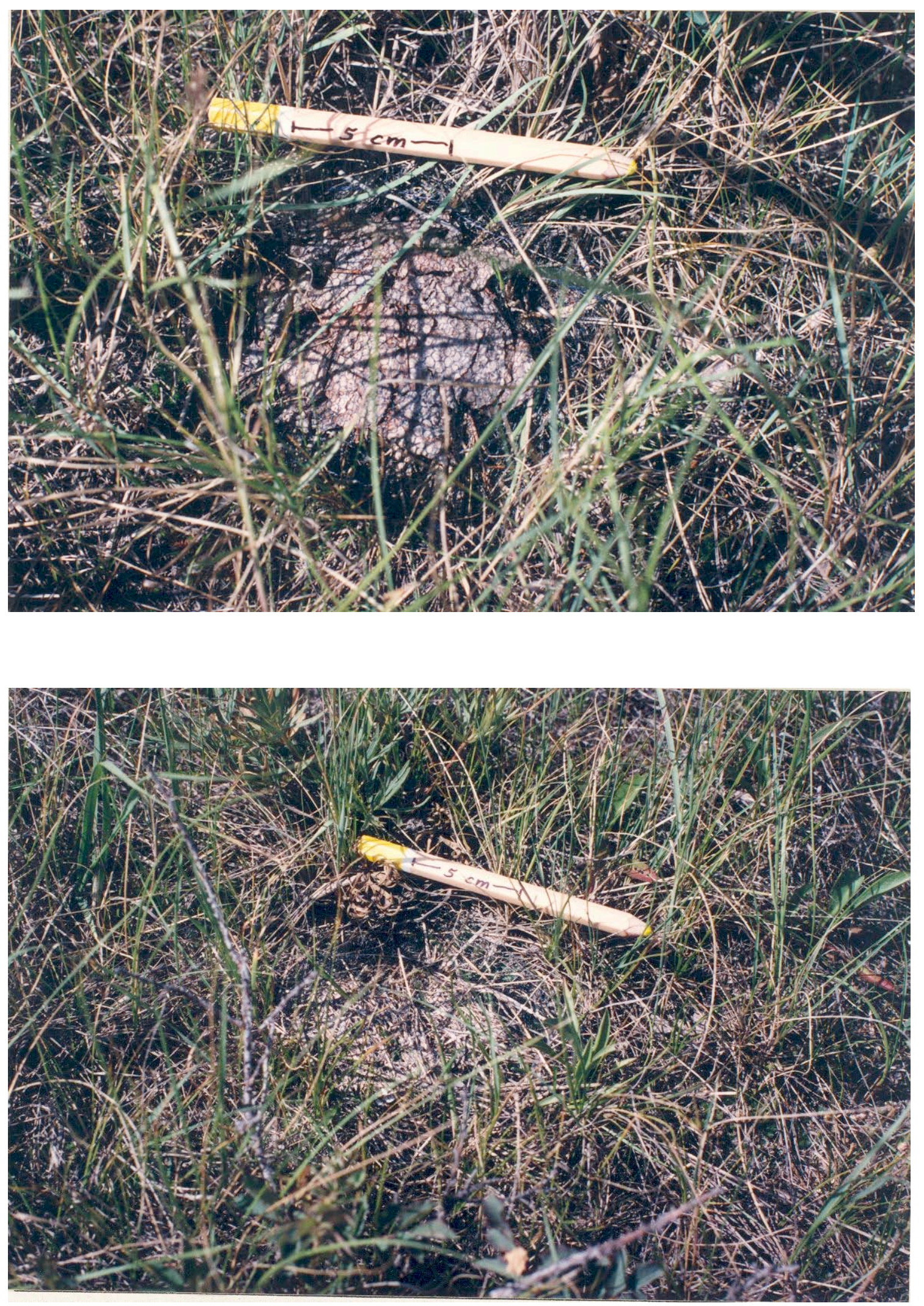

Abb. 6. Netze mit Espen- (oben) und Grasstreu (unten) in Prärieteilflächen. Aufgenommen im Juni 1993.

Fig. 6. Bags containing aspen litter (top) and grass litter (bottom). Photograph taken in June 1993. 
Die Beschattungsmatten wurden so aufgestellt, daß sie die Südost- und Südwestseiten eines $35 \mathrm{~cm}$ hohen Pyramidenstumpfes mit $50^{\circ}$ Innenwinkel bildeten. Auf diese Weise waren die Streunetze den größten Teil des Tages beschattet (Abb. 7). Die Wirksamkeit der Matten wurde durch Lichtmessungen unter den Matten und in den Hainen verglichen. Da es nicht möglich ist, zum Vergleich mit unbeschatteten Prärieteilflächen auf einzelnen Teilflächen in den Hainen die gleichen Lichtverhältnisse zu schaffen wie in der Prärie, wurde auch in den Hainen die Hälfte der Streunetze beschattet, um zu zeigen, daß zusätzliche Beschattung das Mikroklima in den Hainen nicht entscheidend verändert und daher keinen weiteren Einfluß auf die Streuzersetzung hat.

Um zu verhindern, daß sich die Bodenfeuchtigkeit horizontal verteilt, wurden unter den Beschattungsvorrichtungen Plastikröhren (15 cm hoch, Durchmesser $10 \mathrm{~cm}$ ) in den Boden eingeschlagen. Die Röhrenoberkante schloß bündig mit der Bodenoberfläche ab. Die Laubnetze wurden auf dem Boden innerhalb der Röhre befestigt.

Damit die Bodenfeuchte unter den Beschattungsmatten in der Prärie mit der Bodenfeuchte in den Hainen verglichen werden konnte, wurden in jedem Biotop drei beschattete Lysimeter je Versuchsfläche eingesetzt. Die Lysi-

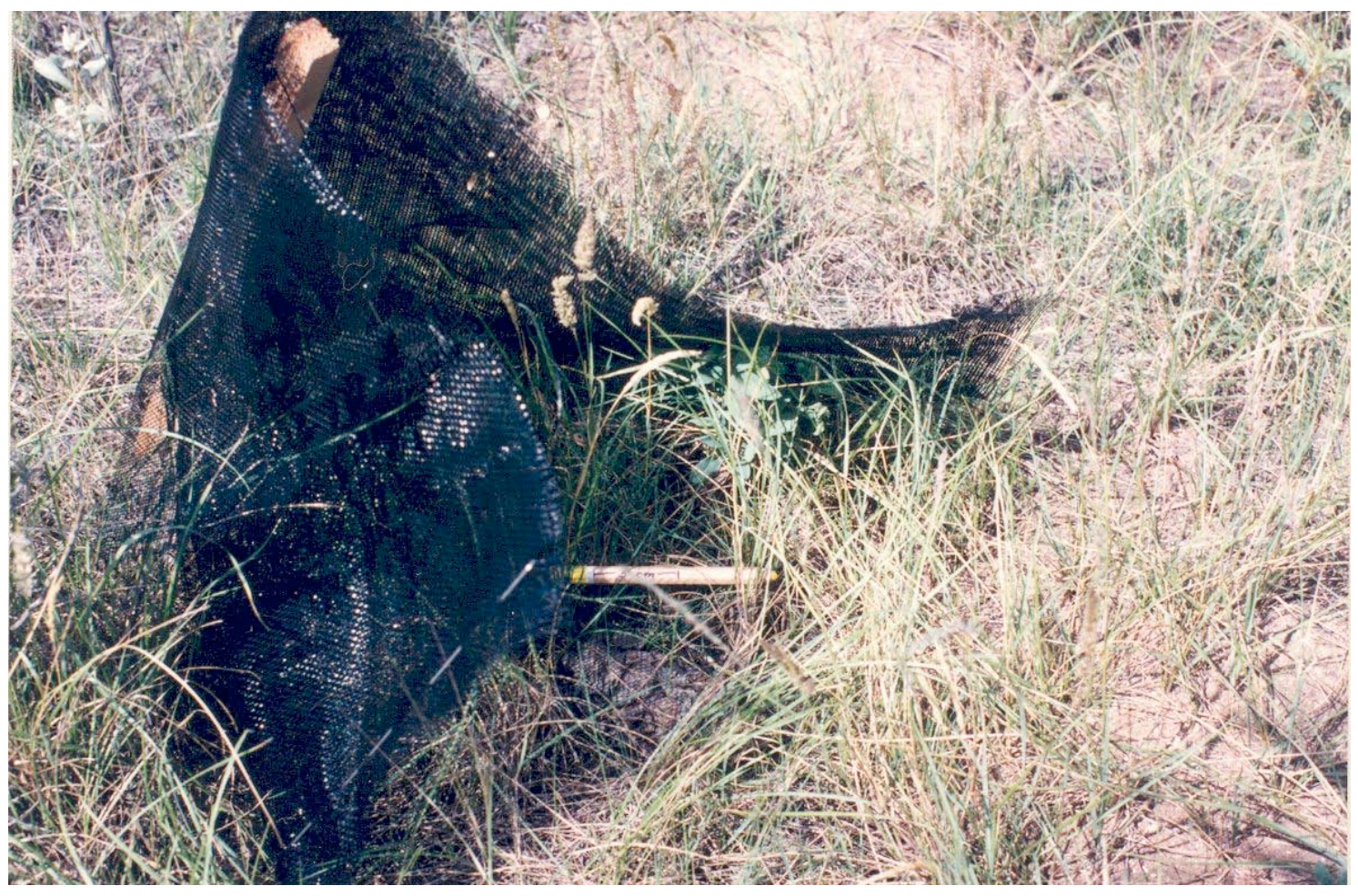

Abb. 7. Beschattungsvorrichtung in einer Prärieteilfläche. Vor dem Buntstift ist ein Laubnetz mit Espenlaub erkennbar. Aufgenommen im Juni 1993

Fig. 7. Shading installation in a prairie sub-plot. In front of the pencil is a litter bag filled with aspen litter. Photograph taken in June 1993. 
meter bestanden ebenfalls aus $15 \mathrm{~cm}$ hohen Plastikröhren mit einem Durchmesser von $10 \mathrm{~cm}$. Die Röhren enthielten einen Bodenkern, der zuvor am Rand einer der Prärieflächen ausgestanzt worden war. Alle Bodenkerne stammten von derselben Stelle. Die auf dem Bodenkern befindliche Vegetation wurde nicht entfernt. Der Kern wurde durch ein grobporiges Plastikgitter, das unter die Röhrenöffnung geklebt worden war, am Herausfallen gehindert. Die gefüllten Röhren wurden vorsichtig zu jeder Versuchsfläche gebracht und in Löcher gleicher Größe eingesetzt. So konnten die Lysimeter wiederholt zum Wiegen aus dem Boden genommen werden. Die Masse der Lysimeter wurde in Abständen von zwei bis drei Wochen gemessen. Am Ende des Experimentes wurden die Bodenkerne bei $90^{\circ} \mathrm{C}$ bis zur Gewichtskonstanz getrocknet, um die Trockenmasse der Bodenkerne zu bestimmen. Die Messung der Trockenmasse wurde benutzt, um den relativen Wassergehalt der Bodenkerne für jeden Meßzeitpunkt zu berechnen.

\subsubsection{Abhängige Größen}

\subsubsection{Masseverlust}

Nach jeder Ernte wurden eingewachsene Pflanzen, sichtbare Tiere und Sand aus den Streunetzen entfernt. Der Sand war von Ameisen eingeschleppt worden, die die Netze kolonisiert hatten und, so schien es, Espenstreu gegenüber Grasstreu bevorzugten. Manchmal war es nicht möglich, den Sand zu entfernen, ohne gleichzeitig auch Streumasse zu verlieren. In diesen Fällen wurden die Streunetze nicht in der Auswertung verwendet. Streunetze auf den Prärieflächen waren gelegentlich von Nagern beschädigt worden, die vermutlich an die lonenaustauscher gelangen wollten. Manchmal schien der Schaden nur das Netzgewebe zu betreffen. Diese Netze wurden aber, wenn sie im Vergleich zu anderen Netzen der gleichen Versuchsvariante einen übergroßen Masseverlust aufwiesen, nicht in die Auswertung einbezogen. Die Streu wurde schließlich mindestens drei Tage lang bei $105^{\circ} \mathrm{C}$ getrocknet und anschließend gewogen. Die Trockenmasse der Streuproben zum Erntezeitpunkt wurde durch die anfängliche Trockenmasse der Streuproben geteilt, um den Restmasseanteil der Streu zu bestimmen. Aus dem Restmasseanteil von je vier Streuproben von vier Ernten wurde die Zersetzungsrate $k$ einzeln für jede Versuchsvariante in jedem Versuchsgebiet berechnet, also insgesamt 24 Zersetzungsraten. Die Zersetzungsraten wurden nach der logarithmisch transformierten exponentiellen Zerfallsgleichung $\ln (Y)=k \cdot t+b$ bestimmt. In dieser Gleichung bezeichnet $Y$ den Restmasseanteil, $t$ die Zersetzungszeit in Jahren und $b$ einen durch die Regression festgelegten Ordinatenabschnitt. Ein lineares Zersetzungsmodell 
wurde verworfen, weil Streu aus mehreren chemischen Fraktionen besteht, die sich in ihrem Widerstand gegenüber enzymatischem Abbau unterscheiden. Deshalb sollte die Zersetzung in erster Näherung einer negativexponentiellen Zerfallsfunktion folgen (OLSON 1963; TAYLOR \& PARKINSON 1988b).

\subsubsection{Stickstoffflüsse}

Die Streunetze wurden auf mit lonenaustauschern gefüllte Beutel gelegt, die den aus der Streu freigesetzten Stickstoff auffangen sollten. Diese Methode ist bislang nur eingesetzt worden, um die Verfügbarkeit mineralischen Stickstoffs im Boden zu messen. Die meisten Erfahrungen mit der Anwendung dieser Methode stammen daher aus Boden- und weniger aus Laboruntersuchungen.

\subsection{Bewertung der lonenaustauschmethode}

Die Verwendung von lonenaustauschern ist vermutlich zuerst von AMER et al. (1955) und später von SIBBESEN (1977) zur Messung der Nährstoffverfügbarkeit im Boden verwendet worden. Seit 1983 wird sie vor allem von D. BINKLEY und Mitarbeitern benutzt (BINKLEY \& MATSON 1983; BINKLEY 1984; HART \& BINKLEY 1985; BINKLEY \& VITOUSEK 1991; BINKLEY \& HART 1989; HART \& FIRESTONE 1989). Die Austauschermethode wurde von DISTEFANO \& GHOLZ (1986) für die Messung von Vertikalflüssen von Bodenlösungen angepaßt.

Die Methode basiert auf dem bekannten lonenaustauscherprinzip. Als Ionenaustauscher wird normalerweise ein Kunstharzpolymer mit stark sauren oder basischen Eigenschaften verwendet, das dementsprechend Kationen oder Anionen an die funktionellen Gruppen binden kann. Mit einem Gemisch aus sauren und basischen Harzen können beide lonensorten gleichzeitig gebunden werden. Vor dem Einsatz des Austauschers werden die funktionellen Gruppen, die Austauscherplätze, mit lonen beladen, die eine geringere Affinität zum Harz besitzen als die lonen, die aufgefangen werden sollen. Das Harz wird dann im Freien am Meßpunkt eingesetzt. Wenn genügend Harz verwendet wird, so daß die Austauscher während der Meßzeit auch nicht annähernd gesättigt werden, werden aus einer perkolierenden Lösung fast alle lonen (GIBLIN et al. 1994), die eine höhere Affinität zu den Austauscherplätzen haben, gegen die vorhandenen lonen ausgetauscht. Nach der Meßperiode werden im Labor die Ionen aus den Austauschern mit einer hochkonzentrierten Salz- oder Säurelösung ausgewaschen. Da die Auswaschung unter Umständen nicht vollständig ist, muß sie entweder mehrmals wiederholt werden oder ein Rückgewinnungsfaktor muß experimentell bestimmt werden. Die Konzentration der zu bestimmenden 
Ionen in der Waschlösung kann dann mit den üblichen Analysemethoden gemessen werden.

Ein Vorteil der lonaustauschmethode ist, daß die Austauscher die verfügbaren Nährstoffe über längere Zeiträume sammeln können und diese langfristigen Messungen die Nährstoffverfügbarkeit oft besser beschreiben als mehrere Punktmessungen. Dadurch werden auch Zeitaufwand und Materialkosten gesenkt. Bei Einsatz der Austauscher im Gelände fließen in die Meßergebnisse auch kleinräumige Umwelteinflüsse auf die Nährstoffverfügbarkeit ein, was ein weiterer Vorteil gegenüber den meisten anderen Methoden ist (HART \& FIRESTONE1989). Gegenüber der Beutelbebrütung ("buriedbag method", ENO 1960), die ebenfalls auf Umwelteinflüsse reagiert, besteht der Vorteil in der einfacheren Handhabbarkeit.

Die Zuverlässigkeit der Austauschermethode ist in einigen Experimenten untersucht worden. So beeinflußt die Fließgeschwindigkeit der perkolierenden Lösung die Rückhaltefähigkeit der Kationenaustauscher; dieser Effekt wurde jedoch erst bei einer höheren Fließgeschwindigkeit als $5 \mathrm{~cm} / \mathrm{h}$ beobachtet, ein Wert an der oberen Grenze der geschätzten Fließgeschwindigkeiten von Bodenlösungen (SCHNABEL 1983). Die Rückhaltefähigkeit der Austauscher wird nicht von der verwendeten Austauschermenge beeinflußt (GIBLIN et al. 1994), solange Austauscherplätze im Überfluß vorhanden sind. Bislang wurden keine Mikroorganismen auf den Austauschern beobachtet, die die Nährstoffe von den Austauschern aufnehmen (SCHNABEL 1983, BINKLEY 1984). Die Austauscher halten Ammoniumionen mindestens neun Wochen (BINKLEY 1984, GIBLIN et al. 1994), Nitrationen bei weniger als drei Prozent Verlust mindestens zwölf Wochen (SCHNABEL 1983) gebunden.

Nach fünf Monaten befinden sich noch etwa $80 \%$ des Ammoniums und $50 \%$ des Nitrats an den Austauschern (HART \& BINKLEY 1985). Unter bestimmten Bedingungen kann der Nitratverlust aber schon nach drei Wochen $80 \%$ betragen (GIBLIN et al. 1994). Dabei könnten hohe Bodenfeuchte, neutrale bis basische Bodenreaktion oder starker Wettbewerb mit Bodenmikroorganismen eine Rolle spielen (AMER et al. 1955; GIBLIN et al. 1994).

Die Menge der aus der Bodenlösung aufgenommenen lonen hängt auch vom Wettbewerb zwischen Pflanzen und Mikroorganismen um diese lonen ab (BINKLEY 1984). Die Beweglichkeit der lonen in der Bodenlösung zeigt sich ebenfalls in den Austauschermessungen. So wird zum Beispiel Nitrat, das beweglicher ist als Ammonium, in größerer Menge gebunden, als es dessen Konzentration in der Bodenlösung erwarten läßt (BINKLEY 1984, HART \& BINKLEY 1985). 
Bei Messungen unter kontrollierten Gewächshausbedingungen stehen die mit lonenaustauschern gewonnenen Ergebnisse im Einklang mit Ergebnissen, die durch andere Methoden erhalten wurden. Die Ergebnisse weichen jedoch stark voneinander $a b$, wenn die Messungen im Gelände durchgeführt werden (BINKLEY \& MATSON 1983; HART \& BINKLEY 1985; LUNDELL 1989; GIBLIN et al. 1994). Das zeigt, daß die lonenaustauschermethode besser auf Umwelteinflüsse anspricht als andere Methoden. Variationskoeffizienten von Austauschermessungen waren in einer Untersuchung größer (HART \& BINKLEY 1985), in einer anderen aber kleiner (GIBLIN et al. 1994) als bei Messungen mit anderen Methoden. Mit der lonenaustauschermethode konnten bisher erfolgreich in einer Reihe von Untersuchungen Ökosystemunterschiede und Einflüsse von Behandlungen auf die Nährstoffverfügbarkeit festgestellt werden, die andere Methoden nicht gezeigt hatten (BINKLEY \& HART 1989).

Aus den Erfahrungen, die bislang mit der lonenaustauschermethode gemacht wurden, kann angenommen werden, daß die Methode auch oberirdisch zufriedenstellend angewendet werden kann. Da das Streuzersetzungsexperiment fünf Monate dauerte, könnten die Austauscher Nitrat verloren haben. Die Durchflußgeschwindigkeit bei Regenfällen ist sicher größer als 5 $\mathrm{cm} / \mathrm{h}$ gewesen, so daß die Aufnahme unvollständig gewesen sein könnte. Die möglicherweise entstandenen Meßfehler können die quantitativen Meßergebnisse beeinflussen, qualitative Ergebnisse sind aber nicht betroffen. Es ist jedoch anzunehmen, daß diese Fehler klein sind, da eine große Menge Ionenaustauscherharz eingesetzt wurde (s. folgender Abschnitt).

\subsection{Durchführung}

Die mit Austauscherharz gefüllten Beutel waren durch ein $4 \times 4 \mathrm{~cm}^{2}$ großes Plastikgitter, Gitterabstand $2 \mathrm{~mm}$, vom Boden getrennt, so daß sie vom Boden keinen Stickstoff aufnehmen konnten. Es wurde angenommen, daß Gegenwart und Größe der Beutel sowie des Gitters Zersetzer nicht davon abhalten würden, die Streubeutel zu besiedeln. Die Austauscherbeutel wurden in der Größe $3 \times 3 \mathrm{~cm} 2$ aus Nylonstrumpfhosen genäht. Vorversuche hatten gezeigt, daß die Harzkügelchen von diesem Stoff ohne Verlust zurückgehalten werden und der Wassereintritt im Vergleich zu anderen Stoffen am geringsten behindert wird. Die Beutel wurden mit je $2 \mathrm{~g}$ feuchten, gemischt-ionischen Austauscherharzperlen (AMBERLITE ${ }^{\circledR}$ MB1, DOWEX ${ }^{\circledR}$ AG 501-X8) gefüllt. Die Perlen hatten einen Durchmessser von 300$1180 \mu \mathrm{m}$ (Herstellerangaben). Die Austauscherkapazität des Harzes im feuchten Zustand betrug jeweils 1,0 meq/g für Anionen und Kationen (aus Herstellerangaben berechnet). Dies entspricht der notwendigen Kapazität für die siebenfache Ionenkonzentration in wässrigen Espenstreu- 
auszügen (PASTOR \& BOCKHEIM 1984; LOUSIER \& PARKINSON 1978), umgerechnet auf die normale Niederschlagsmenge der Monate Mai bis September und unter der Annahme, daß der gesamte Stickstoff in der Streu während dieser Zeit freigesetzt würde. Man konnte also davon ausgehen, daß die Austauscher auch aus schnell fließendem Regen die meisten Ionen aufnehmen und unter keinen Umständen gesättigt werden würden und daß die Nitratverluste gering sein würden. Die Beutel waren gleichmäßig flach ausgelegt worden, so daß die Durchflußgeschwindigkeit innerhalb des Beutels wahrscheinlich gleichmäßig war. Die gefüllten Austauscherbeutel wurden zu fünft $15 \mathrm{~min}$ in $60 \mathrm{ml} 2 \mathrm{M}$ Kochsalzlösung gewaschen und anschließend in destilliertem Wasser gespült (LEE \& MYROLD 1990), um herstellungsbedingtes Nitrat und Ammonium zu entfernen (BINKLEY \& VITOUSEK 1991; SIBBESEN 1977), bevor die Beutel auf den Versuchsflächen ausgelegt wurden. Von den vorbehandelten Austauscherbeuteln wurden sechs bis zur Stickstoffextraktion in Plastiktüten bei Zimmertemperatur aufbewahrt, um die Wirksamkeit der Vorbehandlung zu messen, weitere sechzehn vorbehandelte Austauscherbeutel wurden für die Feststellung der Rückgewinnungsrate verwendet.

Zusätzlich zu den Beuteln unter den Laubnetzen wurden auf jeder Versuchsfläche zwölf Beutel ohne Streubedeckung ausgelegt, um die Stickstoffdeposition mit drei Beuteln je Fläche zu jeder Ernte zu messen. Auch diese Beutel waren durch ein Gitter vom Boden getrennt und durch ein kleineres ungefülltes Streunetz und Stahlheringe auf dem Boden befestigt. Diesen Beuteln wurde in der Prärie von Kleinnagern nachgestellt. Die Netze und Beutel wurden angenagt und das Harz teilweise oder ganz aus dem Beutel verstreut oder sogar gefressen. Einige Beutel wurden ohne Beschädigung, vielleicht vom Wind, fortgetragen. Angenagte Beutel wurden bis zur ersten Ernte durch neue ersetzt. Fortgetragene Beutel, die bei den etwa alle zwei Wochen erfolgten Kontrollen unbeschädigt aufgefunden wurden, wurden wenn möglich an ihren Ort zurückgebracht. Nach der ersten Ernte wurden beschädigte Beutel geflickt oder, wenn dies nicht möglich war, sofort geerntet. Nach dreizehn Wochen waren keine Beutel mehr für die Depositionsmessungen auf den Prärieflächen vorhanden. Deshalb wurden für die dritte und vierte Ernte nochmals frische Beutel ausgelegt, diesmal geschützt durch ein Drahtgitter mit $4 \mathrm{~mm}$ Gitterweite. Die Stickstoffmenge, die bis zur Auslage der neuen Beutel abgelagert worden wäre, wurde durch eine lineare Extrapolation aus den Depositionsmessungen der ersten beiden Ernten geschätzt. Die Stickstoffmenge, die von den neuen Beuteln aufgefangen wurde, wurde zu der geschätzten Menge addiert. Für die drei Gebiete wurde eine gemeinsame Schätzung berechnet, weil sich sowohl die Depo- 
sitionsraten in den drei Hainen für die gesamte Zeit als auch die Depositionsraten in den drei Prärieflächen für die ersten zwei Ernten nicht signifikant unterschieden. Die sich ergebende Parallelität der Depositionskurven für Hain- und Prärieflächen (Abb. 16) zeigt, daß dieses Vorgehen sinnvoll war.

Auch Beutel unter Laubnetzen waren beschädigt oder fortgetragen worden. Sie wurden aber nicht ersetzt.

Die geernteten Austauscherbeutel wurden bis zur Stickstoffextraktion in verschlossenen Plastikbechern bei Zimmertemperatur gelagert. Nach der letzten Ernte wurde das Harz aus den Beuteln in $25 \mathrm{ml}$ einer zweimolaren Kaliumchloridlösung überführt, um Nitrat und Ammonium aus den Austauschern zu extrahieren. Nach der Extraktion wurde die Lösung im Verhältnis 1:2 mit doppelt destilliertem Wasser verdünnt, um in den Meßbereich der lonenelektrode zu kommen. Gelöstes Nitrat und Ammonium wurde wie bei der Messung des Mineralstickstoffgehaltes (Abschnitt 2.1.) zu Ammoniak umgesetzt und dessen Konzentration mit einer lonenelektrode als Stickstoffkonzentration gemessen. Aus den Meßwerten wurde anschließend die Stickstoffmenge und der Stickstoffgehalt der Bodentrockenmasse berechnet.

Der Stickstoffgehalt der sechs vorbehandelten, aber unbenutzten Austauscherbeutel wurde in der gleichen Weise wie der der geernteten Beutel bestimmt, um die Wirksamkeit der Vorbehandlung festzustellen. Obwohl die Austauscher vor der Benutzung in einer Kochsalzlösung gewaschen worden waren, wurde auch auf den unbenutzten Austauschern 0,1 g Stickstoff/m² gemessen. Dieser Hintergrundwert wurde von den Meßwerten abgezogen.

Die Wirksamkeit der Extraktion wurde an den übrigen sechzehn unbenutzten Austauscherbeuteln gemessen. Jeweils zwei Austauscherbeutel wurden in einer Lösung mit 1, 5, 10 und 25 ppm Stickstoff als Ammonium und 1, 5, 10 und 25 ppm Stickstoff als Nitrat beladen und anschließend der Stickstoff aus ihnen wie oben beschrieben extrahiert. Von den eingesetzten Stickstoffmengen wurden durchschnittlich $76 \%$ zurückerhalten. Die Extraktionsraten für Ammonium (81\%) und Nitrat (71\%) unterschieden sich nicht signifikant $(t=1,89, P>|t| 0,08)$. Dies entspricht etwa den Extraktionsraten von LEE \& MYROLD (1990) und BINKLEY \& VITOUSEK (1991) ${ }^{3}$, die mit der gleichen Methode arbeiteten; GIBLIN et al. (1994) konnten jedoch mit

\footnotetext{
${ }^{3}$ BINKLEY \& VITOUSEK (1991) geben eine Extraktionsrate von "0.80-0.90 \%" an. Es handelt sich jedoch um einen Druckfehler, richtig muß es heißen "80-90 \%" (D. BINKLEY, pers. Mitteilung).
} 
einer angesäuerten Kochsalzlösung schon nach einer Extraktion die eingesetzten Mengen vollständig zurückgewinnen. Die Werte der gemessenen Stickstoffkonzentrationen wurden durch den ermittelten Rückgewinnungsfaktor geteilt und auf die gemeinsame Einheit $\mathrm{g} / \mathrm{m}^{2}$ umgerechnet, wobei von einer $9 \mathrm{~cm}^{2}$ großen Grundfläche der Austauscherbeutel ausgegangen wurde. Im Gegensatz zu anderen Untersuchungen (BINKLEY \& MATSON 1983; CARLYLE \& MALCOLM 1986; HART \& BINKLEY 1985; HART \& FIRESTONE 1989; SCHNABEL 1983; LUNDELL 1989) wurde die Masse der Austauscher nicht berücksichtigt, weil im Vergleich zur aufgefangenen lonenmenge ausreichend Austauscherkapazität vorhanden war und eine versuchsweise Berücksichtigung der Masse die Streuung der Ergebnisse übermäßig vergrößerte.

Da die durch Deposition zugeführte Stickstoffmenge bekannt war, konnte die von der Streu zurückgehaltene Stickstoffmenge ermittelt werden:

$\mathrm{N}_{\text {(von der Streu zurückgehalten) }}=\mathrm{N}_{\text {(Deposition) }}-\mathrm{N}_{(\text {von der Streu durchgelassen) }}$. Wenn in der Streu zusätzlich eine Nettomineralisation des Streustickstoffs stattfindet, wird die unter der Streu aufgefangene Stickstoffmenge größer als die Depositionsmenge und der nach obiger Gleichung ermittelte Wert für die zurückgehaltene Stickstoffmenge negativ. In den Tabellen und Abbildungen wurde zurückgehaltener Stickstoff mit positiven und durchgelassener Stickstoff mit negativen Werten dargestellt. Da während des Versuches keine Mineralisation auftrat, ist die Kennzeichnung der durchgelassenen Stickstoffmengen mit einem negativen Vorzeichen eindeutig.

Aus den Stickstoffmessungen von je vier Streuproben von vier Ernten wurden die Stickstoffdurchlaß- und -rückhalteraten der Streu einzeln für jede Versuchsvariante in jedem Versuchsgebiet, also je 24 Raten für Stickstoffdurchlaß und -rückhaltung, berechnet. Da in Analogie zum Streumasseverlust von einem negativ exponentiellen Verlauf ausgegangen wurde, wurden die Daten logarithmisch transformiert und eine Regression für das folgende Modell $\lg (Y+2)=f \cdot t+b$ berechnet. In dieser Gleichung entspricht $Y$ der durchgelassenen oder zurückgehaltenen Stickstoffmenge, $f$ der Durchlaß- beziehungsweise der Rückhalterate , $t$ der Zersetzungszeit in Jahren und $b$ einem durch die Regression festgelegten Ordinatenabschnitt. Der Wert 2 wurde addiert, weil es sich um kleine Werte handelte, die transformiert werden sollten (GLASER 1978:113). Stickstoffdurchlaß- und rückgabe(rate) gemeinsam werden im Folgenden als Stickstoffluß(rate) bezeichnet.

Die Kohlenstoff- und Stickstoffkonzentration der Streu zu Beginn und am Ende des Experimentes wurde mit der Verbrennungsmethode nach DUMAS (DUMAS 1831; BREMNER \& MULVANEY 1982) durch ein automatisiertes 
Analysegerät (CARLO-ERBA CHN-Autoanalyzer) gemessen. Dies diente der Kontrolle der Austauschermethode, zum einen, weil die Methode bislang nicht oberirdisch angewandt worden war, zum anderen, weil die Austauscherbeutel nur etwa ein Drittel der Streufläche erfassen konnten. Für die Bestimmung der Anfangswerte wurde Streu aus überzähligen Streunetzen und unbenutzte Streu aus dem Zersetzungsversuch verwendet. Streunetze und unbenutzte Streu waren bis zur Analyse bei Zimmertemperatur trocken gelagert worden. Für die Endwerte wurden nur Streuproben der letzten Ernte aus den Prärieflächen verwendet, weil sich nur hier beim Masseverlust Unterschiede durch die Beschattung gezeigt hatten und für die Hainvarianten von vornherein keine Unterschiede erwartet worden waren. Die Streuproben, die auf den drei Prärieflächen zur gleichen Versuchsvariante gehörten, wurden vereinigt. Alle Streuproben wurden in einer Wiley-Mühle gemahlen, bis das Streumehl durch ein 0,4 mm-Sieb (60 meshes per linear inch) paßte.

\subsubsection{Unabhängige Größen}

Auf jeder Versuchsfläche wurden in etwa zweiwöchigen Abständen die Lufttemperatur etwa $1 \mathrm{~cm}$ über dem Boden und Niederschläge gemessen. Die Temperatur wurde mit einem Digitalthermometer ( $\left.F^{a} A M S\right)$ gemessen. Für die Niederschlagsmessung wurden handelsübliche Gartenregenmesser verwendet, die aufgefangenen Niederschläge wurden durch eine Ölschicht (Speiseöl), die nach jeder Messung erneuert wurde, vor der Verdunstung bewahrt. In einem Laborversuch wurde festgestellt, daß eine etwa $1 \mathrm{~mm}$ dicke Ölschicht die Verdunstung auf $1 \mu \mathrm{l} \mathrm{cm-2} \mathrm{d-1} \mathrm{begrenzt.} \mathrm{Auf} \mathrm{den}$ Prärieflächen wurde jeweils eine Messung vorgenommen, auf den Hainflächen jeweils drei, um die stärkere Schwankung.des Bestandesniederschlages zu berücksichtigen Die Temperatur wurde im Zeitraum von zwei Stunden vor bis zwei Stunden nach Sonnenhöchststand gemessen. Die Messungen im Gelände wurden nur zur Berechnung des Temperaturunterschiedes zwischen Hain- und Prärieflächen benutzt. Die Temperaturdifferenz wurde zur mittleren Tagestemperatur in Regina addiert, um die mittlere Tagestemperatur in Espenhainen zu schätzen. Es wurde dabei angenommen, daß die mittlere Tagestemperatur auf den Prärieflächen der im 18 km entfernten Regina entspricht.

Aus den Temperaturwerten und den Niederschlagsmessungen wurde die aktuelle Evapotranspiration nach THORNTHWAITE (THORNTHWAITE 1948; THORNTHWAITE \& MATHER 1957) berechnet. Dazu wurde die Wasserkapazität des Bodens, d. h. der gegen die Schwerkraft zurückgehaltene Wasservolumenanteil, benötigt. Die Wasserkapazität wurde an zylindrischen 
Bodenproben (10 cm Durchmesser, $15 \mathrm{~cm}$ tief), die an drei zufälligen Stellen innerhalb jeder Versuchsfläche entnommen wurden, experimentell bestimmt. Die ungestörten Proben wurden $48 \mathrm{~h}$ in Wasser gesättigt und $52 \mathrm{~h}$ abtropfen gelassen. Dann wurden die Proben gewogen, bei $90{ }^{\circ} \mathrm{C}$ bis zur Gewichtskonstanz getrocknet und erneut gewogen. Aus dem Gewichtsunterschied wurde über die Trockenraumdichte die Wasserkapazität berechnet.

\subsubsection{Statistische Auswertung}

Bei dem Zersetzungsexperiment handelt es sich statistisch betrachtet um eine dreifaktorielle Anlage mit randomisierten, vollständigen Blöcken. Streusorte, Biotoptyp und Beschattungsbehandlung sind als feste, die Gebiete (Blöcke) als zufällige Faktorstufen zu betrachten. Die Versuchsvarianten (Faktoren) wurden durch eine passende Varianzanalyse (ANOVA) verglichen (ZAR 1974: 344). Die Voraussetzungen für die Anwendung einer Varianzanalyse sind Homogenität der Varianzen und Normalverteilung der Meßwerte. Die Werte der durchgelassenen und der zurückgehaltenen Stickstoffmenge und des Restmasseanteils wurden in dekadische Logarithmen umgewandelt, um die bestehende Varianzheterogenität zu verringern, doch Homogenität wurde nicht erreicht. Die Werte waren jedoch normalverteilt (SHAPIRO-WILKS-Test, $\alpha=0,10$ ). Die Zersetzungsraten hatten homogene Varianzen (BARTLETT-Test, $F=0,6, P>F \quad 0,76$ ), die Stickstofflüsse jedoch nicht (Rückhalterate: $F=2,63, P>F ~ 0,01$; Durchlaßrate: $F=3,52, P>F \quad 0,001$ ). Zur Beurteilung der Normalität konnte kein statistischer Test verwendet werden, weil nur drei Werte je Versuchsvariante vorlagen. Die Werte erschienen jedoch nach Augenschein normalverteilt. Die Varianzanalyse ist ziemlich robust gegenüber nicht-normalverteilten Meßwerten und Varianzheterogenität, besonders bei gleicher Stichprobengröße (KIRK 1968: 60). Sind die Voraussetzungen der Varianzanalyse nicht erfüllt und die Stichproben nicht in jeder Versuchsvariante gleich, kann das Signifikanzniveau des Tests niedriger als angegeben sein. So kann es sich bei einem AlphaWert von $5 \%$ tatsächlich um einen von $8 \%$ handeln. Tests, die im Grenzbereich des Signifikanzniveaus liegen, müssen deshalb mit Vorsicht interpretiert werden (GLASER 1978: 111).

Es wurde geprüft, ob für Zersetzungsrate und Stickstoffflußraten signifikante Wechselwirkungen zwischen dem Gebietsfaktor und den festen Faktoren bestanden. Dazu wurde eine vollständige Varianzanalyse mit allen Gebietswechselwirkungen berechnet. Da es für jede Versuchsvariante nur einen Wert gab, mußte die Varianz der Vierfachwechselwirkung als Fehlervarianz verwendet werden. Es wurde untersucht, ob die Gebietswechselwirkungen zufällig sind und daher mit der Fehlervarianz zusammengefaßt 
werden können, um die Effektivität der Varianzanalyse zu erhöhen (KIRK 1968: 214). Zur Prüfung der Zufälligkeit wurde ein Signifikanzniveau von 20 $\%$ gewählt, weil die Nullhypothese (Zufälligkeit) bestätigt werden sollte. Die Gebietswechselwirkungen waren nicht signifikant und wurden deshalb mit der Fehlervarianz zusammengefaßt. Die Fehlervarianz für die Analysen des Restmasseanteils, der durchgelassenen und zurückgehaltenen Stickstoffmenge hatte genügend Freiheitsgrade für eine effektive Analyse (KIRK 1968: 216), so daß sie nicht mit Wechselwirkungsvarianzen zusammengefaßt werden mußte.

Bei Anlage des Versuches war angenommen worden, daß künstliche Beschattung auf den Hainflächen keine Wirkung auf Streuzersetzungsvorgänge habe und daß künstliche Beschattung auf den Prärieflächen die gleiche Wirkung habe wie künstliche oder natürliche Beschattung in den Hainen. Diese Annahmen wurden nach der Varianzanalyse durch lineare Kontraste der Masseverlust- und Stickstoffflußraten zum 20\%-Niveau geprüft. Es wurde ein niedriges Signifikanzniveau (=hohes $\alpha$ ) gewählt, weil durch den Test die Nullhypothese unterstützt werden sollte. Da es sich um a-priori-Vergleiche handelt, bleibt das Signifikanzniveau der einzelnen Tests unbeeinflußt (DAY \& QUINN 1989). Weiter war angenommen worden, daß die höchsten Masseverlust- und Stickstoffflußraten in unbeschatteten Prärieteilflächen aufträten. Dies wurde ebenfalls durch lineare Kontraste, allerdings zum üblichen 5\%-Niveau, einseitig getestet.

Für eine Gesamtbetrachtung der Faktorwirkungen auf Streuzersetzungsund Stickstoffflußraten wurde eine multiple Varianzanalyse (MANOVA) berechnet. Eine MANOVA berücksichtigt die korrelativen Zusammenhänge zwischen den abhängigen Variablen und zieht die Variablen zu einem Signifikanztest zusammen (GLASER 1978: 277). Insgesamt ist eine MANOVA aussagekräftiger als die einzelnen Varianzanalysen (RöHR et al. 1983). Da die Rückhalteraten von den Durchlaßraten statistisch abhängig sind, wurde der Merkmalsvektor für die MANOVA als \{1,0 Zersetzungsrate; 0,5 Rückhalterate; 0,5 Durchlaßrate\} vorgegeben. Die Wechselwirkungen zwischen dem Gebietsfaktor und den übrigen Versuchsfaktoren wurden mit der Fehlervarianz zusammengefaßt.

Alle statistischen Tests wurden mit dem Programm JMP (SAS INSTITUTE 1992) berechnet. Wegen eines Programmierfehlers in JMP mußten aber die F-Quotienten für jene Varianzanalysen, die alle Wechselwirkungen enthielten, in einem Tabellenkalkulationsprogramm berechnet werden. 


\section{Ergebnisse}

\subsection{Untersuchung des Transektes}

Das Alter der Bäume nahm zur Hainmitte hin zu $\left(R^{2}=0,84, n=32\right)$. Die höchsten Stickstoffgehalte wurden bei sechs- bis elfjährigen und nicht ganz so hohe Werte bei 21-23jährigen und 40jährigen Bäumen gefunden.

Zwischen dem Gehalt an mineralischem Stickstoff und dem Alter der Bäume bestand kein Zusammenhang (Abb. 8a), denn sowohl Maß- als auch Rangkorrelation sind auf dem 5\%-Niveau nicht signifikant. Allein mit dem gravimetrischen Wassergehalt des Bodens bestand ein signifikanter linearer Zusammenhang (Abb. 8b). Die Maßkorrelation des Stickstoffgehaltes mit dem Lichtdurchlaß (Abb. 8c) erscheint nicht linear, besitzt aber einen signifikanten linearen Anteil. Die Rangkorrelation ist jedoch nicht signifikant. Die Korrelation des Stickstoffgehaltes mit der bodennahen Lufttemperatur hatte keinen signifikanten linearen Anteil, deshalb wurde eine Rangkorrelation berechnet. Auch die Rangkorrelation ist nicht signifikant ( $P>0,05, n=35)$. Die Beziehung des Stickstoffgehaltes zum Lichtdurchlaß sowie zum Bodenwassergehalt konnte durch Transformation der Daten nicht linearisiert werden oder es ergab sich keine wesentlich bessere Regression.

Um den Vergleich mit Ergebnissen aus anderen Versuchen zu erleichtern, wurden die vier inneren Punkte des Transektes dem Hain, die zwei äußeren der Prärie zugeordnet und die Mittelwerte der Messungen zwischen beiden Biotopen verglichen (Tab. 4). Auch nach dieser Einteilung besteht kein signifikanter Unterschied zwischen Hain und Prärie bezüglich des Mineralstickstoffgehaltes im Boden. Allerdings hängt die Signifikanz von einem hohen Ausreißerwert in der Prärie ab. Wenn dieser Wert unberücksichtigt bleibt, ist der Unterschied zwischen Prärie $(0,98 \mu \mathrm{g} / \mathrm{g})$ und Hain $(2,36$ $\mu \mathrm{g} / \mathrm{g})$ signifikant $(\mathrm{t}=2,21 ; \mathrm{P}>\mathrm{lt} \mathrm{0} 0,034)$. Auch im Zusammenhang mit den anderen Variablen ist diese Stickstoffmessung ein Ausreißer. Dies wird bestätigt $(P<0,05)$, wenn als Abgrenzung zwischen den Biotopen statt des subjektiv beurteilten Kronendachschlusses (s. Abschnitt 2.1) als Definition des Hainrandes $20 \%$ Lichtdurchlaß gesetzt wird. Der Wassergehalt des Bodens war in beiden Biotopen etwa gleich. Der Lichtdurchlaß und die Lufttemperatur am Boden waren in der Prärie signifikant größer als im Inneren des Haines (Tab. 4). 


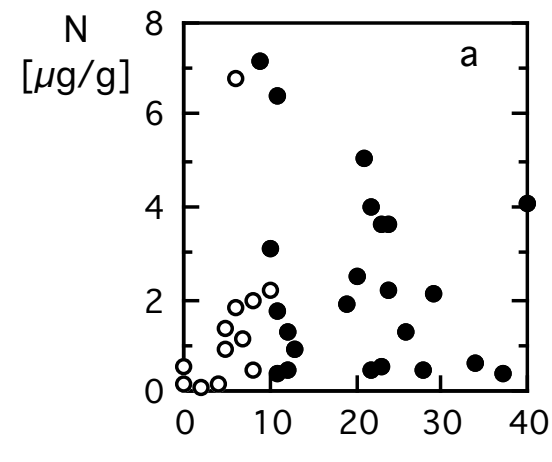

Alter der Bäume [Jahre]

Age of trees [yrs.]

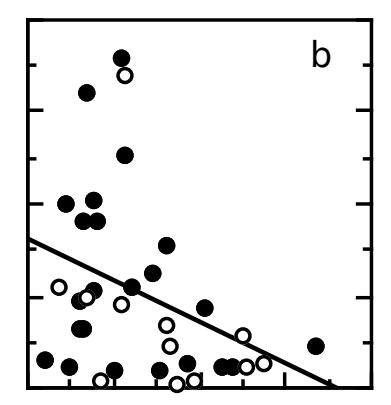

Bodenwassergehalt $[\mathrm{g} / \mathrm{g}]$

Soil moisture $[\mathrm{g} / \mathrm{g}]$

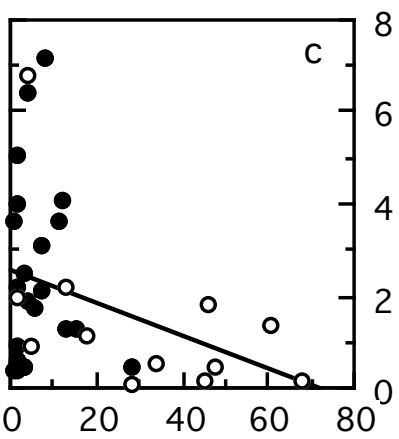

Lichtdurchlaß [\%]

Light penetration [\%]

Abb. 8a-c. Abhängigkeit des Gehaltes an mineralischem Stickstoff im Boden $(N)$ von (a) dem Alter der Bäume, (b) dem Bodenwassergehalt (W) und (c) dem Lichtdurchlaß (L). $n=35$. Die Gleichungen der Regressionsgeraden lauten. $N=4,171-4,552 W\left(R^{2}=0,13 ; P=0,032\right)$ und $N=2,581-3,610 L\left(R^{2}=0,12 ; P=0,045\right)$. Symbole: $\cdot$ Hain, o Prärie (zur Definition vgl. Abschnitt 2.1).

Fig. 8a-c. Relation between mineral nitrogen content in soil $(N)$ and (a) age of trees, (b) soil moisture $(W)$, and (c) light penetration ( $L)$. $n=35$. The regression equations are $N=4.171$ 4.552W ( $\left.R^{2}=0.13 ; P=0.032\right)$ and $N=2.581-3.610 L\left(R^{2}=0.12 ; P=0.045\right)$. Symbols: $\cdot B l u f f$, o Prairie (see section 2.1. for habitat classification)

Tab. 4. Mittlerer Gehalt an mineralischem Stickstoff im Boden und Mittelwerte der unabhängigen Variablen. $\Delta T$ ist der Temperaturunterschied zur Hainmitte. $(n=12$ für die Prärie und $n=23$ für die Haine). In den letzten zwei Spalten sind die t-Statistik und die Überschreitungswahrscheinlichkeit für den Mittelwertvergleich angeführt. * Der Unterschied wird signifikant ( $\mathrm{P}=0,034)$, wenn ein Ausreißerwert ausgeschlossen wird (vgl. Text).

Tab. 4. Soil mineral nitrogen and independent variables averaged for each habitat. $\Delta T$ is the difference in temperature to bluff centre. ( $n=12$ for prairie and $n=23$ for bluffs). The last two columns contain the $t$-statistic and the error rate for a comparison of means. * The difference becomes significant $(P=0.034)$ when one outlying value is excluded (s. text).

\begin{tabular}{lcccc}
$\begin{array}{l}\text { Variable } \\
\text { Variable }\end{array}$ & $\begin{array}{c}\text { Prärie } \\
\text { Prairie }\end{array}$ & $\begin{array}{l}\text { Hain } \\
\text { Bluff }\end{array}$ & $\mathrm{t}$ & $\mathrm{P}>\mathrm{|t|}$ \\
Stickstoffgehalt Nitrogen cont. [mg/g] & 1,5 & 2,4 & 1,29 & $0,21^{*}$ \\
& & & & \\
$\Delta \mathrm{T}[\mathrm{K}]$ & 2,9 & 0,8 & 4,7 & 0,00 \\
Lichtgenuß Light penetration [\%] & 31 & 5 & 4,9 & 0,00 \\
Bodenfeuchte Soil moisture [g/g] & 0,52 & 0,44 & 1,37 & 0,18 \\
\hline Baumalter Tree age [a] & 5 & 21 & 5,9 & 0,00
\end{tabular}




\subsection{Experiment zur Streuzersetzung}

\subsubsection{Umweltbedingungen}

Die Mittagstemperaturen (Abb. 8) in den Hainen waren im Durchschnitt

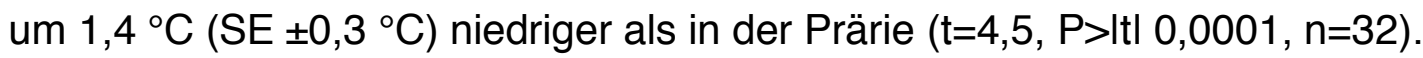
Die mittleren Tagestemperaturen in der Prärie (Abb. 5 u. 9) waren durchschnittlich $1,5^{\circ} \mathrm{C}$ niedriger als das langjährige Mittel in Regina (Wetteramt Regina 1993; $t=2,34, P>|t| 0,04$ ).

Die Bestandesniederschläge in Hainen (Abb. 10a) betrugen im Mittel $63 \%$ der Freilandniederschläge ( $S E= \pm 2 \%, t=29, P>|t|<0,0001, n=36)$. Während des Versuchs fielen auf den Prärieversuchsflächen am White Butte im Mai nur $45 \%$ der normalen Regenmenge, von Juni bis August war der Niederschlag jedoch höher als normal (Juni: $130 \%$, Juli $230 \%$, August $210 \%$, September $130 \%$; Abb. 5 u. 10; Wetteramt Regina 1993).

Der Wassergehalt des Bodens zeigte den gleichen zeitlichen Verlauf wie die Niederschläge (Abb. 11). Der gravimetrische Wassergehalt der Lysimeter war 1,4 mal höher in den Hainen als in der Prärie $(t=14, n=30, P>|t|<0,0001)$, da aber in den oberen $15 \mathrm{~cm}$ die Trockenraumdichte des Hainbodens nor $0,73 \mathrm{~g} / \mathrm{cm}^{3}$, im Prärieboden aber $1,23 \mathrm{~g} / \mathrm{cm}^{3}$ betrug (Mittelwertvergleich $\mathrm{t}=47,5, \mathrm{n}=51, \mathrm{P}>|\mathrm{t}| \mathrm{0}, 02)$, war der volumetrische Wassergehalt in der Prärie höher als in den Hainen $\left(0,15 \mathrm{~m}^{3} / \mathrm{m}^{3}\right.$, Haine $0,11 \mathrm{~m}^{3} / \mathrm{m}^{3}$, Abb.11). Die Wasserkapazität in den oberen $15 \mathrm{~cm}$ des Bodens beträgt in beiden Biotopen $55 \mathrm{~mm}$.

Die tägliche aktuelle Evapotranspiration (Abb. 12) war in den Hainen durchschnittlich um 0,4 mm niedriger als in der Prärie $(t=7, P>|t| 0,001$, $n=151$ ). Die gesamte aktuelle Evapotranspiration für den Zeitraum des Experimentes betrug $218 \mathrm{~mm}$ in den Hainen und $275 \mathrm{~mm}$ in der Prärie. 


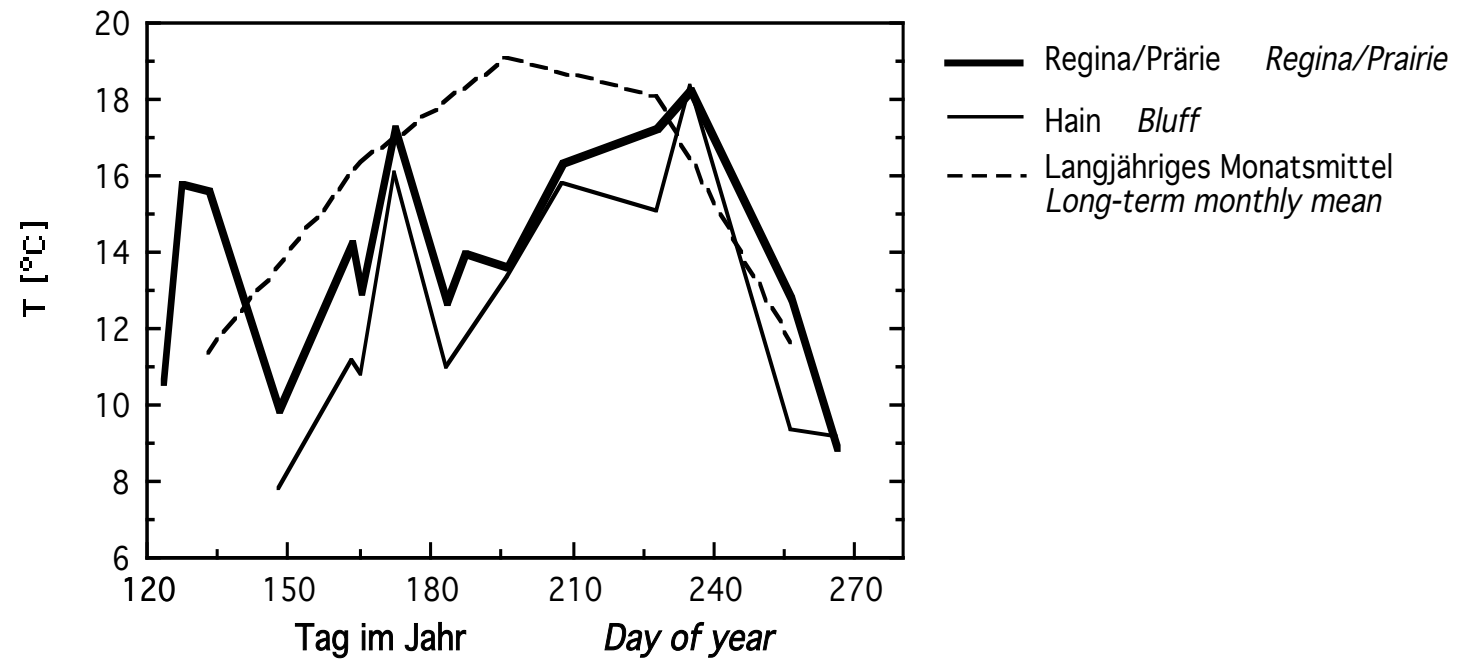

Abb. 9. Temperaturverlauf in Prärie und Hainen am White Butte während des Versuches. Es wurde angenommen, daß die Temperatur in der Prärie die gleiche wie in Regina ist. Der Temperaturunterschied zwischen Prärie und Hainen wurde in etwa zweiwöchigen Abständen in der Mittagszeit gemessen. Langjähriges Mittel gilt für Regina, 1960-1990 (ENVIRONMENT CANADA 1993).

Fig. 9. Temperatures in prairie and bluffs at White Butte during the experiment. It was assumed that temperatures in the prairie were the same as in Regina. The temperature difference between prairie and bluffs was measured approximately two-weekly around noon. Long-term means are valid for Regina, 1960-1990 (ENVIRONMENT CANADA 1993).
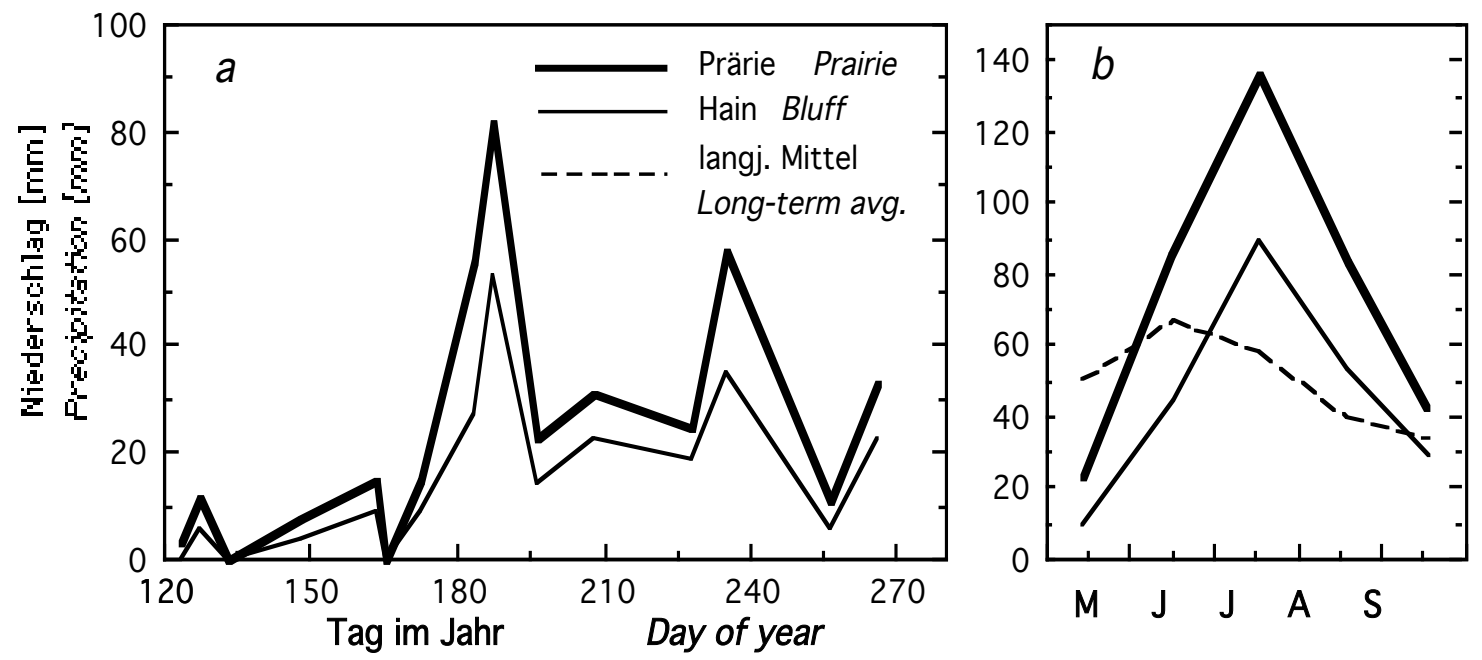

Abb. 10. Niederschläge in Prärie und Hainen in White Butte während des Experimentes. a) Messungen in etwa zweiwöchigem Abstand, b) Monatswerte und langjähriges Mittel 1960-1990 für Regina (Wetteramt Regina; ENVIRONMENT CANADA 1993).

Fig. 10. Precipitation in prairie and in bluffs at White Butte during the experiment. a) Approximately two-weekly measurements, b) monthly values and long-term monthly averages 1960-1990 [Regina Weather office; ENVIRONMENT CANADA 1993]). 


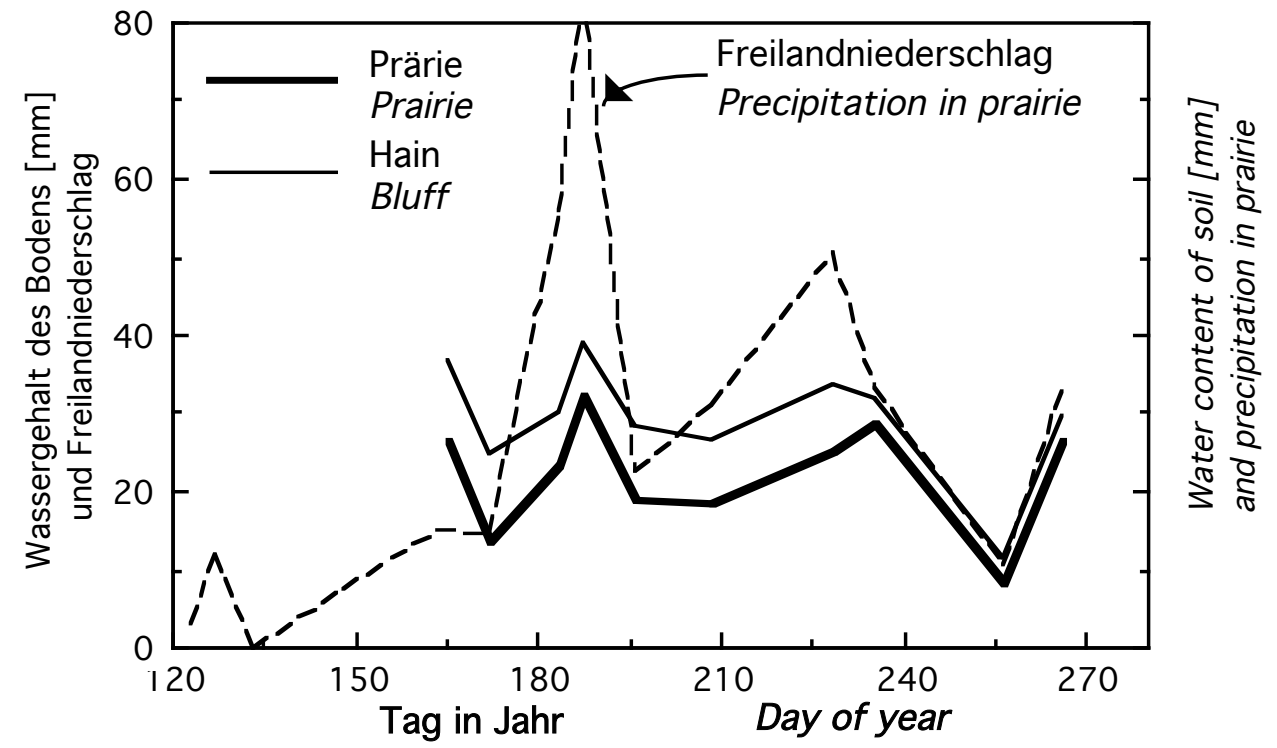

Abb.11. Volumetrischer Wassergehalt des Bodens in den oberen $15 \mathrm{~cm}$ sowie zum Vergleich der Freilandniederschlag.

Fig. 11. Volumetric soil water content of the upper $15 \mathrm{~cm}$, and precipitation in prairie for comparison.

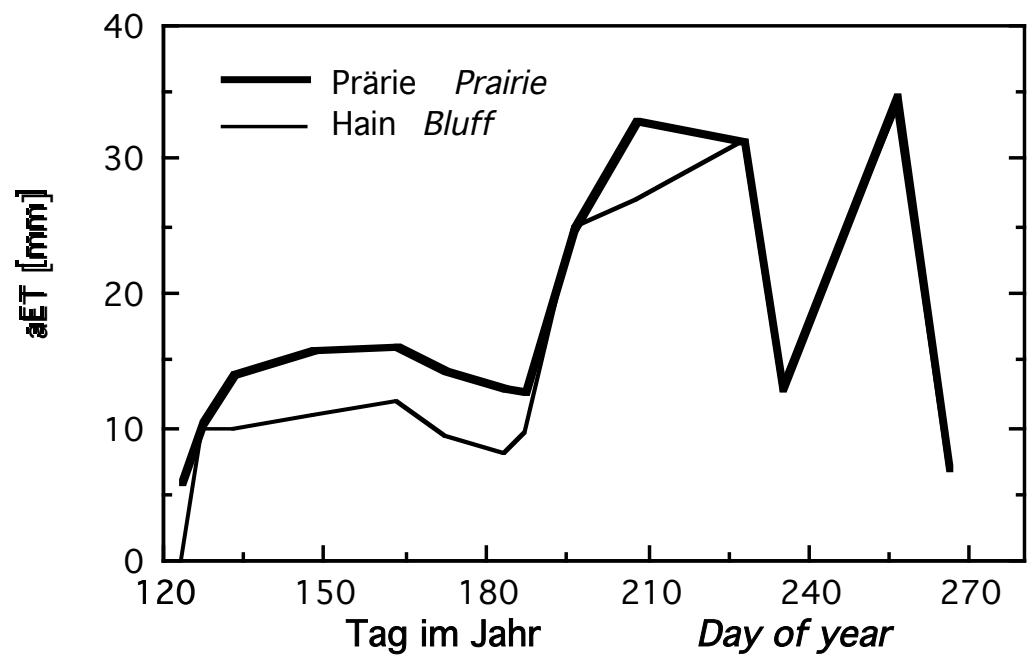

Abb. 12. Aktuelle Evapotranspiration nach THORNTHWAITE, gehäuft über etwa zweiwöchige Abschnitte.

Fig. 12. Actual evapotranspiration according to THORNTHWAITE, accumulated over approximately two-weekly periods.

\subsubsection{Streuzersetzung und Stickstoffflüsse}

Bei einer gleichzeitigen Betrachtung der Masseverlust-, Stickstoffdurchlaß- und Stickstoffrückhalteraten zeigt sich, daß alle Zweifachwechselwirkungen zwischen den Versuchsfaktoren signifikant sind (Tab. 5), wobei die Streusorte den stärksten Einfluß auf die Zersetzungsvorgänge hatte. Das heißt, daß die Streusorten sowohl auf den Biotoptyp als auch auf die Beschattung unterschiedlich reagiert haben, daß aber auch die Wirkung 
der Beschattung vom Biotoptyp abhing. Letzteres bestätigt die Wirksamkeit der Beschattungsbehandlung. In den folgenden Abschnitten wird die Wirkung der Versuchsvarianten auf die einzelnen Zersetzungsvorgänge genauer untersucht.

Tab. 5. Ergebnisse der multiplen Varianzanalyse. Zugrunde liegt der Meßwertvektor \{1 Zersetzungsrate; 0,5 Rückhalterate; 0,5 Durchlaßrate\}. Es wurden exakte F-Werte berechnet. "DF": Freiheitsgrade (Zähler; Nenner). Buchstabenkombinationen stehen für die Wechselwirkungen der jeweiligen Faktoren.

Tab. 5. Results of a multiple analysis of variance. The variable matrix $\{1$ decomposition rate; 0.5 retention rate; 0.5 loss rate\} was used. Exact $F$-values were calculated. "DF": degrees of freedom (numerator; denominator). Combination of letters represent interactions between the effects.

$\begin{array}{lccc}\text { Variable } & \mathbf{F} & \text { DF } & \text { P>F } \\ \text { P } \quad \text { (Gebiet Location) } & 0,2660 & 2 ; 14 & 0,7702 \\ \text { H (Habitat Biotop) } & 2,9371 & 1 ; 14 & 0,1086 \\ \text { L (Streu Litter) } & 498,2849 & 1 ; 14 & 0,0000 \\ \text { S (Beschattg. Shading) } & 5,8663 & 1 ; 14 & 0,0296 \\ \text { HL } & 11,1005 & 1 ; 14 & 0,0049 \\ \text { HS } & 15,1779 & 1 ; 14 & 0,0016 \\ \text { LS } & 13,7500 & 1 ; 14 & 0,0023 \\ \text { HLS } & 1,2552 & 1 ; 14 & 0,2814\end{array}$

\subsubsection{Masseverlust}

Bei keiner der beiden Streusorten konnten deutliche Zeichen der Vermoderung festgestellt werden. Grasstroh war ausgeblichen, erschien aber noch vollständig. Espenstreu war nur teilweise geblichen und verfärbt, sie begann zu fragmentieren, aber nicht zu skelettieren. Die Streumasse nahm gleichmäßig bis zur dritten Ernte ab, danach verlangsamte sich die Abnahme bei der Grasstreu, die Masse der Espenstreu nahm zu. Die Zunahme war aber nicht signifikant $(P>|t| 0,1)$ (Abb. 13).

Nach 146 Tagen im Feld verblieben im Mittel noch $82 \%$ der ursprünglichen Espenstreumasse und $60 \%$ der Grasstreumasse (Abb. 13 und 14). Die Varianzanalyse zeigt, daß eine signifikante Wechselwirkung zwischen Biotoptyp und Beschattung besteht. Diese beruht darauf, daß nicht beschattete Streu in der Prärie mehr Masse verloren hatte als beschattete, daß aber in den Hainen das Verhältnis umgekehrt war. Die Signifikanz der Wechselwirkung zwischen Streusorte und Beschattung liegt im Grenzbereich zur Nichtsignifikanz ( $p=0,045)$, und da die Voraussetzungen der Varianzanalyse nicht vollständig erfüllt waren, könnte es sich um ein zufälliges Ergebnis handeln. 


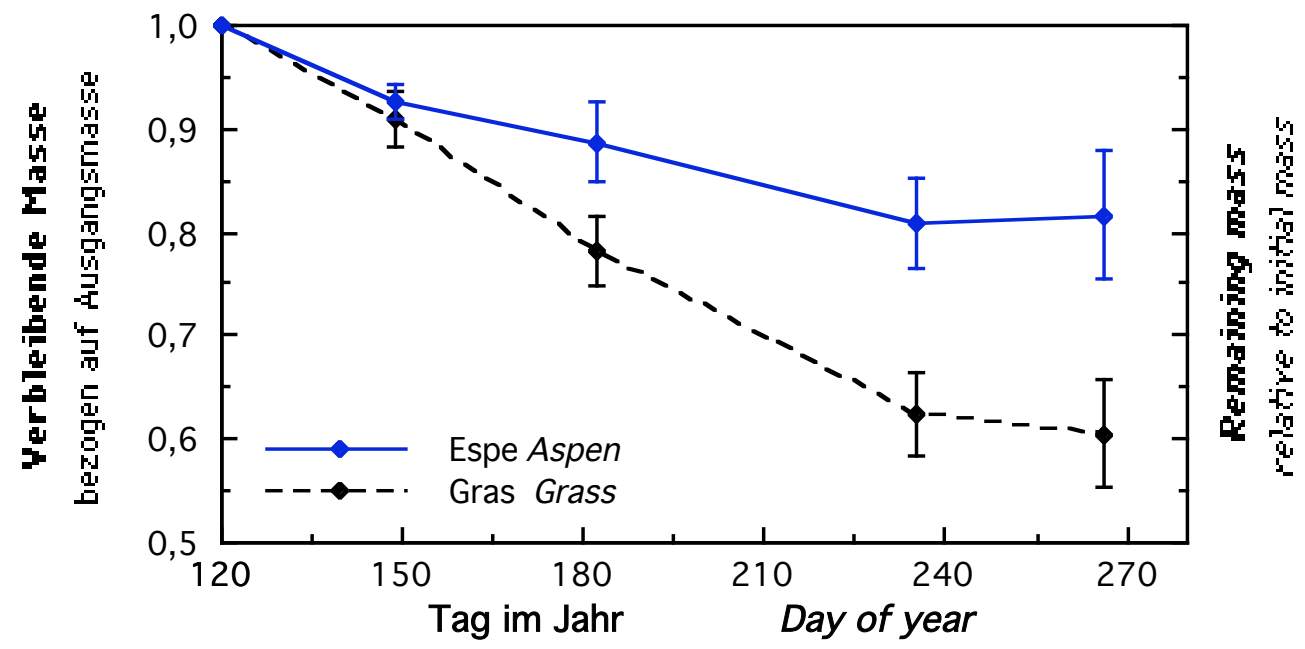

Abb. 13. Zeitlicher Verlauf der Zersetzung von Espen- und Grasstreu, gemittelt über alle Versuchsvarianten. Die Fehlerbalken entsprechen der Standardabweichung ( $n=90 \ldots 94)$. Zur besseren Lesbarkeit wurde die Probennahme in Hain und Prärie in der Abbildung zeitlich leicht entzerrt dargestellt.

Fig. 13. Decomposition of aspen and grass litter over time, averaged over all treatments. Error bars correspond to one standard deviation $(n=90 \ldots 94)$. For better readability sampling time of prairie and bluff has been slightly separated in time in the figure.

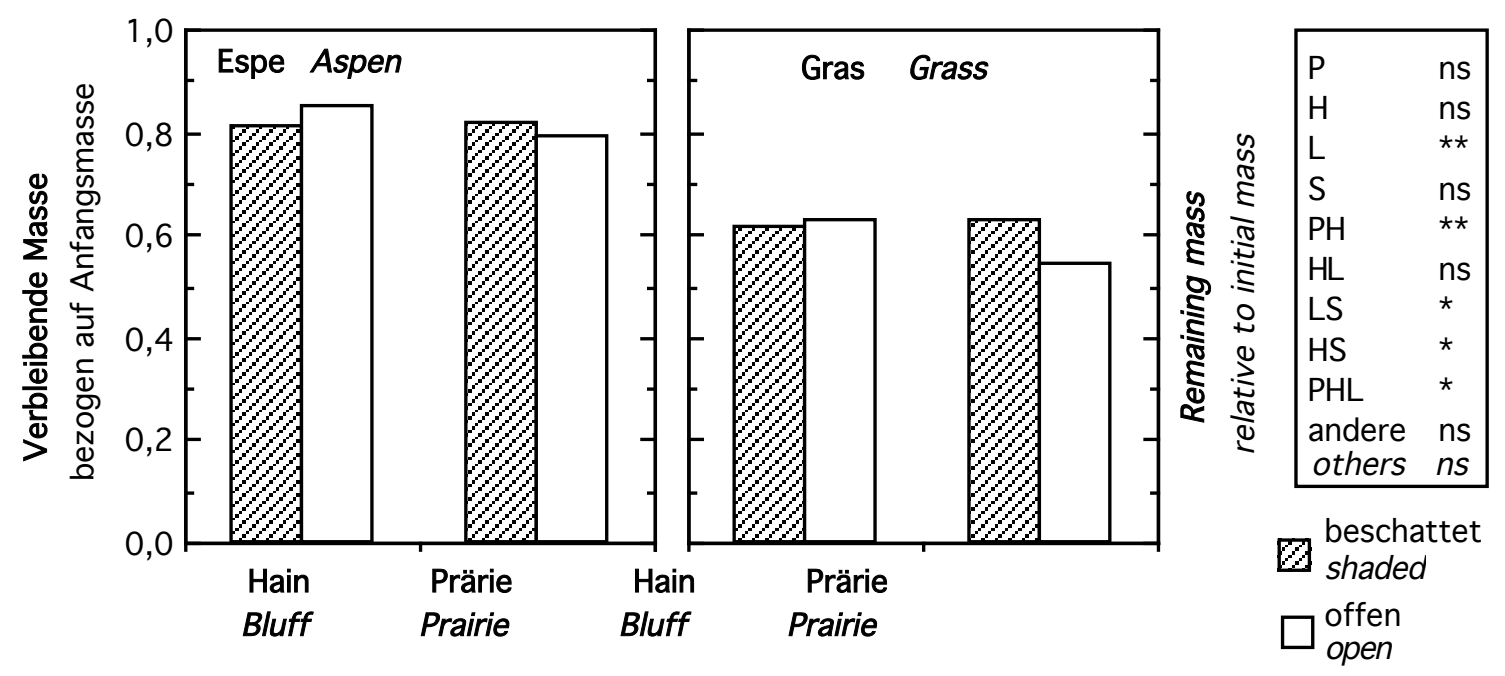

Abb. 14. Einfluß von Biotoptyp, Streusorte und Beschattung auf die Streuzersetzung. Die Abbildung zeigt den Restmasseanteil nach 21 Wochen (Mai-September). P: Gebietseffekt, $\mathrm{H}$ : Biotoptypeffekt, L: Streusorteneffekt, S: Beschattungseffekt, Buchstabenkombinationen stehen für die Wechselwirkungen zwischen den jeweiligen Faktoren. Signifikanzniveaus: ${ }^{*} \mathrm{P}<0,05 ;{ }^{*} \mathrm{P}<0,01 ;{ }^{* * *} \mathrm{P}<0,001$; ns $\mathrm{P}>0,05$.

Fig. 14 Influence of habitat type, litter type, and shade on litter decomposition. The figure shows the realtive mass remaining after 21 weeks (May - September). P: Location effect, $H$ : habitat type effect, L: litter type effect, S: shade effect, combination of letters denote the interactions of the respective treatment effects. Significance levels: ${ }^{*} P<0.05 ;{ }^{* *} P<0.01$; ${ }^{* *}$ $P<0.001$; ns $P>0.05$. 


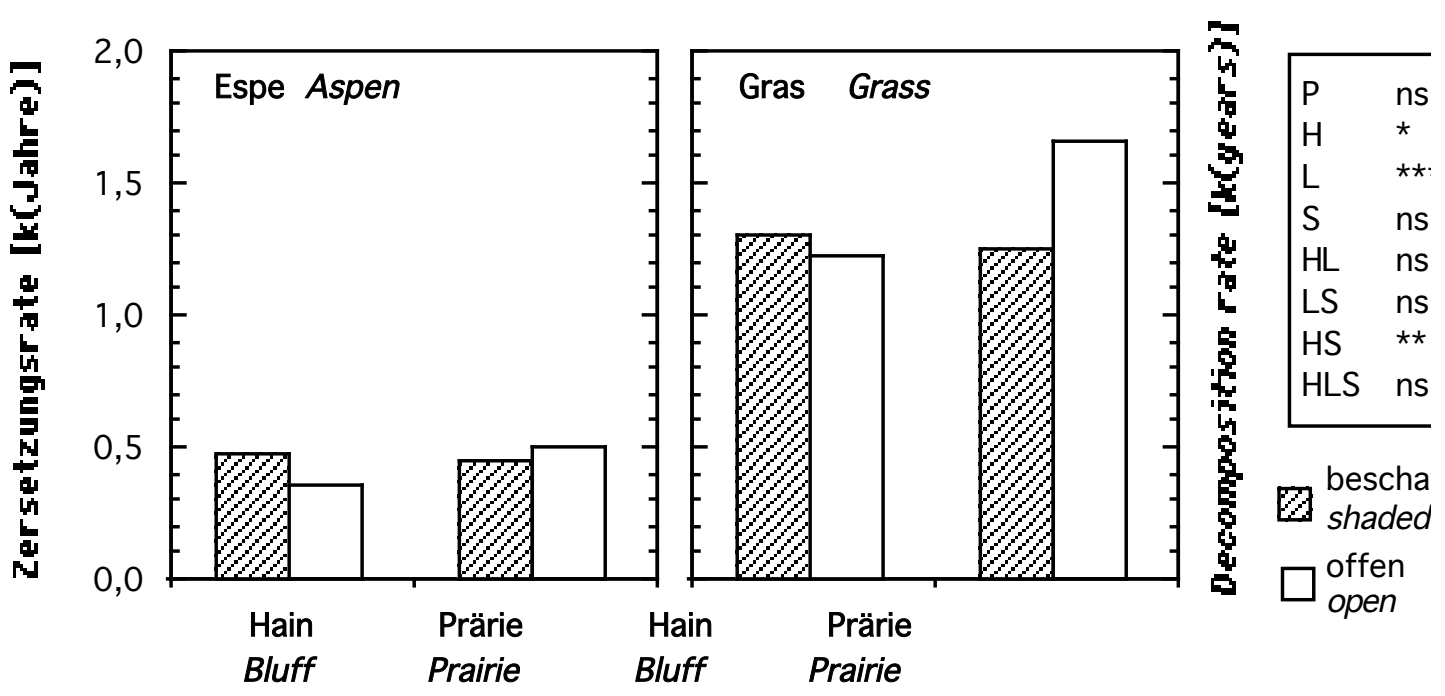

Abb. 15. Einfluß von Biotoptyp, Streusorte und Beschattung auf die Streuzersetzungsrate k. Der Kasten rechts gibt die Ergebnisse der Varianzanalyse wieder. Zeichenerklärung s. Abb. 14.

Fig. 15. Influence of habitat type, litter type, and shade on litter decomposition rate $k$. The right box represents results of an analysis of variance, Symbols as in Fig. 14 .

Die Wechselwirkungen zwischen dem Gebietsfaktor und den übrigen Faktoren erklären sich dadurch, daß Grasstreu in einem Gebiet einen größeren Restmasseanteil in der Präriefläche hatte als in der Hainfläche, wohingegen Grasstreu in den anderen Gebieten und Espenstreu in allen drei Gebieten das entgegengesetzte Verhältnis zeigten. Der Unterschied ist fast doppelt so groß wie die Biotoptyp x Beschattungs-Wechselwirkung. Der Einfluß des Gebietsfaktors war jedoch während des Experimentes nicht konstant und zeigte keinen durchgehenden Trend, der Effekt tritt folglich auch nicht in der Analyse der Masseverlustraten auf.

Die statistische Überprüfung der Wirksamkeit der Beschattung ergab, daß künstliche Beschattung in Hainen keinen signifikanten Einfluß auf die Zersetzungsrate hatte $(\mathrm{t}=1,328, P>|\mathrm{t}| \mathrm{0,205})$, und daß sich die Zersetzungsrate in Hainen nicht signifikant von der in beschatteten Prärieteilflächen unterschied $(t=0,144, P>|t| 0,89)$. Daraus folgt, daß die Beschattungsmatten die beabsichtigte Wirkung hatten.

Die Spannweite der gemessenen Zersetzungsraten reichte von $-0,59$ bis $-0,19$ bei Espenstreu und von $-1,72$ bis $-1,08$ bei Grasstreu. Grasstreu wurde signifikant schneller zersetzt als Espenstreu ( $F=324, P>F \quad 0,0001 ; A b b .15)$. Der Biotoptyp hatte einen signifikanten Einfluß auf die Zersetzungsrate, der aber von der Art der Beschattung abhängig war. Diese Biotoptyp $\times$ Beschattungs-Wechselwirkung ist signifikant ( $F=10,4, P>F$ 0,006). Sie besteht darin, daß die Zersetzung in unbeschatteten Prärieteilflächen am schnellsten war. Die Wechselwirkung trat bei beiden Streusorten auf, der lineare Kontrast war 


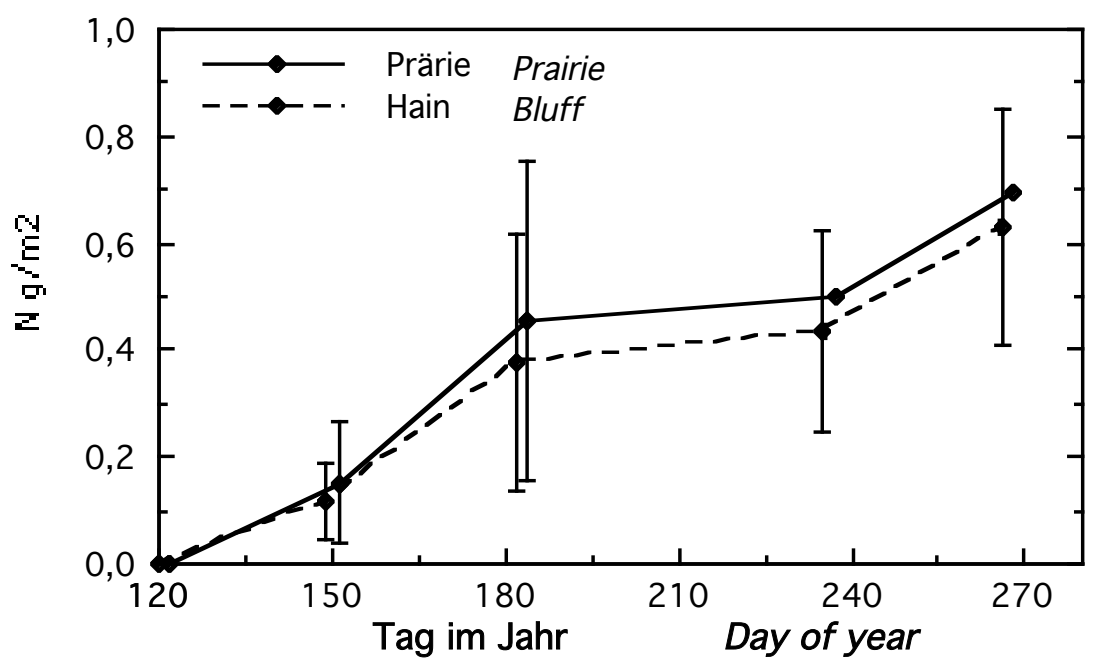

Abb. 16. Stickstoffdeposition im Versuchsgebiet. Senkrechte Balken entsprechen der Standardabweichung, $n=7 \ldots 10$. Die letzten beiden Punkte der Präriekurve tragen keine Fehlerbalken, weil sie teilweise auf Schätzungen beruhen, siehe Abschnitt 2.2.5.2.2.

Fig. 16. Nitrogen deposition in experimental plots. Vertical bars represent one standard deviation, $n=7 \ldots 10$. The last two prairie points do not have error bars, because they depend partly on estimates, see section 2.2.5.2.2.

aber nur für Grasstreu signifikant ( $\mathrm{t}=4,8, \mathrm{P}>|\mathrm{t}| \mathrm{0,0001)}$. Es bestand keine signifikante Dreifachwechselwirkung.

\subsubsection{Stickstoffdeposition}

Die Stickstoffdeposition zur ersten und zweiten Ernte unterschied sich nicht signifikant zwischen Hain und Prärie (Abb. 16). Die Daten der dritten und vierten Ernte können statistisch nicht verglichen werden, weil die Präriewerte zum Teil auf Schätzungen beruhen (vgl. Abschnitt 2.2.5.2.2.). Linear auf ein Jahr hochgerechnet betrug die jährliche Stickstoffdeposition am White Butte $1,0 \mathrm{~g} / \mathrm{m}^{2}$. Das entspricht der oberen Grenze von Schätzwerten $\left(0,2\right.$ and $\left.0,9 \mathrm{~g} \mathrm{~m}^{-2} \mathrm{a}^{-1}\right)$ der Gesamtdeposition in den Central Great Plains (WOODMANSEE 1979; PAUL 1976) und stimmt mit Messungen der nassen Deposition von 1980 in Südsaskatchewan in einer Höhe von $0.3 \mathrm{~g} \mathrm{~m}-2 \mathrm{a}$-1 überein (ESSA 1987), wenn berücksichtigt wird, daß die Gesamtdeposition bis zum Dreifachen der nassen Deposition betragen kann (ULRICH et al. 1979). 


\subsubsection{Stickstoffflüsse}

Durch Deposition abgelagerter Stickstoff wurde in den Streunetzen zum Teil zurückgehalten. Nach 146 Tagen im Feld hatte Espenstreu signifikant mehr Stickstoff zurückgehalten als Grasstreu (Abb. 17 u. 18). Biotoptyp und Beschattung weisen Haupteffekte auf, aber es bestanden keine Wechselwirkungen zwischen den Faktoren. Der Gebietsfaktor hatte jedoch auf die Stickstoffrückhaltung einen starken Einfluß, welcher zusätzlich vom Biotoptyp abhing (Abb. 18). Die Wechselwirkung bestand darin, daß in zwei Gebieten die von der Streu durchgelassene Stickstoffmenge auf der Präriefläche höher, im Gebiet $S$ aber niedriger als auf der Hainfläche war. Bei der zurückgehaltenen Stickstoffmenge trat die Abweichung jedoch im Gebiet $\mathrm{E}$ auf. Hier wurde auf der Hainfläche mehr Stickstoff zurückgehalten als auf der Präriefläche, während es in den anderen zwei Gebieten umgekehrt war. Bei beiden Variablen war der Gebietseffekt nicht konstant, was wiederum durch den Vergleich der Stickstoffflußraten bestätigt wird.

Die Ergebnisse der Varianzanalyse der Stickstofflußraten zeigen keine signifikanten Einflüsse des Gebietes. Die einzigen signifikanten Auswirkungen auf die Durchlaßrate hatten Biotoptyp und Streusorte (Abb. 18 u. 19).

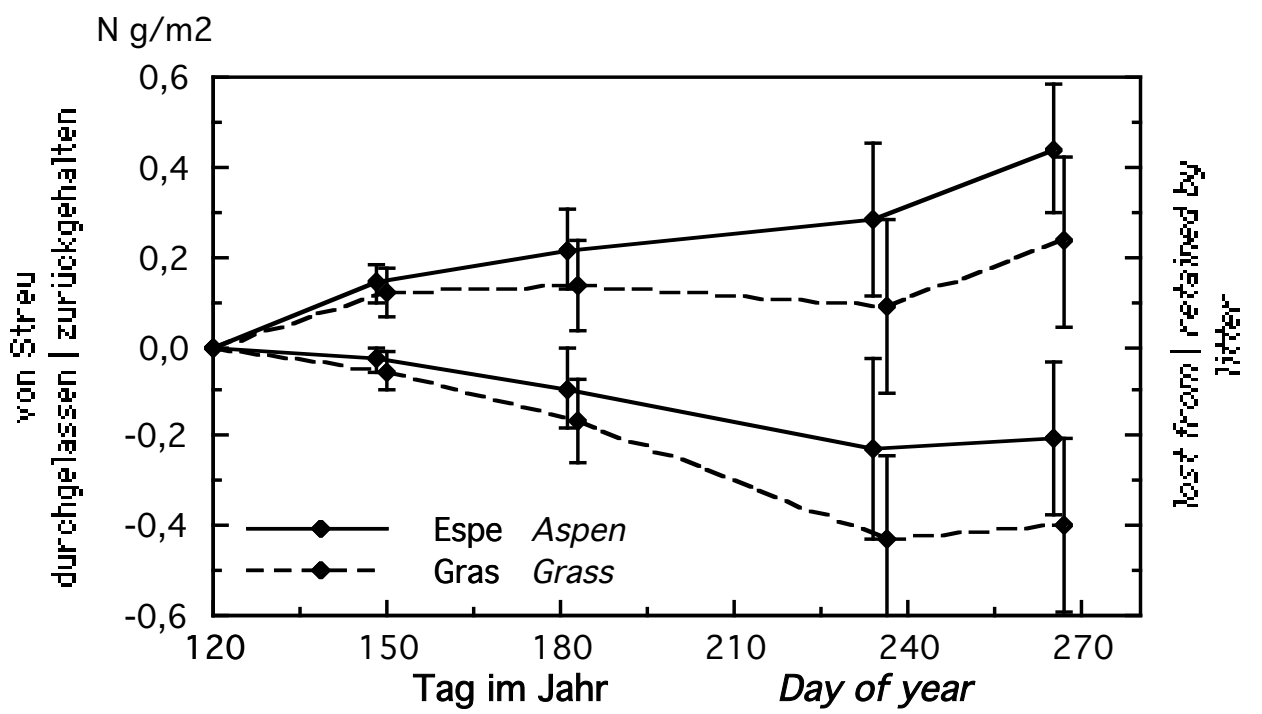

Abb. 17. Zeitlicher Verlauf des Stickstoffflußes bei Espen- und Grasstreu. Die Fehlerbalken entsprechen der Standardabweichung $(n=87 \ldots 93)$. Zur besseren Lesbarkeit wurde die Probennahme von Espe und Gras in der Abbildung zeitlich leicht entzerrt dargestellt.

Fig. 17. Nitrogen flux through aspen and grass litter over time. Error bars correspond to one standard deviation ( $n=87 \ldots 93$ ). For better reading sampling time of aspen and grass has been slightly distorted in time in the figure. 
Auch für die Stickstoffflußraten wurde statistisch überprüft, ob die künstliche Beschattung die erwünschte Wirkung hatte. Wiederum wurde bestätigt, daß künstliche Beschattung in den Hainen keinen weiteren Einfluß auf die Durchlaßrate hatte $(\mathrm{t}=0,98, P>|t| 0,34)$. Die Durchlaßrate in den Hainen war aber signifikant größer als in den beschatteten Prärieteilflächen ( $t=-2,189$, $P>|t| 0,046)$, ja größer als in der Prärie insgesamt $(F=7,8, P>F \quad 0,014)$. Nähere Betrachtung zeigt, daß sich vor allem Espenstreu in beschatteten Prärieteilflächen schneller zersetzt hatte $(t=-2,509, P>|t| 0,025)$.

Darüberhinaus kann nicht völlig ausgeschlossen werden, daß die künstliche Beschattung in den Hainen einen Einfluß auf die Durchlaßrate bei der Grasstreu hatte $(t=1,747, P>|t| 0,103)$. Keine der Wechselwirkungen ist signifikant. Bei der Rückhalterate wurde die Wirksamkeit der Beschattung bestätigt, wenn die Streusorten gemeinsam verglichen wurden, bei getrenntem Vergleich wurde die Annahme abgelehnt, daß die Stickstoffrückhalterate der Espenstreu in beschatteten Prärieteilflächen

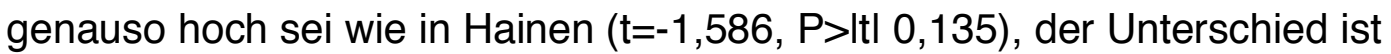
aber auch nicht zum 5\%-Niveau gesichert. Auch die Annahme, daß künstliche Beschattung in Hainen keinen Einfluß auf die Rückhalterate der

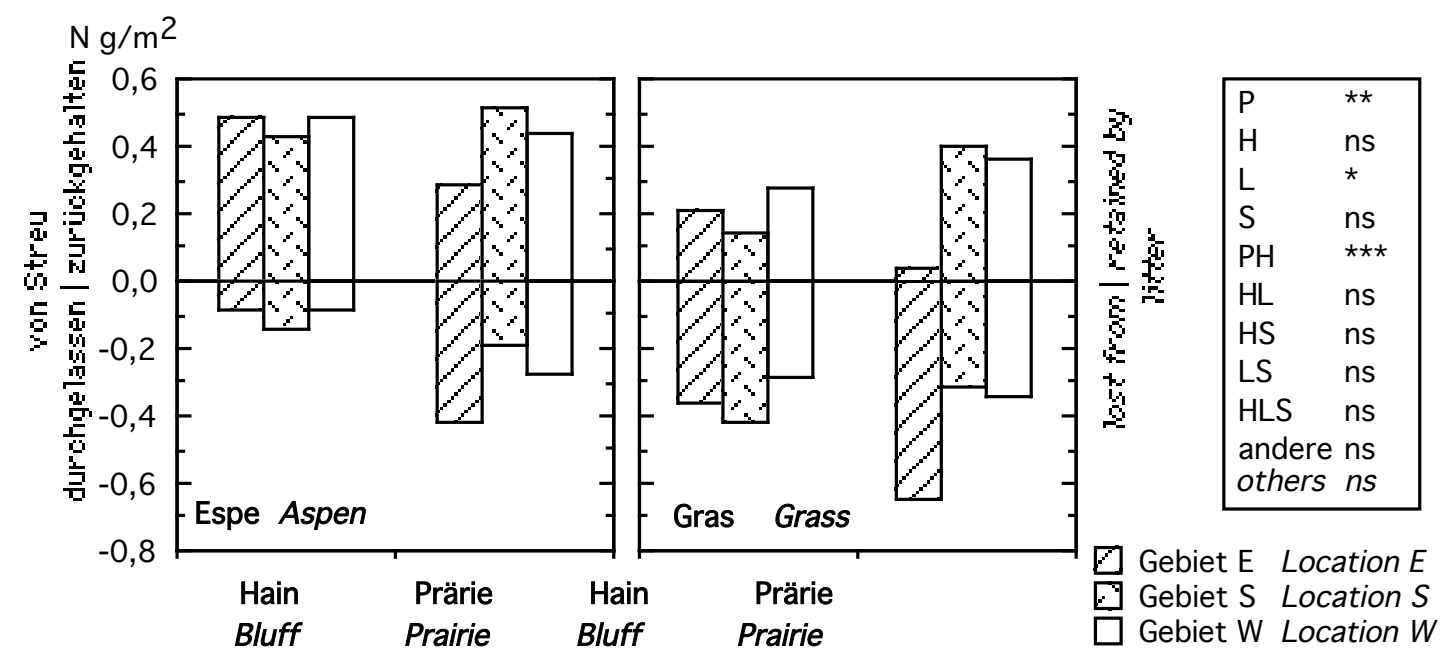

Abb. 18. Einfluß von Gebiet, Streusorte und Biotop auf den Stickstofffluß in Gras- und Espenstreu nach 21 Wochen (Mai bis September). Unterhalb der Nullinie ist die Stickstoffmenge (mit negativem Vorzeichen) aufgetragen, die unter der Streu aufgefangen wurde, über der Linie die Menge des zurückgehaltenen Stickstoffs, berechnet als N(Deposition) $\mathrm{N}$ (durchgelassen). Die ANOVA beruht auf logarithmisch transformierten Werten. Zeichenerklärung s. Abb. 14.

Fig. 18. Influence of location, litter type, and habitat type on nitrogen flux in grass and aspen litter after 21 weeks (May to September). Nitrogen lost from the litter is entered below the zero line (negative sign), litter retained by the litter above the line. Nitrogen retention was calculated as N(deposition) - N(lost). ANOVA was calculated on log-transformed values. Symbols as in Fig. 14. 


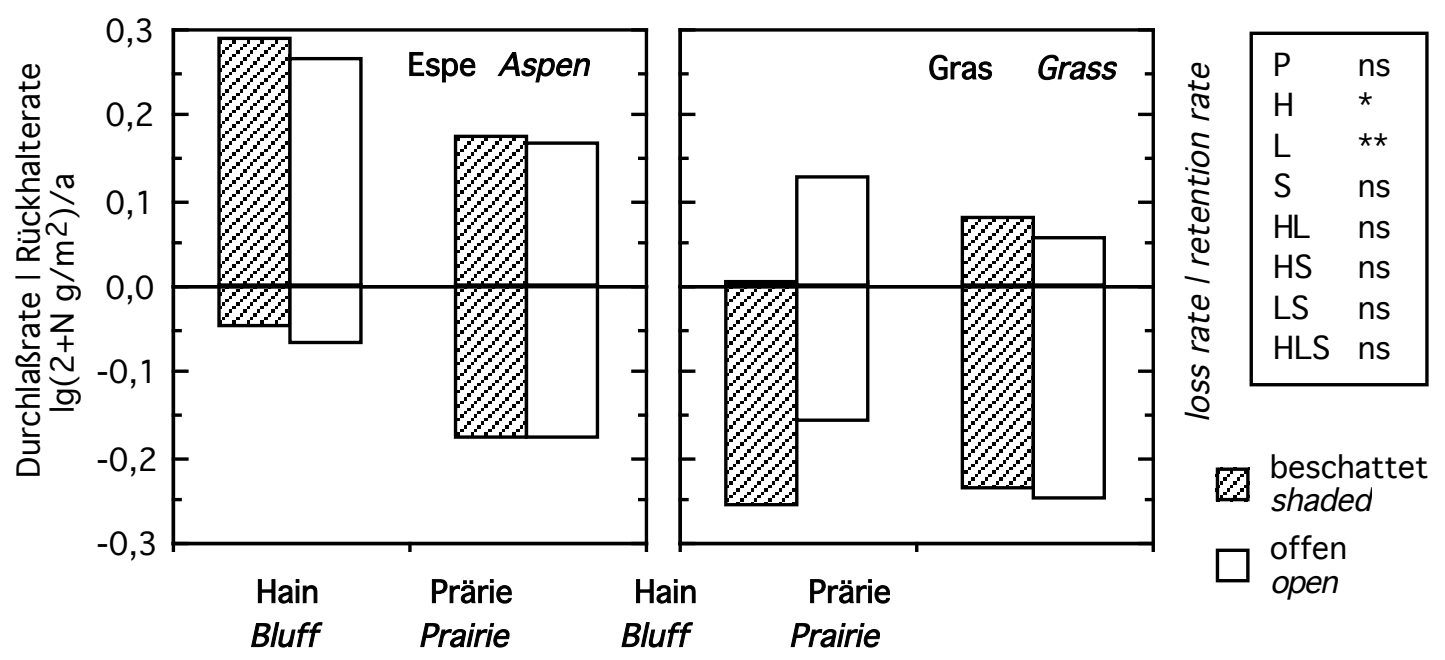

Abb. 19. Einfluß von Biotoptyp, Streusorte und Beschattung auf die Stickstoffrückhalte(über der Nullinie) und -durchlaßraten (unter der Nullinie, negative Vorzeichen). Der Kasten rechts gibt die ANOVA-Ergebnisse für die Durchlaßraten wieder. Die Rückhalteraten wurden teilweise aus Durchlaßwerten berechnet und sind daher statistisch abhängig von den Durchlaßraten. Die ANOVA der Rückhalteraten ergibt nur einen signifikanten $(p=0,001)$ Streusorteneffekt. Zeichenerklärung, s. Abb. 14.

Fig. 19. Influence of habitat type, litter type, and shade on nitrogen retention (above the zero line) and loss rates (below the line, negative signs). The right box represents results of ANOVA of loss values. Retention rates were calculated partially from loss data and therefore they are not independent of the loss rates. The ANOVA of retention rates showed only a significant litter type effect ( $p=0.001)$ Symbols as in Fig. 14.

Grasstreu habe, wurde abgelehnt $(t=1,612, P>|t| 0,13)$, der Unterschied ist aber ebenfalls nicht zum 5\%-Niveau gesichert.

\subsubsection{Stickstoffgehalt der Streu}

Obwohl der Stickstoffgehalt beider Streusorten während des Experimentes deutlich zunahm (Abb. 20, oben), nahm die Stickstoffmenge in der Espenstreu um $4 \%$ zu und in der Grasstreu um $37 \%$ ab (Abb. 20, Mitte). Das C/N-Verhältnis beider Streusorten nahm mit der Zeit ab (Abb. 20, unten). Stickstoffmenge, -vorrat und $\mathrm{C} / \mathrm{N}-$ Verhältnis wurden nicht durch die Beschattung beeinflußt (Abb. 20). 

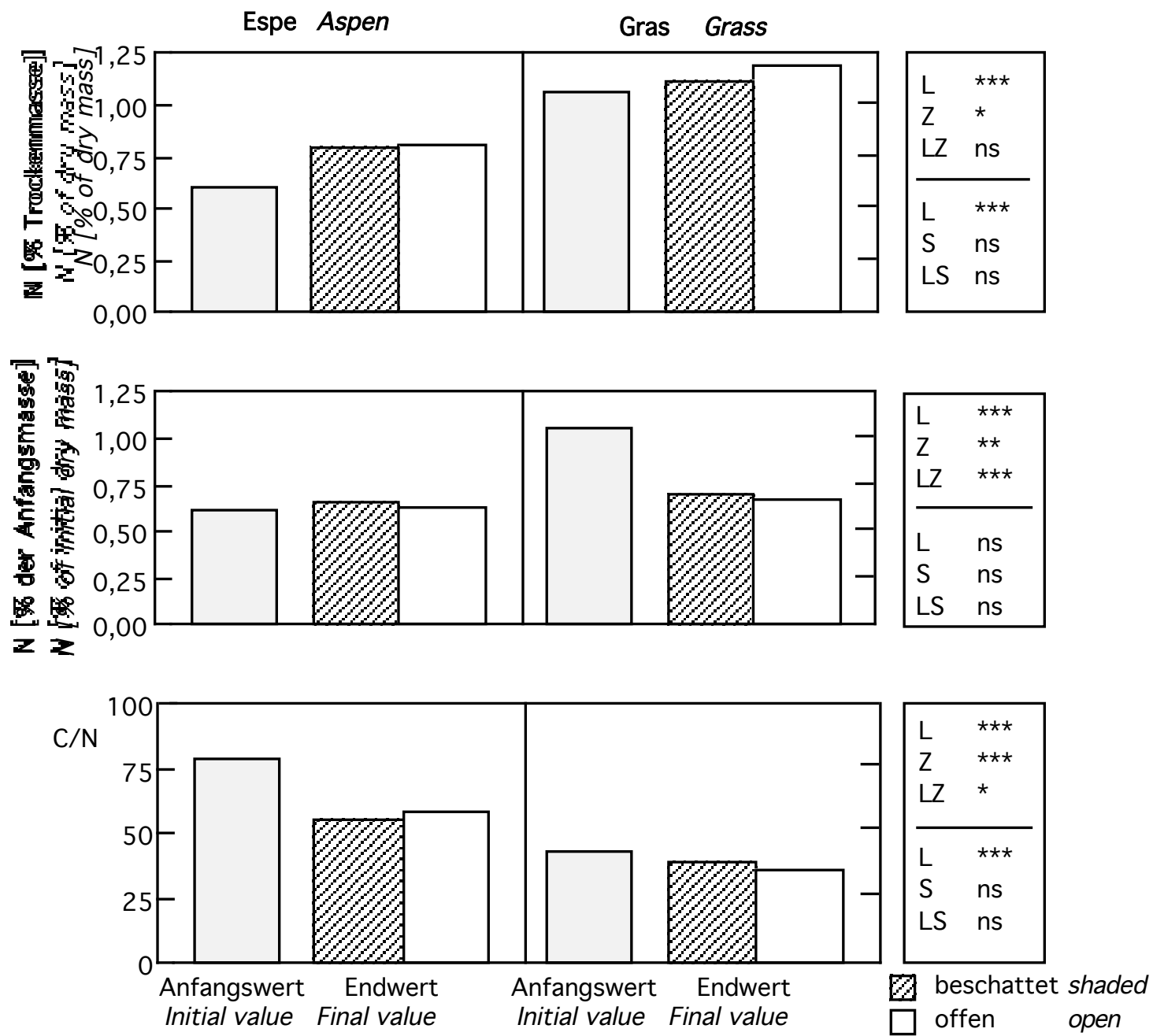

Abb. 20. Einfluß von Streusorte und Beschattung nach 21 Wochen Streuzersetzung (Mai - September) in Prärieflächen auf den Stickstoffgehalt (oben), auf die Stickstoffmenge (Mitte) und das $\mathrm{C} / \mathrm{N}$-Verhältnis (unten). Es wurde je eine Varianzanalyse für die Variablen Zeit (Z) und Streusorte und für die Variablen Beschattung und Streusorte berechnet. Die Ergebnisse sind in den Kästen rechts dargestellt. Zeichenerklärung s. Abb. 14.

Fig. 20. Influence of litter type and shading on nitrogen content after 21 weeks of decomposition (May - September) in prairie plots, relative to litter dry mass at the time of measurement (top), relative to initial dry mass (middle) and the C/N ratio. Separate ANOVAs have been calculated for the variables time $(Z)$ and litter type and for shading and litter type. The results are represented in the boxes on the right. Symbols as in Fig. 14.

Abbildung 20, Mitte, und ein Vergleich durch linearen Kontrast zeigen, daß die Zeit $\times$ Streu-Wechselwirkung bei der Stickstoffmenge auftritt, weil nur die Grasstreu Stickstoff verloren hatte. Da die zersetzte Streu, die für die Analyse verwendet worden war, auf ihrer Oberfläche auch aus Deposition stammenden Stickstoff enthielt, muß dieser von den Stickstoffvorräten abgezogen werden. Dadurch ergibt sich wieder ein anderes Bild (Abb. 21). Demnach hätte Espenstreu 0,35 g Stickstoff (=27 \%) und Grasstreu 0,99 g Stickstoff $(=50 \%)$ je Quadratmeter verloren. 


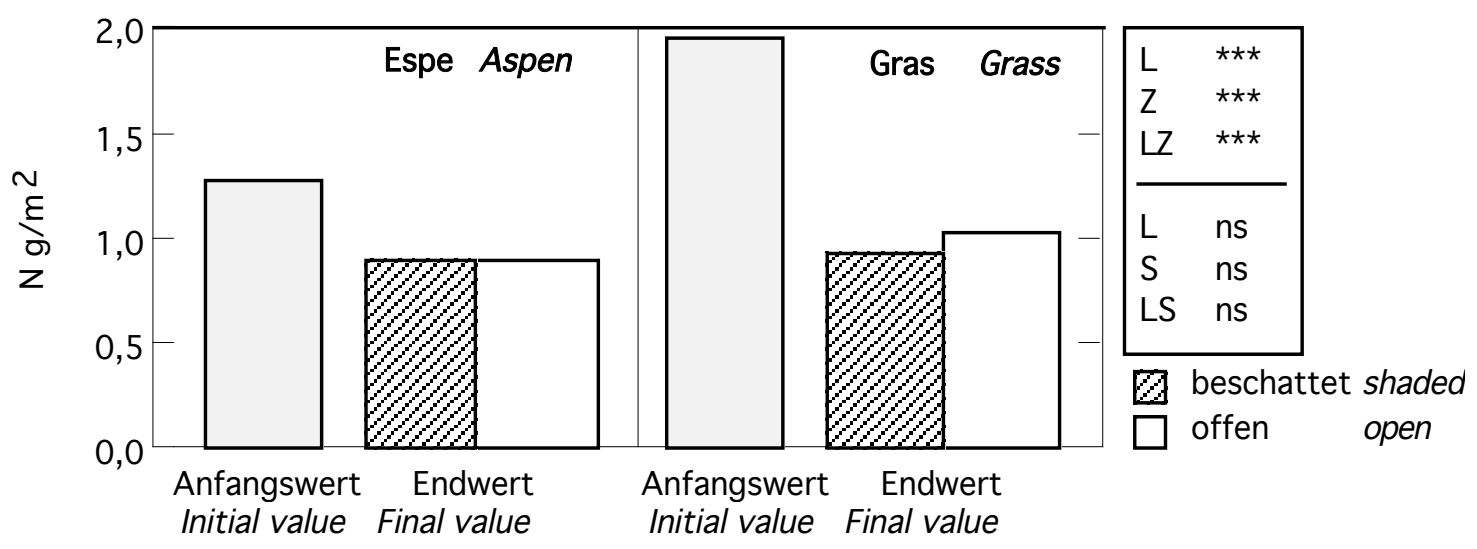

Abb. 21. Stickstoffvorrat der Streu unter Berücksichtigung der Deposition. Im Kasten rechts die Ergebnisse der ANOVAs. Zeichenerklärung s. Abb. 14 und 15.

Fig. 21 Nitrogen storage of litter accounted for nitrogen deposition. The box on the right presents results from ANOVAs. Symbols as in Fig. 14 and 15. 
4. Diskussion

\subsection{Espenhaintransekt}

Der mineralische Stickstoffgehalt des Bodens in Oakshela wies eine große Schwankungsbreite auf. Dennoch war der Mineralstickstoffgehalt in Hainböden signifikant höher als in Prärieböden. Das heißt, daß dieser Unterschied nicht nur im White-Butte-Gelände, sondern auch anderswo im Espenparkland auftreten kann. Von den gemessenen Variablen stand Mineralstickstoffgehalt nur mit dem Wassergehalt des Bodens und dem Lichtdurchlaß in einem signifikanten Zusammenhang. Zum Alter der Bäume und zur Lufttemperatur am Boden bestand hingegen keine signifikante Beziehung. Hohe Stickstoffwerte kamen mit einer Ausnahme nur unter geschlossenem Kronendach vor. Ob der hohe Stickstoffgehalt an dem einen Punkt in der Prärie die tatsächliche Schwankungsbreite des Stickstoffgehaltes des Biotopes widerspiegelt oder ein außergewöhnlicher Wert ist, kann anhand der vorliegenden Messungen nicht entschieden werden. Dies wäre nur durch eine Verlängerung der Transekte in die Prärie und zusätzliche Meßpunkte möglich.

Aus der graphischen Auftragung von Stickstoffgehalt gegen Lichtdurchlaß (Abb. 8c) geht am deutlichsten hervor, daß im Hainboden höhere Stickstoffgehalte auftreten können als im Prärieboden. Dies scheint den signifikanten linearen Anteil der Maßkorrelation zu erklären. Anscheinend besteht aber weder innerhalb noch außerhalb der Haine ein Zusammenhang mit der Höhe des Lichtdurchlasses, was sich in der Nichtsignifikanz der Rangkorrelation zeigte. Anscheinend spiegeln die Lichtverhältnisse nur den Biotoptyp wieder.

Der Gehalt an mineralischem Stickstoff im Boden nahm deutlich mit zunehmendem Wassergehalt ab. Bis auf einen Ausreißerwert ist die Stickstoffverfügbarkeit in der Prärie auch bei geringem Wassergehalt niedrig und sinkt bei höherem Wassergehalt noch weiter ab. In Hainen können bei niedrigem Wassergehalt hohe Stickstoffgehalte auftreten, aber bei hohem Wassergehalt sinkt der Gehalt auf das Niveau der Prärie ab. Wenn der Prärieboden austrocknet, sinkt die Diffusionsrate des Bodens und behindert wahrscheinlich physikalisch die Stickstoffaufnahme der Pflanzen und Mikroorganismen (DAVIDSON 1990), so daß mehr mineralischer Stickstoff im Boden verbleibt (JACKSON et al. 1989; STANTON 1988). Darüberhinaus werden die zersetzenden Bakterien und Pilze bei Trockenheit von Nematoden und Flagellaten gefressen, wodurch mehr Stickstoff mineralisiert wird (STANTON 1988). Möglicherweise sind die Pflanzen und Mikroorganismen in den 
Hainen schlechter an Trockenheit angepaßt und stellen daher ihre Stickstoffaufnahme bereits bei geringerer Trockenheit ein als die Prärieorganismen. Genausogut läßt sich durch Umkehrung der Argumentation die geringere Stickstoffverfügbarkeit durch eine wirksamere Nährstoffaufnahme bei höherer Bodenfeuchte erklären (SRIVASTAVA 1992, DAVIDSON 1990).

Wie bereits in der Einleitung erwähnt wurde, wird die Erhöhung des Stickstoffgehaltes im Boden unter Bäumen von einigen Autoren auf Stammabfluß und Kronenauswaschung zurückgeführt (GERSPER \& HOLLOWAYCHUK 1970; KELLMAN 1979). Der Stickstoffgehalt im Stammabfluß der Espen unterscheidet sich jedoch nicht vom Stickstoffgehalt im Freilandniederschlag (PASTOR \& BOCKHEIM 1984). Darüberhinaus ist nicht genau bekannt, wie hoch der Stickstoffgehalt im "Stammabfluß" bei Gräsern ist. Zumindest das Interzeptionsvermögen und der Stammabfluß von Gräsern ist höher als der von Bäumen (CLARKE 1940; SEASTEDT 1985). Der Beitrag des im Bestandesniederschlag gelösten Stickstoffs, der sehr groß sein kann (PASTOR \& BOCKHEIM 1984), war in diesem Versuch gering, denn er vermochte nicht die geringere Deposition in Hainen auszugleichen und die äußere Stickstoffzufuhr auf Prärieniveau anzuheben.

Es ergibt sich daher folgendes Bild: Die höhere Stickstoffverfügbarkeit im Boden von Espenhainen ist ein Ergebnis der schlechteren Anpassung der Stickstoffnutzer an Bodentrockenheit. In Hainen wird die Stickstoffaufnahme durch die Espen und Hain-Mikroorganismen durch Bodentrockenheit eher gehemmt als die Stickstoffaufnahme durch die Gräser und Prärie-Mikroorganismen in der Prärie. Dies erklärt auch, warum das Verhältnis des Stickstoffgehaltes zwischen Hain und Prärie von Jahr zu Jahr schwanken kann. So wurde 1991 am White Butte weniger Stickstoff in der Prärie als in Hainen gemessen (WILSON 1993a), 1993 bestand jedoch, vielleicht wegen der höheren Niederschläge zum Meßzeitpunkt, kein signifikanter Unterschied $(\mathrm{H}$. KLEB, unveröffentlichte Magisterarbeit).

\subsection{Streuzersetzung}

\subsubsection{Vergleichbarkeit von Klima und Streu}

Obwohl die Mittagstemperatur in Hainen um $1,4^{\circ} \mathrm{C}$ niedriger war als in der Prärie, ist der Unterschied wohl zu gering, um einen Einfluß auf die Streuzersetzung zu haben. Da physikalisch-chemische Vorgänge und der Stoffwechsel ektothermer Zersetzer ungefähr der "RGT-Regel" (Verdoppelung der Reaktionsgeschwindigkeit bei Erhöhung der Temperatur um $10 \mathrm{~K}$ ) folgen (BEGON et al. 1990: 51; TAYLOR \& PARKINSON 1988C), wird daher die 
Streuzersetzungsrate durch den Temperaturunterschied nur um etwa $10 \%$ vermindert.

Der Niederschlag während des Versuches war höher als im langjährigen Mittel (Abb. 9b). Der reichliche Niederschlag könnte die Lebensbedingungen für die Zersetzer entscheidend verändert und damit die Ergebnisse beeinflußt haben. - Vielleicht sind es die Jahre mit außergewöhnlichem Klima, die den längerfristigen Einfluß auf ein Ökosystem ausüben (HOBBS \& MOONEY 1991; TILMAN 1990).

Der Stickstoffgehalt der Espenstreu zu Beginn des Versuches lag nicht wesentlich unter dem aus Literaturangaben ermittelten Durchschnitt (Tab. 1), obwohl die Streu zum Zeitpunkt des Einsammelns bereits seit etwa sechs Monaten am Boden gelegen hatte. Im allgemeinen nimmt die Stickstoffkonzentration der Streu während dieser Zeit zu, weil zu Beginn der Zersetzung zunächst nur die Streumasse abnimmt, die Stickstoffmenge aber gleich bleibt oder zunimmt (für die Stickstoffzunahme gibt es eine Vielfalt von möglichen Ursachen [LOUSIER \& PARKINSON 1978; BERG \& STAAF 1981], auf die hier nicht weiter eingegangen werden kann). So besaß die Streu in anderen Versuchen im Frühjahr einen anderthalbfachen bis doppelt so hohen Stickstoffgehalt wie die frische Streu im vorausgegangenen Winter (BARTOS \& DEBYLE 1981; LOUSIER \& PARKINSON 1978; beide Untersuchungen im Gebirge in $>1000 \mathrm{~m}$ Höhe). Die Konzentrationszunahme wurde von BARTOS \& DEBYLE (1981) bei einem sehr niedrigen anfänglichen Stickstoffgehalt $(0,44 \%)$ beobachtet, daher hängt der niedrige Stickstoffgehalt der Espenstreu am White Butte im Mai wohl nicht von einem bereits sehr niedrigen Wert schon beim Laubfall ab. Daraus kann gefolgert werden, daß am White Butte die Streuzersetzung im Winter sehr gering ist, vermutlich weil die starke Kälte nicht durch eine dicke Schneedecke gemildert wird und die Zersetzer deshalb inaktiv sind.

Die Höhe des Stickstoffgehaltes der Grasstreu zu beurteilen, ist schwierig. Das liegt zum einen daran, daß nur wenige Autoren Stickstoffkonzentrationen im Frühjahr mitteilen (VAN VUUREN \& VAN DER EERDEN 1992), zum anderen daran, daß die Anteile der verschiedenen Arten im Grasstreugemisch in diesem und in ähnlichen Versuchen (ABOUGUENDIA \& WHITMAN 1979; TAYLOR et al. 1989) unbekannt sind. Es scheint aber, daß auch der Stickstoffgehalt der Grasstreu im vorliegenden Versuch nicht sehr von Werten in anderen Versuchen abweicht, obwohl die Stickstoffgehalte in den anderen Versuchen vor dem Winter gemessen worden waren. Vermutlich ist auch die Grasstreu am White Butte von der eingeschränkten Zersetzertätigkeit im Winter betroffen. 


\subsubsection{Masseverlust}

Der Zersetzungsversuch hat deutlich gezeigt, daß die Streusorte einen viel stärkeren Einfluß auf den Masseverlust hatte als der Biotoptyp oder die Beschattung (Abb. 13 u. 15). Es bestand dennoch ein schwächerer Einfluß durch eine Wechselwirkung zwischen Biotoptyp und Beschattung, die sich darin zeigte, daß in allen vor der Sonneneinstrahlung geschützten Teilflächen (Hainflächen mit und ohne künstliche Beschattung sowie beschattete Prärieflächen) die Streuzersetzung langsamer war. Damit ist die anfängliche Annahme, daß Schutz vor Sonneneinstrahlung die Streuzersetzung durch Verminderung der Evapotranspiration beschleunigt, widerlegt. Statt dessen zeigen die Ergebnisse, daß die Streuzersetzung zuvörderst durch die Eigenschaften der Streu und erst an zweiter Stelle durch abiotische Einflüsse geregelt worden ist. Die ausschlaggebenden Unterschiede der Streu waren der anfängliche Stickstoffgehalt und das davon abhängige $\mathrm{C} / \mathrm{N}-$ Verhältnis der Streu (Abb. 19, unten; vgl. TAYLOR et al. 1989). Versuche in der russischen Steppe legen nahe, daß der Einfluß der Sonneneinstrahlung auf die Streuzersetzung auf photochemischen Vorgängen beruhen könnte (R. I. ZLOTIN, persönl. Mitteilungen an N. FRENCH, R. T. COUPLAND und G. M. VAN DYNE [FRENCH 1979b; COUPLAND \& VAN DYNE 1979]). Möglicherweise beschleunigt die Sonneneinstrahlung durch den damit verbundenen Anstieg der Temperatur (ELLENBERG 1986: 616) den Stoffwechsel und damit die Umsatzrate der Zersetzer, deren Temperaturoptimum bei 30 bis $55^{\circ} \mathrm{C}$ liegt (HAGIN \& AMBERGER 1974). Andererseits erhöht sich mit der Temperatur auch die Verdunstung und damit die Trockenheit der Streu, was sich ungünstig auf die Tätigkeit der Zersetzer auswirkt (ELLENBERG 1986: 655; TAYLOR \& PARKINSON 1988c). Vielleicht ist dieser Einfluß aufgrund des außergewöhnlich reichlichen Regens in diesem Versuchsjahr unterdrückt worden.

Zusammenfassend läßt sich feststellen, daß die chemische Zusammensetzung der Streu einen weitaus stärkeren Einfluß auf die Streuzersetzung hatte als die Sonneneinstrahlung. Diese Ergebnisse gelten allerdings nur bei gleichem Lokalklima, denn weltweit gesehen hat das Großklima den entscheidenden Einfluß auf die Streuzersetzung (MEENTEMEYER 1978).

Die Ergebnisse des Versuches tragen auch zur Diskussion über den Anteil abiotischer und biotischer Faktoren bei der Streuzersetzung, sei es in Grasland oder in Wäldern, bei. ZLOTIN \& KHODASHOVA (1980) zeigten, daß Laubstreu in Wäldern vor allem von der Mikro- und Mesofauna zersetzt wird (81 \% des Masseverlustes bei der Europäischen Espe Populus tremula L.), daß aber Gras in der Steppe vor allem durch abiotische Vorgänge zerfällt (70 $\%$ des Masseverlustes). VossBRINCK et al. (1979), die in der Kurzgrasprärie 
mit einem anderen Biozid arbeiteten, konnten jedoch bei einem Präriegras nur für $36 \%$ des Masseverlustes abiotische Vorgänge ausmachen.

Das Fehlen eines Biotopeinflusses auf die Streuzersetzung wurde bisher vor allem bei Laubblattstreu festgestellt (HOWARD \& HOWARD 1980; WITKAMP 1966; MCCLAUGHERTY et al. 1985; HUNT et al. 1988). Bei Nadelstreu von Kiefern (Pinus sp.) tritt jedoch häufig ein Einfluß des Biotoptyps auf, da Kiefernnadeln in ihrem ursprünglichen Biotop am schnellsten zersetzt werden (HUNT et al. 1988). Als Ursache wird angenommen, daß in Kiefernwäldern besonders angepaßte Zersetzer vorhanden sind, die die Kiefernnadeln mit ihrem hohen Ligningehalt zersetzen können (WITKAMP 1963, 1966; HUNT et al. 1988).

Die Zersetzung im vorliegenden Versuch war schneller als in anderen Feldversuchen (Tab. 6). Die höhere Zersetzungsrate der Grasstreu beruht sehr wahrscheinlich auf derem höheren Stickstoffgehalt. Andropogon gerardii und Schizachyrium scoparium verfügen nur über 0,3 - 0,5\% Stickstoff, das C/N-Verhältnis von $A$. gerardii beträgt nur 122 und von S. scoparium 110 (WEDIN \& TILMAN 1990; PASTOR et al. 1987). Die Zersetzung der Grasstreu wurde bei den Versuchen von ABOUGUENDIA \& WHITMAN (1979) vielleicht behindert, weil die Makrofauna wegen der Verwendung engerer Maschen für die Streunetze $(1 \mathrm{~mm}$ ) nicht an die Streu gelangen konnte (VosSBRINCK et al. 1979). Allerdings hatten SEASTEDT et al. (1992) bei Verwendung von Netzen mit ein und drei Millimeter weiten Maschen keinen Einfluß der Maschenweite auf die Grasstreuzersetzung feststellen können. Der wichtigste Unterschied zwischen dem vorliegenden Versuch und ABOUGUENDIA \& WHITMANS (1979) ist aber wohl, daß in jenem die Laubnetze auf eine vegetationsfreie Bodenoberfläche gelegt worden waren. Durch das Entfernen der Vegetation ist vermutlich die Zersetzergemeinschaft stark gestört und verändert worden. Die Zersetzung der Grasstreu im vorliegenden Versuch verlief fast so schnell wie in Klimakammerversuchen (TAYLOR et al. 1989). Das könnte bedeuten, daß die Umgebungstemperatur und die vorhandene Feuchtigkeit am White Butte annähernd wie die Kammerbedingungen (gleichmäßige Temperatur von $26^{\circ} \mathrm{C}$, eine wöchentliche Wassergabe von $30 \mathrm{ml}$ ) gewirkt haben.

Nur zwei Berichte sind hinreichend genau, um aus ihnen die Zersetzungsrate von Espenstreu für den Zeitraum von Mai bis September zu berechnen (Tab. 6). Demnach liegt die Zersetzungsrate der Espenstreu im vorliegenden Versuch zwischen den Zersetzungsraten, die in der russischen Waldsteppe (ZLOTIN \& KHODASHOVA 1980) und im Felsengebirge (LOUSIER \& PARKINSON 1976) gemessen worden sind. Die langsamere Zersetzung im Felsengebirge scheint nicht durch den anfänglichen Stickstoffgehalt der Streu beeinflußt 
gewesen zu sein, weil die dort verwendete Streu einen höheren Stickstoffgehalt besaß (1,05\%; LOUSIER \& PARKINSON 1978). Auch ein Einfluß der Evapotranspiration ist unwahrscheinlich, da sie in beiden Untersuchungsgebieten fast gleich ist (White Butte: 481 mm [1993], Kananaskis, Felsengebirge, 440 mm [Mittelwert für 1951-1971, CRAGG et al. 1977]).

Tab. 6. Vergleich von Zersetzungsraten für den Zeitraum Mai-September, berechnet aus Tabellen und Abbildungen der angegebenen Quellen. In der Spalte "Biotop" ist abzulesen, wo das Zersetzungsexperiment durchgeführt wurde und $t_{0,5}$ gibt die Zeit an, in der die Hälfte der anfänglichen Streumasse zersetzt wurde ( $\left.\mathrm{t}_{0,5}=\ln 0,5 / \mathrm{k}\right)$

Tab 6. Comparison of decomposition rates for the period May-September, calculated from tables and graphs of the cited references. The column "habitat" shows where decomposition was studied and to.5 is the time necessary to decompose half of the initial litter mass

(t $0,5=\ln 0.5 / \mathrm{k}$ ).

\begin{tabular}{|c|c|c|c|c|}
\hline Streusorte & Biotop & k & $t_{0,5}$ & Quelle \\
\hline Litter type & Habitat & & & Reference \\
\hline $\begin{array}{l}\text { Schizachyrium scoparium } \\
\text { (MICHX.) NASH-GOULD }\end{array}$ & $\begin{array}{l}\text { Brachacker } \\
\text { Old field }\end{array}$ & $-0,129$ & 5,4 & PASTOR et al. 1987 \\
\hline Andropogon gerardii VIT. & $\begin{array}{l}\text { Kurzgrasprärie } \\
\text { Short-grass prairie }\end{array}$ & $-0,496$ & 1,4 & SEASTEDT et al. 1992 \\
\hline $\begin{array}{l}\text { Mischgräser } \\
\text { Mixed-Grasses }\end{array}$ & $\begin{array}{l}\text { Mischgrasprärie } \\
\text { Mixed-grass Prairie }\end{array}$ & $-0,796$ & 0,9 & $\begin{array}{l}\text { ABOUGUENDIA \& WHITMAN } \\
1979\end{array}$ \\
\hline $\begin{array}{l}\text { Gräser } \\
\text { Grasses }\end{array}$ & $\begin{array}{l}\text { Steppe } \\
\text { Steppe }\end{array}$ & $-0,892$ & 0,8 & $\begin{array}{l}\text { ZLOTIN \& KHODASHOVA } \\
1980\end{array}$ \\
\hline $\begin{array}{l}\text { Mischgräser } \\
\text { Mixed-Grasses }\end{array}$ & $\begin{array}{l}\text { Mischgrasprärie } \\
\text { Mixed-grass Prairie }\end{array}$ & $-1,358$ & 0,5 & $\begin{array}{l}\text { diese Diplomarbeit } \\
\text { this thesis }\end{array}$ \\
\hline $\begin{array}{l}\text { Hochgräser } \\
\text { Tall-Grases }\end{array}$ & $\begin{array}{l}\text { Klimakammer } \\
\text { Microcosm }\end{array}$ & $-1,391$ & 0,5 & TAYLOR et al. 1989 \\
\hline $\begin{array}{l}\text { Gräser } \\
\text { Grasses }\end{array}$ & $\begin{array}{l}\text { Wiesensteppe } \\
\text { Meadow-steppe }\end{array}$ & $-1,515$ & 0,5 & $\begin{array}{l}\text { ZLOTIN \& KHODASHOVA } \\
1980\end{array}$ \\
\hline P. tremuloides & $\begin{array}{l}\text { Gebirge } \\
\text { Mountains }\end{array}$ & $-0,175$ & 4,0 & $\begin{array}{l}\text { LOUSIER \& PARKINSON } \\
1976\end{array}$ \\
\hline P. tremuloides & $\begin{array}{l}\text { Parkland } \\
\text { Parkland }\end{array}$ & $-0,444$ & 1,6 & $\begin{array}{l}\text { diese Diplomarbeit } \\
\text { this thesis }\end{array}$ \\
\hline$P$. tremula & $\begin{array}{l}\text { Waldsteppe } \\
\text { Forest-steppe }\end{array}$ & $-1,229$ & 0,6 & $\begin{array}{l}\text { ZLOTIN \& KHODASHOVA } \\
1980\end{array}$ \\
\hline P. tremuloides & $\begin{array}{l}\text { Klimakammer } \\
\text { Microcosm }\end{array}$ & $-1,351$ & 0,5 & TAYLOR et al. 1989 \\
\hline
\end{tabular}

a) Agropyron smithii, Stipa comata und Bouteloua gracilis .

b) Stipa stenophylla CZEM., St. pennata L., Calamagrostis epigeios (L.) ROTH und Bromus riparius REHM.

c) Bouteloua gracilis, Stipa comata und Agropyron spp.

d) $70 \%$ Gräser (Bromus riparius, Agropyron repens (L.) P.B. und Poa angustifolia L.) und 30\% Krautige (Achillea millefolium L., Adonis vernalis L., Vicia tenuifolia ROTH., Filipendula hexapetala GILIB., Trifolium pratense L. u. a.). 


\subsubsection{Stickstoffflüsse}

Auch auf die Stickstoffdurchlaß- und -rückhalterate hatte die Streusorte stärksten Einfluß. Die Art des Biotops hatte eine Wirkung auf die Durchlaßrate, aber nicht auf die Rückhalterate. Da bei allen Versuchsvarianten unterhalb der Streu weniger Stickstoff aufgefangen als durch Deposition auf der Streu abgelagert wurde, hat offenbar in der Streu noch keine Nettomineralisation stattgefunden. Versuche mit $15 \mathrm{~N}$-markierter künstlicher Deposition haben gezeigt, daß der abgelagerte Stickstoff von den mikrobiellen Zersetzern aufgenommen wird (VAN VUUREN \& VAN DER EERDEN 1992). Wäre Stickstoff die begrenzende Ressource für die Zersetzer, hätte der abgelagerte Stickstoff die Zersetzung und damit die Mineralisation gefördert. Die Messungen deuten aber nicht auf eine solche Wirkung hin. Sie lassen sich dadurch erklären, daß mikrobielle Zersetzer über ihren physiologischen Bedarf hinaus Stickstoff aufnehmen können und erst dann Stickstoff freisetzen, wenn das $\mathrm{C} / \mathrm{N}$-Verhältnis der Streu sehr niedrig (etwa unter 25) ist (FOG 1988). So zeigen Versuche mit Streu von verschiedenen Laubbaumarten, daß erst zwei Jahre nach dem Blattfall eine Nettomineralisation eintritt (MCCLAUGHERTY et al. 1985). Es wird angenommen, daß ein hoher Ligningehalt - der bei Gras- und Espenstreu etwa so hoch ist wie in Nadelstreu der Weiß-Fichte (Picea glauca; TAYLOR et al. 1989) - zu Beginn der Streuzersetzung für die Festsetzung des Stickstoffs (Immobilisierung) verantwortlich ist (BERG \& STAAF 1981; FOG 1988), weil Lignin schwer zersetzbar ist. FOG (1988) vermutet aber auch, daß von außen zugeführter Stickstoff gewisse Abbauenzyme hemmt und daß zusätzliche Stickstoffgaben den Ausgang des mikrobiellen Wettbewerbes beeinflussen könnten, indem Ligninzersetzer von den durch die Stickstoffzufuhr begünstigten Zellulosezersetzern verdrängt werden.

Die Messung der Gesamtstickstoffmenge in der Streu zeigte allerdings bei Berücksichtigung der aus der Deposition stammenden Stickstoffmenge einen Stickstoffverlust an (Abb. 20). Wäre der Stickstoff von den Zersetzern aufgenommen (immobilisiert) worden, wäre diese Menge im gemessenen Stickstoffgehalt enthalten gewesen. Da der Stickstoffverlust auch nicht von den lonenaustauschern gemessen wurde und ungefähr so groß ist wie die Stickstoffmenge im Streumasseverlust war (Gras: 0,81 g/m², Espe: 0,26 $\mathrm{g} / \mathrm{m} 2)$, liegt der Gedanke nahe, daß der Stickstoff durch Fragmentierung und nicht durch mikrobielle Zersetzung der Streu verlorengegangen ist. So könnten Wind, Regen oder Tiere (Ameisen!) Streuteilchen aus den Streunetzen entfernt haben. Es ist auch möglich, daß Zersetzerpilze den Stickstoff durch ihre Hyphen aus der Streu verlagert haben. Dieser Transportweg ist allerdings bisher nur für die entgegengesetzte Richtung als 


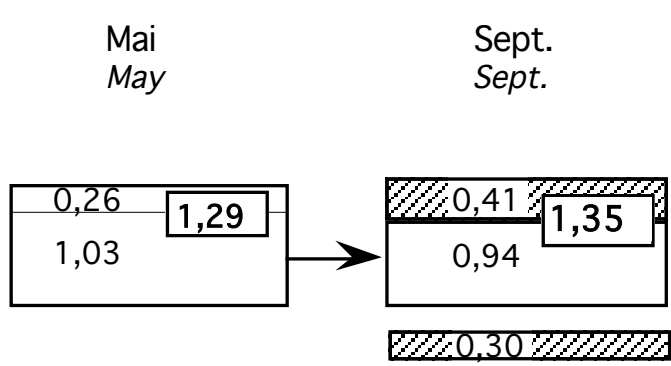

Espe Aspen

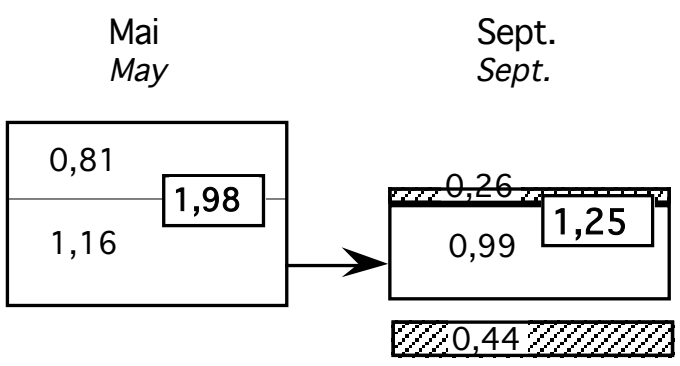

Gras Grass

Abb. 22. Kompartimentmodell der Stickstoffumsetzung (in g Stickstoff $/ \mathrm{m}^{2}$ ) in der Prärie. Schraffierte Rechtecke zeigen den Depositionsanteil, aufgeteilt in den von den Streunetzen aufgefangenen und den durchgelassenen Anteil. Die weißen Rechtecke zeigen den Stickstoffgehalt der Streunetze, für Mai aufgeteilt in den Anteil, der in der später zersetzten Masse und in den, der in der verbleibenden Masse enthalten ist. Die Zahlen unter der Linie sind die Summen der darüberliegenden Kompartimente.

Fig. 22. Compartment model of nitrogen fluxes (as g nitrogen $/ \mathrm{m}^{2}$ ) in the prairie. Hatched rectangles show nitrogen from deposition separated into the part that was retained by the litter bags and the one that was measured by the ion-exchange resin under the bags. White rectangles show the amount of nitrogen in the litter bag, for May separated into the amount contained in the mass that will decompose and the one that will remain. Numbers under the bottom line are the sum of all compartments.

Erklärung für eine Stickstofferhöhung in der Streu erwogen worden (Gosz et al. 1973).

Die Stickstoffflüsse, wie sie sich durch diese Überlegung ergeben, sind in einem Kompartimentmodell in Abbildung 22 dargestellt.

Das Kompartimentmodell geht davon aus, daß der Stickstoff zu Beginn der Zersetzung nicht mikrobiell auf oder in der Streu mineralisiert wird, sondern zusammen mit Streufragmenten aus der Streu entfernt wird. Vermutlich findet die Mineralisation der Streufragmente erst im Boden und nicht in der Streu statt (SEASTEDT et al. 1992). Unter dieser Annahme lassen sich die Unterschiede zwischen den Stickstoffflüssen der Gras- und Espenstreu als Ergebnis der räumlichen Struktur der Streusorten erklären. Die Halme und Spreiten der Grasstreu bedecken eine viel geringere Fläche als die breiten Espenblätter, so daß aus der Deposition stammender Stickstoff viel leichter durch Grasstreu als durch Espenstreu hindurchtreten kann.

Dennoch verbleibt ein nicht erklärter Stickstoffverlust während des Versuches. Er beruht zum Teil darauf, daß bei der Umrechnung auf Vorratsangaben die Flächen der Laubnetze $\left(1,0 \mathrm{dm}^{2}\right)$ verwendet wurden, die maximale Schätzwerte der Streuoberfläche sind und dadurch Meßfehler vergröBern. Es ist auch nicht völlig auszuschließen, daß die Austauscher nicht den 
gesamten Stickstoffdurchlaß aufgefangen haben, obwohl die Ergebnisse der Depositionsmessung mit den Literaturwerten übereinstimmten.

Zusätzlich zum Einfluß der Streusorte wurde im Versuch eine Wirkung des Biotoptyps auf die Stickstoffdurchlaßrate gemessen. Da die Stickstoffrückhalterate in Prärie und Hainen fast gleich groß war, ist die höhere Durchlaßrate in der Prärie am einfachsten durch eine entsprechend höhere Depositionsrate zu erklären. Im Gegensatz zu den vorliegenden Ergebnissen fanden HUNT et al. (1988) einen deutlichen Einfluß des Biotops auf die Stickstoffanreicherung in Grasstreu. So war die Anreicherung auf Wiesenflächen höher als auf Prärieflächen. Für diesen Unterschied konnten die Autoren keine überzeugende Erklärung finden. Eine im vorliegenden Versuch fehlende Wechselwirkung zwischen Biotoptyp und Streusorte auf die Stickstoffanreicherung wurde von HUNT et al. (1988) beobachtet. Sie war auf die abweichende Reaktion von Kiefernstreu, die vermutlich besonders angepaßte Zersetzer benötigt (s. Abschnitt 4.2.2), zurückzuführen.

Die Stickstoffdeposition hatte die gleiche Größenordnung wie der Stickstoffverlust durch Fragmentierung. Wäre die Deposition unberücksichtigt geblieben, wären die Ergebnisse der Gesamtstickstoffanalyse bei Grasstreu als Mineralisation und bei Espenstreu als Immobilisation gedeutet worden. Da in vielen Zersetzungsversuchen die Depositionsmenge als vernachlässigbar klein eingeschätzt wird, ist zu befürchten, daß die Aussagen dieser Versuche nur eingeschränkt gültig sind.

\subsubsection{Gesamtwirkung der Faktoren}

Die Streusorte hatte deutlich den stärksten Einfluß auf alle untersuchten Zersetzungsvorgänge. Außerdem wirkte in geringerem Maße die Sonneneinstrahlung in Wechselwirkung mit der Streusorte auf die Zersetzungsvorgänge, also auch auf die Stickstoffflüsse, ein. Insgesamt lassen die Ergebnisse des Streuzersetzungsversuches nicht erkennen, daß die Espe an einem rückgekoppelten Kreislauf, der das Stickstoffangebot erhöht, beteiligt ist. Es ist wahrscheinlicher, daß sie wegen des geringen Stickstoffgehaltes in ihren Blättern durch einen rückgekoppelten Kreislauf die Stickstoffverfügbarkeit vermindert (vgl. Abb. 8a).

\subsection{Streuzersetzung und Mineralstickstoff}

Die Geschwindigkeit der Streuzersetzungsvorgänge beruht entgegen der Arbeitshypothese weniger auf der Stärke der Sonneneinstrahlung, als viel mehr auf der Zersetzbarkeit der Streu. So wurde Grasstreu unter Sonneneinstrahlung am schnellsten zersetzt. Da bei einer schnelleren Zersetzung 
auch mehr Stickstoff freigesetzt wird (BERG \& STAAF 1981; FOG 1988), kann die langsamere Streuzersetzung nicht als Erklärung für die höhere Verfügbarkeit von Stickstoff in Espenhainböden dienen. Es ist wahrscheinlicher, daß die Espe wegen ihrer im Verhältnis zu den Gräsern schlecht zersetzbaren Streu die Stickstoffverfügbarkeit verringert. Dies zeigt sich ansatzweise bei einem Vergleich der Gesamtstickstoffvorräte eines Espenhaines und der Prärievegetation:

Der Anteil der Espen am Stickstoffvorrat der Prärie ist schwer einzuschätzen, da der Stickstoffvorrat in Graswurzeln auf groben Schätzungen beruht. So ergeben sich nach den Angaben aus der Literatur (PASTOR \& BOCKHEIM 1984; LI \& REDMANN 1992; CLARK 1977; PAUL 1976; RodIN \& BAZILEVICH 1967) für die am White Butte geschätzte Masse der ober- und unterirdischen Pflanzenteile samt der Laubstreu (WILSON 1993a) für Espen ein Vorrat von $11,1 \mathrm{~g} / \mathrm{m}^{2}$ und für Gräser ein Vorrat von 10,4 g/m². Der Stickstoffvorrat im Wurzelabfall der Espen dürfte bei $0,6 \mathrm{~g} / \mathrm{m}^{2}$, der der Gräser bei $8,8 \mathrm{~g} / \mathrm{m}^{2}$ (vgl. Abschnitt 1.4.) liegen. Demnach ist der Gesamtvorrat in Espenhainen wahrscheinlich kleiner als in der Prärie. Der geringere Stickstoffgehalt der Espenstreu erklärt eine Differenz von 0,69 $\mathrm{g} / \mathrm{m}^{2}$ (Abb. 20), ein Bruchteil der Differenz zwischen den Wurzelvorräten. Insgesamt sinkt also der Stickstoffvorrat nach der Einwanderung der Espe, weil sie im Verhältnis zum Gras weniger Stickstoff umsetzt. Der Beitrag der Laubzersetzung zur Senkung des Vorrats ist sehr gering.

Der gefundene Zusammenhang zwischen der Stickstoffverfügbarkeit und der Bodenfeuchte beruht aber nicht auf einer schnelleren Zersetzung der Streu in den Hainen, wie der Versuch zeigte, sondern auf einer höheren Trockenheitsgrenze der Stickstoffaufnahmefähigkeit der Stickstoffnutzer im Hain gegenüber den Präriearten. Dies erklärt vielleicht auch, warum das Verbreitungsgebiet der Espe nicht weiter nach Süden, wo es trockener ist, reicht. Möglicherweise wird die Einwanderung der Espe in die Prärie durch einen längerfristigen Anstieg der Regenmenge im Frühjahr begünstigt (ENVIRONMENT CANADA 1993; MüLLER 1982). Die Einwirkung der Espen auf den Stickstoffkreislauf der Prärie ist offenbar Folge und nicht Mittel der Einwanderung. 


\section{Zusammenfassung}

In einem Grasland-Wald-Ökoton wurde untersucht, ob der gegenüber dem Graslandboden höhere Mineralstickstoffgehalt des Waldbodens mit dem Alter der Bäume, der Bodenfeuchte, der Lufttemperatur oder dem relativen Lichtgenuß im Wald zusammenhängt. Dazu wurden diese Faktoren in Espenhainen (Populus tremuloides) auf Radialtransekten, die in die angrenzende Prärie verlängert wurden, gemessen. Es zeigte sich, daß der Stickstoffgehalt mit abnehmender Bodenfeuchte ansteigt. Nur diese Korrelation war signifikant. Die Ergebnisse deuten an, daß der höhere Stickstoffgehalt in Hainböden auf eine geringere Stickstoffaufnahme der Hainarten bei Bodentrockenheit zurückzuführen ist.

Als Alternative zu dieser Erklärung wurde die Annahme geprüft, daß die stickstoffärmere Streu in Wäldern wegen geringerer Evapotranspiration im Schatten schneller zersetzt wird als die stickstoffreichere Streu im benachbarten Grasland und dies zu einem höheren Mineralstickstoffgehalt im Waldboden führt. Dazu wurde der Einfluß der Streusorte (Grasgemisch oder Espe), des Biotoptyps (Grasland oder Espenhain) und der Beschattung (ohne oder mit künstlicher Beschattung) auf die Raten des Trockenmasseverlustes und der Stickstoffabgabe der Streu bestimmt.

Je $2 \mathrm{~g}$ Ende April gesammelter Vorjahresstreu wurde in $1 \mathrm{dm}^{2}$ großen Netzen Anfang Mai auf die Versuchsflächen ausgebracht. Zur Messung der Stickstoffauswaschung wurden unter die Streunetze Beutel mit lonenaustauschern gelegt. Mit unbedeckten Austauscherbeuteln wurde die Stickstoffdeposition bestimmt. Je ein Viertel der Streunetze und Austauscherbeutel wurden nach 4, 9, 16 und 21 Wochen geerntet. Aus dem Masseverlust der Streu und der Stickstoffauswaschung wurden die Raten der Zersetzung, Stickstoffabgabe- und -anhäufung berechnet.

Grasstreu wurde signifikant schneller $(k=-1,36)$ als Espenstreu $(k=-0,44)$ und beide Sorten jeweils in unbeschatteten Prärieteilflächen schneller als in anderen Teilflächen zersetzt. Die Grasstreu fing weniger Stickstoff aus der Deposition auf und ließ mehr davon durch als Espenstreu. Eine chemische Analyse der zersetzten Streu zeigte, daß bei Berücksichtigung der Deposition beide Sorten Stickstoff verloren hatten. Dieser Verlust war vermutlich durch Fragmentierung der Streu, jedoch nicht durch Mineralisation entstanden.

Da entgegen der Annahme Espenstreu trotz Beschattung am langsamsten zersetzt wurde, wird Streuzersetzung als Erklärung des höheren Stickstoffgehaltes in Hainböden verworfen und stattdessen die Annahme beibehalten, daß Trockenheit die Stickstoffaufnahme im Hain begrenzt. 


\section{Summary}

Variables that contribute to a higher soil mineral nitrogen content in forest soil than in adjacent grassland soil were studied in a Canadian forestgrassland ecotone. For this, the correlations of soil mineral nitrogen with tree age, soil moisture, air temperature and light penetration were studied along transects extending from the centre of aspen groves (Populus tremuloides) 5 $\mathrm{m}$ far into the prairie. Among all correlations only the increase of nitrogen content with decreasing soil moisture was significant. The results indicate that nitrogen uptake by plants and microbes in the forest is limited at a higher level of soil moisture than plants and microbes in the grassland.

As an alternative explanation I have tested the assumption that, because of canopy shading, litter decomposition in forests is faster than in adjacent grassland and that therefore the mineral nitrogen content of forest soil is higher than that of grassland soil. For this, the effects of litter type (aspen or grass mix), habitat type (forest or grassland), and shading (with or without artificial shading) on the rates of litter mass loss and nitrogen release were investigated

Previous year's litter was collected in April and put in $1 \mathrm{dm} 2$ large litter bags in portions of $2 \mathrm{~g}$. The bags were laid out in the experimental plots in the first week of May. Bags containing ion-exchange resin were put under the litter bags to measure nitrogen release. Uncovered resin bags were used to measure nitrogen deposition. One fourth of the litter bags and resin bags were each retrieved after $4,9,16$, and 21 weeks. Decomposition rates were calculated from litter mass loss measurements. Nitrogen release measurements were converted to rates of nitrogen retention and nitrogen loss.

Grass litter ( $\mathrm{k}=-1.36)$ decomposed signifcantly faster than aspen litter $(k=-0.44)$. Decomposition of both litter types was fastest in unshaded prairie plots, thus there was a significant habitat type $x$ shading interaction. Grass litter captured less and released more nitrogen from deposition than aspen litter. An analysis of total $\mathrm{N}$ content of litter showed that when deposition was accounted for both litter types had lost nitrogen. This nitrogen was probably lost by fragmentation and not by mineralization.

Aspen litter decomposed slower than grass litter, even in shade. Thus, decomposition is rejected as an explanation for the higher nitrogen content in forest soils, but the first explanation should be retained. 


\section{Quellenverzeichnis}

ABOUGUENDIA, Z. M., und W. C. WHITMAN (1979) Disappearance of dead plant material in a mixed grass prairie. Oecologia 42: 23-29.

AMER, F., D. R. BOULDIN, C. A. BLACK und F. R. DUKE (1955) Characterization of soil phosphorus by anion exchange resin adsorption and P32-Equilibration. Plant and Soil 6 : 391-408.

ARCHIBOLD, O. W., und M. R. WILSON (1980) The natural vegetation of Saskatchewan prior to agricultural settlement. Can. J. Bot. 58: 2031-2042.

BARNES, B. V. (1966) The clonal growth habit of American aspens. Ecology 47: 439-447.

BARTOS, D. L., und N. V. DEBYLE (1981) Quantity, decomposition and nutrient dynamics of aspen litter fall in Utah. For. Sci. 27: 381-390.

BARTOS, D. L., und R. S. JOHNSTON (1978) Biomass and nutrient content of quaking aspen at two sites in the western United States. For. Sci. 24: 273-280.

BEGON, M., J. L. HARPER und C. R. TOWNSEND (1990) Ecology: Individuals, Populations and Communities. Boston u. a.: Blackwell.

BERG, B., und H. STAAF (1981) Leaching, accumulation and release of nitrogen in decomposing forest litter. In: Terrestrial Nitrogen Cycles, hrsg. von F. E. Clark und T. Rosswall = Ecol. Bull. (Stockholm) 33: 163-178.

BINKLEY, D. (1984) lon exchange resin bags: factors affecting estimates of nitrogen availability. Soil Sci. Soc. Am. J. 48: 1181-1184.

BINKLEY, D., und S. C. HART (1989) The components of nitrogen availability assessments in forest soils. Adv. Soil Sci. 10: 57-112.

BINKLEY, D., und P. MATSON (1983) lon exchange resin bag method for assessing forest soil nitrogen availability. Soil Sci. Soc. Am. J. 47: 1050-1052.

BINKLEY, D., und P. M. VITOUSEK (1991) Soil nutrient availability. In: Plant physiological ecology: field methods and instrumentation, hrsg. von R. W. Pearcy, J. Ehleringer, H. A. Mooney und P. W. Rundel, pp. 75-96. London: Chapman and Hall.

BIRD, R. D. (1930) Biotic communities of the aspen parkland of central Canada. Ecology 11: 356-442.

BIRD, R. D. (1961) Ecology of the aspen parkland of Western Canada. Can. Dep. Agric. Publ. 1066.

BLACK, A. L., und J. R. WIGHT (1979) Range fertilization: nitrogen and phosphorus uptake and recovery over time. J. Range Manage. 32: 349-353.

BRAUN-BLANQUET, J. (1928) Pflanzensoziologie. Grundzüge der Vegetationskunde. = Biologische Studienbücher 7. Berlin: Springer.

BREMNER, J. M., und C. S. MULVANEY (1982) Nitrogen - total. In: Methods of Soil Analysis. Part 2: Chemical and Microbiological Properties. 2. Aufl. Hrsg. von A. L. Page, R. H. Miller und D. R. Keeney. Madison, Wisconsin: ASA-SSSA = Agronomy Monograph 9: 595-624.

BUELL, F. M., und H. F. BUELL (1959) Aspen invasion of prairie. Bull. Torrey Bot. Club 86: 264-265.

BUELL, F. M., und V. FACEY (1960) Forest-prairie transition west of Hasca park, Minnesota. Bull. Torrey Bot. Club 87: 46-58.

CARLYLE, J. C., und D. C. MALCOLM (1986) The use of ion exchange resin bags to assess $\mathrm{N}$ availability beneath pure spruce and larch + spruce stands growing on a deep peat soil. Plant and Soil 93: 123-127.

CHAPIN III, F. S., P. M. VITOUSEK und K. VAN CLEVE (1986) The nature of nutrient limitation in plant communities. Am. Nat. 127: 48-58. 
CHAPIN, F. S. (1980) The mineral nutrition of wild plants. Ann. Rev. Ecol. Syst. 11: 233-260.

CLARK, F. E. (1977) Internal cycling of ${ }^{15}$ Nitrogen in a short-grass prairie. Ecology 58: $1322-$ 1332.

CLARKE, O. R. (1940) Interception of rainfall by prairie grasses, weeds, and certain crop plants. Ecol. Monogr. 10: 243-277.

CLARKE, S. E., E. W. TISDALE und N. A. SKOGLUND (1943) The effect of climate and grazing practices on short-grass prairie vegetation. Dom. Can., Dept. Agr. Tech. Bul. 54.

CLAYTON, J. S., W. A. EHRLICH, D. B. CANN, J. H. DAY, and I. B. MARSHALL (1977) Soils of Canada, Vol I.: Soil Report. Research Branch, Can. Dep. Agric.

Clements, F. E, J. E. WeAVER und H. C. HANSON (1929) Plant competition. Carnegie Inst. Publ. 398.

COUPLAND, R. T. (1950) Ecology of mixed prairie in Canada. Ecol. Monogr. 20: 271-315.

COUPLAND, R. T. (1958) The effects of fluctuations in weather upon the grasslands of the Great Plains. Bot. Rev. 24: 273-317.

COUPLAND, R. T. (1961) A reconsideration of grassland classification in the northern Great Plains of North America. J. Ecol. 49: 135-167.

COUPLAND, R. T. , und G. M. VAN DYNE (1979) Systems synthesis. In: Grassland ecosystems of the world: analysis of grasslands and their use, hrsg. von R. T. Coupland = IBP 18; pp. 97-106

CRAGG, J. B., A. CARTER, C. LeISChNeR, E. B. Peterson und G. N. SYKeS (1977) Litter fall and chemical cycling in an aspen (Populus tremuloides) woodland ecosystem in the Canadian Rockies. Pedobiologia 17: 428-443.

DANSEREAU, P. (1957) Biogeography, an ecological perspective. New York: Ronald Press Company.

DAUBENMIRE, R. (1953) Nutrient content of leaf litter of trees in the Northern Rocky Mountains. Ecology 34: 786-793.

DAUbenmiRE, R., und D. C. PRUSSO (1963) Studies of the decomposition of tree litter. Ecology 44: 589-592.

DAY, R. W., und G. P. QUINN (1989) Comparisons of treatments after an analysis of variance in ecology. Ecol. Monogr. 59: 433-463.

DAVIDSON, E. A., J. M. STARK und M. K. FIRESTONE (1990) Microbial production and consumption of nitrate in an annual grassland. Ecology 71: 1968-1975.

DISTEFANO, J., und H. GHOLZ (1986) A proposed use of ion exchange resin to measure nitrogen mineralization and nitrification in intact soil cores. Comm. Soil Sci. Plant Anal. 17: 989-998.

DUMAS, J. B. A. (1831) Procédés de l'analyse organique. Ann. Chim. Phys. 247: 198-213.

ELLENBERG, H. (1986) Vegetation Mitteleuropas mit den Alpen in ökologischer Sicht. Stuttgart: Ulmer.

ENO, C. (1960) Nitrate production in the field by incubating the soil in polyethylene bags. Soil Sci. Soc. Am. Proc. 24: 277-279.

ENVIRONMENT CANADA (1993) Canadian climate normals 1960-1990 [Bd. 2] Prairie provinces. Ottawa: Atmospheric Environment Service.

ESSA [Environmental and Social Systems Analysts Ltd.] and Concord Scientific Corporation (1987) Interim target loadings for acidic deposition in western Canada: a synthesis of existing information. Victoria, BC: Technical Committee in Western and Northern Canada.

ETHERINGTON, J. R. (1982) Environment and plant ecology. Chichester: Wiley.

FOG, K. (1988) The effect of added nitrogen on the rate of decomposition of organic matter. Biol. Rev. 63: 433-462. 
FRANK, J., und I. BORCHGREVINK (1982) Jordsmonnutviklingen under bestand av gran (Picea abies) og osp (Populus tremula) i Ås (The soil development under Norway spruce (Picea abies) and aspen (Populus tremula) at Ås). Meldinger fra Norges landbrukshøgskole/ Scientific Rep. Agric. Univ. Norway 61(19): 1-30.

FRENCH, N. R. (Ed.) (1979a) Perspectives in grassland ecology. = Ecol. Stud. 32. New York: Springer.

FRENCH, N. R. (1979b) Principle subsystems interactions in grasslands. In: Perspectives in Grassland Ecology, hrsg. von N. R. French, pp. 173-190. New York : Springer.

GERSPER, P. L., und N. HOLLOWAYCHUK (1970) Effects of stemflow water on a Miami soil under a beech tree I. + II. Soil Sci. Am. Proc. 34: 779-194.

GIBLIN, A. E., J. A. LAUNDRE, K. J. NADELHOFFER und G. R. SHAVER (1994) Measuring nutrient availability in arctic soils using ion exchange resins: a field test. Soil Sci. Soc. Am. J.: in press.

GLASER, W. R. (1978) Varianzanalyse. Stuttgart und New York: Fischer.

GOSZ, J. R., G. E. LIKENS und F. H. BORMANN (1973) Nutrient release from decomposing leaf and branch litter in the Hubbard Brook Forest, New Hampshire. Ecol. Monogr. 43: 173-191.

HAGIN, J., und A. AMBERGER (1974) Contribution of fertilizers and manures to the $\mathrm{N}$ - and Pload of waters. Ber. Deutsche Forschungsgemeinschaft.

HART, S. C., und D. BINKLEY (1985) Correlations among indices of forest soil nutrient availability in fertilized and unfertilized loblolly pine plantations. Plant and Soil 85: 11-21.

HART, S. C., und M. K. FIRESTONE (1989) Evaluation of three in situ soil nitrogen availability assays. Can. J. For. Res. 19: 185-191.

HEINRICHS, D. H., und R. B. CARSON (1955) Chemical composition of nine grasses at six stages of development. Can. J. Agric. Sci. 36: 95-106.

HOBBIE, S. E. (1992) Effects of plant species on nutrient cycling. Trends Ecol. Evol. 10: 336339.

HOBBS, R. J., und H. A. MOONEY (1991) Effects of rainfall variability and gopher disturbance on serpentine annual grassland dynamics. Ecology 72: 59-68.

HOWARD, D. M., und P. J. A. HOWARD (1980) Effect of species, source of litter, type of soil, and climate on litter decomposition. Microbial decomposition of tree and shrub litter 3. Oikos 34: 115-124.

HUNT, H. W., E. R. INGHAM, D. C. COLEMAN, E. T. ELLIOT und C. P. P. REID (1988) Nitrogen limitation of production and decomposition in prairie, mountain meadow, and pine forest. Ecology 69: 1009-1016.

JACKSON, L. E., J. P. SCHIMEL und M. K. FIRESTONE (1989) Short-term partitioning of ammonium and nitrate between plants and microbes in an annual grassland. Soil Biol. Biochem. 21: 409-415.

KELLMAN, M. (1979) Soil enrichment by neotropical savanna trees. J. Ecol. 67: 565-577.

KILLINGBECK, K. T., J. D. MAY und S. NYMAN (1990) Foliar senescence in aspen (Populus tremuloides) clone: the response of element resorption to interramet variation and timing of abscission. Can. J. For. Res. 20: 1156-1164.

KIRK, R. E. (1968) Experimental design: procedures for the behavioral sciences. Belmont, CA, USA: Brooks/Belmont.

LARCHER, W., (1973) Ökologie der Pflanze. UTB 232. Stuttgart: Ulmer.

LAUENROTH, W. K. (1979) Grassland primary production: North American grasslands in perspective. In: Perspectives in grassland ecology, hrsg. von N. French, pp. 3-24. New York: Springer. 
LAYCOCK, W. A. (1958) The initial patterns of revegetation of pocket gopher mounds. Ecology 38: 346-351.

LEE, C. Y., und D. D. MYROLD (1990) Nitrogen mineralization and nitrification in forest soils: Effect of chemical treatment on nitrogen adsorption by ion exchange resin. J. Korean For. Soc. 79: 285-289.

LI, Y. S. und R. E. REDMANN (1992) Nitrogen budget of Agropyron dasystachium in Canadian Mixed Prairie. Am. Midl. Nat. 128: 61-71.

LOOMAN, J (1978) The vegetation of the Canadian prairie provinces. I An overview. Phytocoenologica 5: 347-366.

LOOMAN, J. (1980) The vegetation of the Canadian prairie provinces II. The grasslands. Part I. Phytocoenologia 8: 153-190.

LOOMAN, J. (1983) The vegetation of the Canadian prairie provinces IV. The woody vegetation. Part 1. Phytocoenologica 11: 297-330.

LOOMAN, J. (1987) The vegetation of the Canadian prairie provinces IV. The woody vegetation. Part 3. Deciduous woods and forests. Phytocoenologica 15: 51-84.

LOOMAN, J. (1992) Prairie grasses: identified and described by vegetative characters. Ottawa: Canada Communication Group.

LOUSIER, J. D., und D. PARKINSON (1976) Litter decomposition in a cool temperate deciduous forest. Can. J. Bot. 54: 419-436.

LOUSIER, J. D., und D. PARKINSON (1978) Chemical element dynamic in decomposing leaf litter. Can. J. Bot. 56: 2795-2812.

LUNDELL, Y. (1989) In situ ion exchange resin bags to estimate forest site quality. Plant and Soil 119: 186-190.

MAINI, J. S. (1960) Invasion of grassland by Populus tremuloides in the northern Great Plains. Diss. Univ. Saskatchewan, Saskatoon.

MCCLAUGHERTY, C. A., J. PASTOR und J. D. ABER (1985) Forest litter decomposition in relation to soil nitrogen dynamics and litter quality. Ecology 66: 266-275.

MEENTEMEYER, V. (1978) Macroclimate and lignin control of litter decomposition rates. Ecology 59: 465-472.

MELILLO, J. M., J. D. ABER und J. F. MURATORE (1982) Nitrogen and lignin control of hardwood leaf litter decomposition dynamics. Ecology 63: 621-626.

MITCHELL, J., H. C. MOSS und J. S. CLAYTON (1944) Soil survey of southern Saskatchewan. Soil Survey Report. [Saskatoon:] Univ. Saskatchewan.

MORECROFT, M. D., R. H. MARRS und F. I. WOODWARD (1992) Altitudinal and seasonal trends in soil nitrogen mineralization rate in the Scottish Highlands. J. Ecol. 80: 49-56.

MÜLLER, M. J. (1982) Selected climatic data for a global set of standard stations for vegetation science. Tasks for vegetation sciences 5. The Hague (Den Haag): Junk.

NADELHOFFER, K. J., A. E. GIBLIN, G. R. SHAVER und J. A. LAUNDRE (1991) Effects of temperature and substrate quality on element mineralization in six arctic soils. Ecology 72: 242-253.

OLSON, J. S. (1963) Energy storage and the balance of producers and decomposers in ecological systems. Ecology 44: 322-331.

PASTOR, J., und J. G. BOCKHEIM (1984) Distribution and cycling of nutrients in an aspenmixed-hardwood-spodosol ecosystem in Northern Wisconsin. Ecology 65: 339-353.

PASTOR, J., J. D. ABER, C. A. MCCLAUGHERTY und J. M. MELILLO (1984) Aboveground production and $\mathrm{N}$ - and $\mathrm{P}$-cycling along a nitrogen mineralization gradient on Blackhawk Island, Wisconsin. Ecology 65: 256-268.

PASTOR, J., M. A. STILLWELL und D. TILMAN (1987) Little bluestem litter dynamics in Minnesota old fields. Oecologia 72: 327-330. 
PAUL, E. A. (1976) Interecosystem nitrogen transfers. In: Environmental Biogeochemistry. Vol. 1. Carbon, Nitrogen, Phosphorus, Sulfur and Selenium Cycles, hrsg. von J. O. Nriagu, pp. 225-243 = Proceedings of the 2nd International Symposium on Environmental Biogeochemistry. Ann Arbor, Michigan: Ann Arbor Science.

PETERSON, E. B., und N. M. PETERSON (1992) Ecology, management, and use of aspen and balsam poplar in the prairie provinces, Canada. Edmonton, Alberta: Forestry Canada, Northwest Region.

PETRANKA, J. W., und J. K. MCPHERSON (1979) The role of Rhus copallina in the dynamics of the forest-prairie ecotone in north-central Oklahoma. Ecology 60: 956-965.

PIGDEN, P. J. (1953) The relation of lignin, cellulose, protein, starch and ether extract to the "curing" of range grasses. Can. J. Agric. Sci. 33: 365-378.

PYNE, S. J. (1986) "These conflagrated prairies." A cultural fire history of the grasslands. Proc. Ninth North-American Prairie Conf., pp. 131-137.

REDMANN, R. E. (1991) Nitrogen losses to the atmosphere from grassland fires in Saskatchewan, Canada. Int. J. Wildland Fire 1: 239-244.

RODIN, L. E., und N. I. BAZILEVICH (1967) Production and mineral cycling in terrestrial vegetations. Translation by Scripta Technica Ltd., hrsg. von G. E. Fogg. London: Oliver and Boyd. Originaltitel: RODIN, L. E., und N. I. BAZILEVICH (1965) "Dynamics of the organic matter and biological cycling of ash elements and nitrogen in the main types of the world's vegetation". Moskva: Izd. Nauka .

RÖHR, M., H. LOHSE und R. LUDWIG (1983) Statistik für Soziologen, Pädagogen, Psychologen und Mediziner. Bd. 2. Statistische Verfahren. Thun und Frankfurt am Main: Deutsch.

SCHNABEL, R. R. (1983) Measuring nitrogen leaching with ion exchange resin: a laboratory assessment. Soil Sci. Am. J. 47: 1041-1042.

SEASTEDT, T. R. (1985) Canopy interception of nitrogen in bulk precipitation by annually burned and unburned tallgrass prairie. Oecologia 66: 88-92.

SEASTEDT, T. R., J. M. Briggs und D. J. Gibson (1991) Controls of nitrogen limitation in tallgrass prairie. Oecologia 87: 72-79.

SEASTEDT, T. R., W. J. PARTON und D. S. OJIMA (1992) Mass loss and nitrogen dynamics of decaying litter of grasslands - the apparent low nitrogen immobilization potential of root detritus. Can. J. Bot. 70: 384-391.

SEVERSON, K. E. (1982) Production and nutritive value of aspen understory, Black Hills. J. Range Manage. 35: 786-789.

SHANTZ, H. L. (1954) The place of grasslands in the earth's cover of vegetation. Ecology 35 : 142-145.

SHELFORD, V. E. (1963) The ecology of North America. Urbana: University of Illinois Press.

SIBBESEN, E. (1977) A simple ion-exchange resin procedure for extracting plant-available elements from soil. Plant and Soil 46: 665-669.

SIMS, P. L., und R. T. COUPLAND (1979) Producers. In: Grassland ecosystems of the world: analysis of grasslands and their uses, hrsg. von R. T. Coupland, pp. 49-72. Cambridge: Cambridge University Press.

SKIDMORE, E. L., und L. J. HAGEN (1973) Potential evaporation as influenced by barrierinduced microclimate. In: Physical Aspects of Soil Water and Salt in Ecosystems, hrsg. von A. Hadas, D. Swartzendruber, P. E. Rijtema, M. Fuchs und B. Yaron = Ecol. Stud. (Berlin u. a.: Springer) 4: 237-244.

SMOLIAK, S., und L. M. BEZEAU (1967) Chemical composition and in vitro digestibility of range forage plants of the Stipa-Bouteloua prairie. Can. J. Plant Sci. 47: 161-167.

SRIVASTAVA, S. C. (1992) Microbial C, N, and P in dry tropical soils: seasonal changes and influence of soil moisture. Soil Biol. Biochem. 24: 711-714. 
STANTON, N. L. (1988) The underground in grasslands. Ann. Rev. Ecol. Syst. 19: 573-589.

STOECKLER, J. H. (1961) Organic layers in Minnesota aspen stands and their role in soil improvement. For. Sci. 7: 66-71.

STUMP, L. M., und D. BINKLEY (1993) Relationships between litter quality and nitrogen availability in Rocky Mountain forests. Can. J. For. Res. 23: 492-502.

TAMM, C. O. (1991) Nitrogen in terrestrial ecosystems. Questions of productivity, vegetational changes, and ecosystem stability. Berlin und New York: Springer.

TAYLOR, B. R., und D. PARKINSON (1988a) Annual differences in quality of leaf litter of aspen (Populus tremuloides) affecting rates of decomposition. Can. J. Bot. 66: 19401947.

TAYLOR, B. R., und D. PARKINSON (1988b) Aspen and pine leaf litter decomposition in laboratory microcosms. I. Linear versus exponential models of decay. Can. J. Bot. 66: 1960-1965.

TAYLOR, B. R., und D. PARKINSON (1988c) Aspen and pine leaf litter decomposition in laboratory microcosms. II. Interactions of temperature and moisture level. Can. J. Bot. 66: 1966-1973.

TAYLOR, B. R., D. PARKINSON und W. F. J. PARSONS (1989) Nitrogen and lignin as predictors of litter decay rates: a microcosm test. Ecology 70: 97-104.

TEW, R. K. (1970) Seasonal variation in the nutrient content of aspen foliage. J. Wildlife Manage. 34: 475-478.

THORNTHWAITE, C. W. (1948) An approach toward a rational classification of climate. Geogr. Rev. 38: 55-94 +Karte.

THORNTHWAITE, C. W., und J. R. MATHER (1957) Instructions and tables for computing potential evapotranspiration and the water balance. Centerton, New Jersey: Drexel Publications in Climatology, Institute of Technology, Laboratory of Climatology 10: 183311.

TILMAN, D. (1982) Resource competition and community structure. Princeton, New Jersey: Princeton University Press.

TILMAN, D. (1990) Constraints and tradeoffs: toward a predictive theory of competition and succession. Oikos 58: 3-15.

TILMAN, D., und D. WEDIN (1991) Dynamics of nitrogen competition between successional grasses. Ecology 72: 1038-1049.

ULRICH, B., R. MAYER und P. K. KHANNA (1979) Deposition von Luftverunreinigungen und ihre Auswirkungen in Waldökosystemen im Solling. Schriften Forstl. Fak. Univ. Göttingen (Sauerländer Verlag) 58.

UPADHYAY, V. P., U. PANDEY und J. S. SINGH (1985) Effect of habitat on decomposition of standard leaf-litter species. Biol. Fert. Soils 1: 201-207.

VAN CLEVE, K., und L. L. NOONAN (1975) Litter fall and nutrient cycling in the forest floor of birch and aspen stands in interior Alaska. Can. J. For. Res. 5: 626-631.

VERRY, E. S., und D. R. TIMMOS (1976) Elements in leaves of a trembling aspen clone by crown position and season. Can. J. For. Res. 6: 434-440.

VITOUSEK, P. (1982) Nutrient cycling and nutrient use efficiency. Am. Nat. 119: 553-572.

VITOUSEK, P. M. (1986) Biological invasions and ecosystem properties: Can species make a difference? In: Ecology of Biological Invasions of North America and Hawaii, hrsg. von $\mathrm{H}$. A. Mooney und J. Drake, pp.163-176. New York: Springer.

VITOUSEK, P. M. (1990) Biological invasions and ecosystem processes: towards an integration of population biology and ecosystem studies. Oikos 57: 7-13.

VITOUSEK, P. M., J. R. GOSZ, C.C. GRIER, J. M. MELLILO, W. A. REINERS und R. L. TODD (1979) Nitrate losses from disturbed ecosystems. Science 204: 469-474. 
VossBrinCK, C. R., D. COLEMAN und T. A. WOOLLEY (1979) Abiotic and biotic factors in litter decomposition in a semiarid grassland. Ecology 60: 265-271.

VAN VUUREN, M. M., und L. J. VAN DER EERDEN (1992) Effects of three rates of atmospheric nitrogen deposition enriched with $15 \mathrm{~N}$ on litter decomposition in a heathland. Soil Biol. Biochem. 24: 527-532.

WALTER, H. (1935) Ist die Prärie von Natur aus baumlos? Geogr. Z. 41: 16-26.

WALTER, H. (1984) Vegetation und Klimazonen: Grundriß der globalen Ökologie. Stuttgart: Ulmer.

WALTER, H. (1985) Vegetation of the Earth and Ecological Systems of the Geo-biosphere. Berlin und New York: Springer.

WALTER, H., und H. LIETH (1967) Klimadiagramm-Weltatlas. Jena: Fischer.

WEDIN, D. A., und D. TILMAN (1990) Species effects on nitrogen cycling: a test with perennial grasses. Oecologia 84: 433-441.

WILSON, S. D. (1993a) Belowground competition in forest and prairie. Oikos 68: 146-150.

WILSON, S. D. (1993b) Competition and resource availability in heath and grassland in the Snowy Mountains of Australia. J. Ecol. 81: 445-451.

WITKAMP, M. (1963) Microbial populations of leaf litter in relation to environmental conditions and decomposition. Ecology 44: 370-377.

WITKAMP, M. (1966) Decomposition of leaf litter in relation to environment, microflora and microbial respiration. Ecology 47: 194-201.

WOODMANSEE, R. G. (1979) Factors influencing input and output of nitrogen in grasslands. In: Perspectives in Grassland Ecology, hrsg. von N. R. French, pp. 117-134. New York: Springer.

WRIGHT, H. A., und A. W. BAILEY (1982) Fire ecology - United States and southern Canada. New York: Wiley.

ZAHNER, R. und N. V. DEBYLE (1965) Effect of pruning the parent root on growth of aspen suckers. Ecology 46: 373-375.

ZAR, J. H. (1974) Biostatistical analysis. Englewood Cliffs, New Jersey: Prentice Hall.

ZINKE, P. (1962) The pattern of individual trees on soil properties. Ecology 43: 130-133.

ZLOTIN , R. I. und K. S. KHODASHOVA (1980) The role of animals in biological cycling of forest-steppe ecosystems. Stroudsburg, Pa.: Hutchinson Ross 1980. 
